\title{
METODOLOGÍAS PARA LA ESTIMACIÓN DE SOSTIENIBILIDAD AGROPECUARIA
}

Jorge Armando Fonseca Carreño - Edwin Manuel Páez Barón - Emma Sofía Corredor Camargo

e-ISBN 978-958-651-650-1

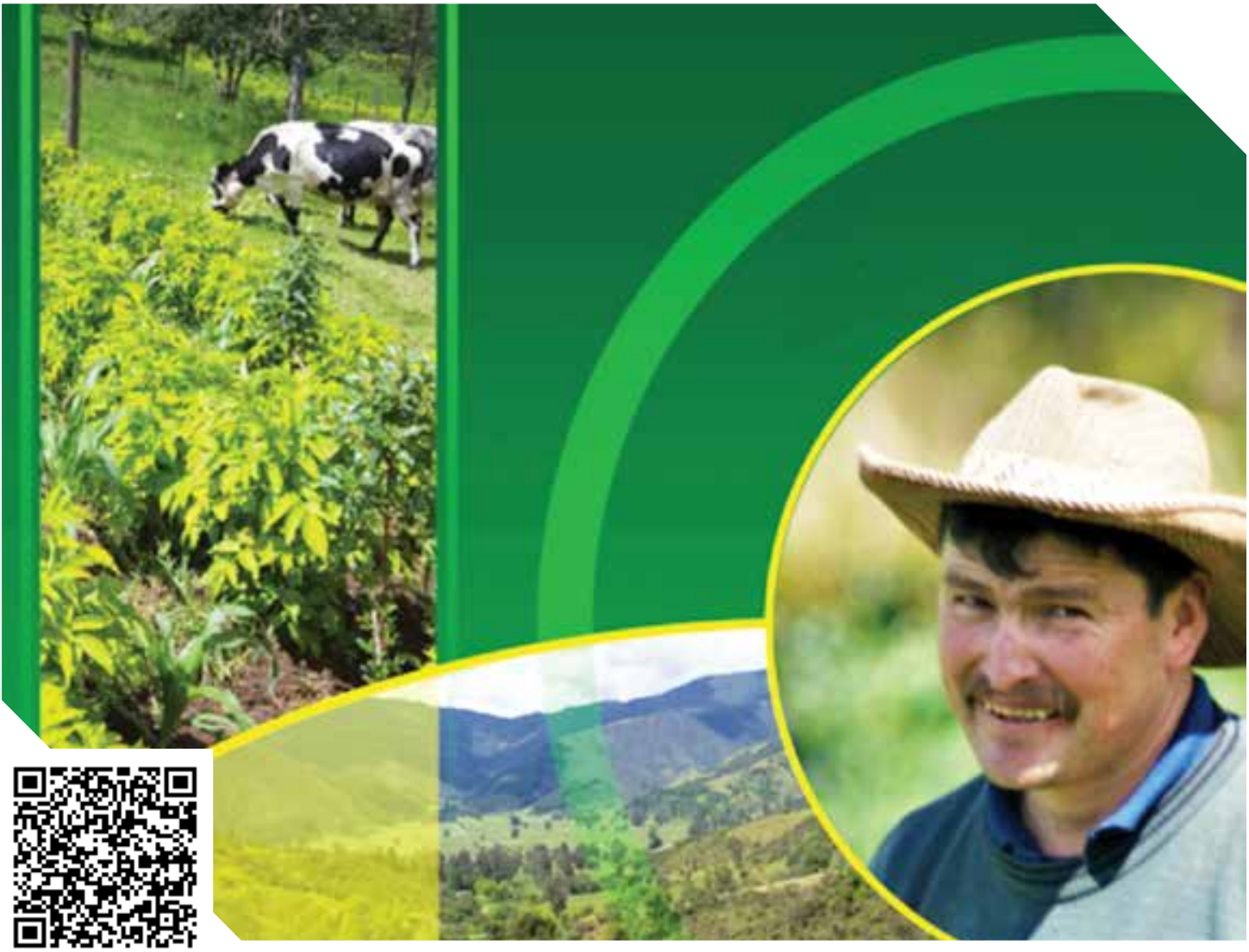

Grupo de Investigación en Sistemas Sostenibles de Producción GIGASS 


\title{
METODOLOGÍAS PARA LA ESTIMACIÓN DE SOSTENIBILIDAD AGROPECUARIA
}

ISBN: 978-958-651-650-1

\author{
AUTORES \\ Jorge Armando Fonseca Carreño \\ Edwin Manuel Páez Barón \\ Emma Sofía Corredor Camargo
}

Universidad Nacional Abierta y a Distancia UNAD

Escuela de Ciencias Agrícolas, Pecuarias y del Medio Ambiente

Línea de Investigación: Desarrollo rural 


\title{
UNIVERSIDAD NACIONAL ABIERTA Y A DISTANCIA
}

\author{
Rector
}

Jaime Alberto Leal Afanador.

Vicerrectora Académica y de Investigación

Constanza Abadía García.

Vicerrector de Medios y Mediaciones Pedagógicas

Leonardo Yunda Perlaza.

Vicerrector de Desarrollo Regional

y Proyección Comunitaria

Leonardo Evemeleth Sánchez Torres.

Vicerrector de Servicios a Aspirantes,

Estudiantes y Egresados

Edgar Guillermo Rodríguez Díaz.

Vicerrector de Relaciones Internacionales

Luigi Humberto López Guzmán.

Decana Escuela de Ciencias de la Salud

Myriam Leonor Torres.

Decana Escuela de Ciencias de la Educación

Clara Esperanza Pedraza Goyeneche.

Decana Escuela de Ciencias Jurídicas y Políticas

Alba Luz Serrano Rubiano.

Decana Escuela de Ciencias Sociales, Artes y Humanidades

Sandra Milena Morales Mantilla.

Decano Escuela de Ciencias Básicas,

Tecnología e Ingeniería

Claudio Camilo González Clavijo.

Decana Escuela de Ciencias Agrícolas,

Pecuarias y del Medio Ambiente

Julialba Ángel Osorio.

Decana Escuela de Ciencias Administrativas,

Económicas, Contables y de Negocios

Sandra Rocío Mondragón. 


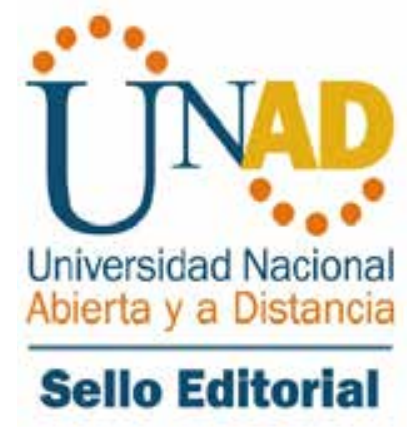

\title{
METODOLOGÍAS PARA LA ESTIMACIÓN DE SOSTENIBILIDAD AGROPECUARIA
}

\author{
AUTORES \\ Jorge Armando Fonseca Carreño \\ Edwin Manuel Páez Barón \\ Emma Sofía Corredor Camargo
}

\begin{abstract}
Metodologías para la estimación de sostenibilidad agropecuaria / Fonseca Carreño, Jorge Armando ... [et al.] -- [1.a. ed.]. Bogotá: Sello Editorial UNAD/2018. (Línea de investigación: Desarrollo rural. Escuela de Ciencias Agrícolas, Pecuarias y del Medio Ambiente - ECAPMA)

ISBN: e-ISBN:978-958-651-650-1

1. RECURSOS NATURALES Y ENERGIA 2. SUSTENTABILIDAD AMBIENTAL 3. SOSTENIBILIDAD AGROPECUARIA I. Páez Barón, Edwin Manuel II. Corredor Camargo, Emma Sofia III. Título.
\end{abstract}




\title{
Título de Libro \\ METODOLOGÍAS PARA LA ESTIMACIÓN DE SOSTENIBILIDAD AGROPECUARIA
}

\author{
Autores \\ Jorge Armando Fonseca Carreño \\ Edwin Manuel Páez Barón \\ Emma Sofía Corredor Camargo
}

e-ISBN: 978-958-651-650-1

Escuela de Ciencias Agrícolas, Pecuarias y del Medio Ambiente (ECAPMA)

Fotografía de la portada "Agroecosistemas familiares campesinos de Boyacá", tomada y cedida por Jorge Armando Fonseca Carreño

\section{(C)Editorial}

Sello Editorial UNAD

Universidad Nacional Abierta y a Distancia

Calle 14 Sur No. 14-23

Bogotá D.C

Diciembre de 2018.

\footnotetext{
(c) 1 Esta obra está bajo una licencia Creative Commons - 


\section{CAPÍTULO 1. Evaluación de Agroecosistemas Familiares Campesinos Mediante Indicadores de Sustentabilidad}

1.1. Resumen

1.2. Introducción

1.3. Uso de indicadores e índices para evaluar sustentabilidad

1.3.1. Agregación de indicadores simples

1.3.2. Construcción participativa de indicadores

1.3.3. Construcción de indicadores mediante de análisis multivariante

1.4. Evaluación de sustentabilidad de agroecosistemas

familiares campesinos mediante el MESMIS

1.5. Evaluación de la sustentabilidad de agroecosistemas

familiares campesinos mediante MESMIS

1.5.1. Criterio Retorno

1.5.2. Criterio Eficiencia del agroecosistema

1.5.3 Criterio de Conservación

1.5.4 Criterio Diversidad

1.5.5. Criterio Participación 38

1.6. Criterio de Capacidad de Cambio e Innovación 40

1.6.1 Criterio de Suficiencia del Agroecosistema

Conclusiones

Bibliografía 


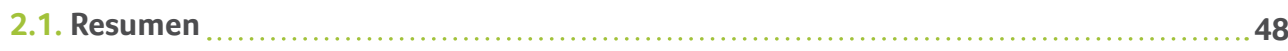

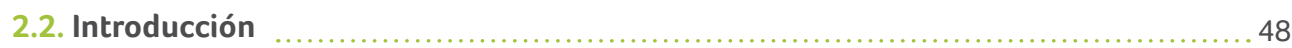

2.3 Aspectos Generales del Cambio Climático .......................................... 49

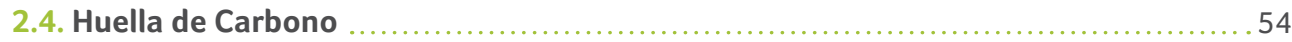

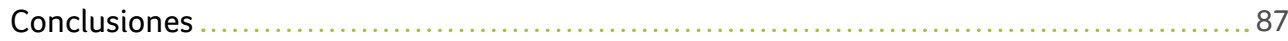

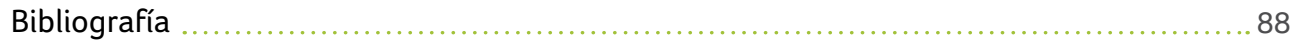

CAPÍTULO 3. Huella Hídrica

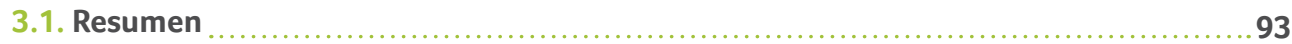

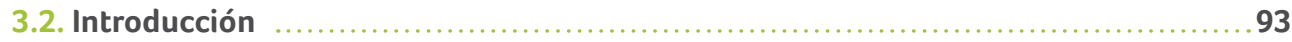

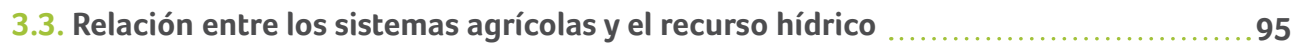

3.4. Descripción metodológica para la estimación de la huella hídrica .................. 100

3.5 Aplicabilidad de la HH para evaluación

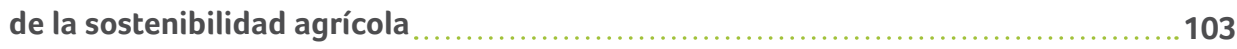

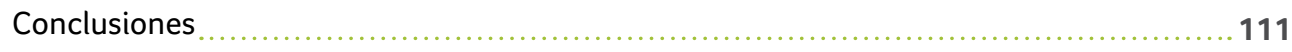

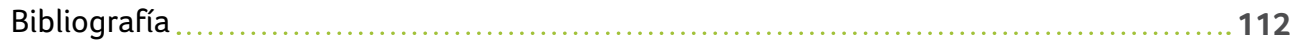


En las últimas décadas las fuerzas vivas de la sociedad han iniciado a comprender que los cambios a los que se enfrenta el planeta por actividades antrópicas representan un gran riesgo para la estabilidad de la humanidad. Factores como la creciente emisión de gases de efecto invernadero principales causantes del calentamiento global y a la postre del cambio climático, la deforestación a gran escala en zonas de reserva del mundo, el cambio en el uso de los suelos que favorece la industrialización y la urbanización, el desarrollo y uso intensivo de tecnologías altamente contaminantes en diferentes sectores productivos, son entre otros, factores inductores y aceleradores de los cambios en las condiciones de la naturaleza a escala global que inciden en el deterioro de la oferta ambiental (también se asocia con los servicios ecosistémicos o servicios ambientales, que desde la lógica capitalista son sujetos de monetización), tales como la biodiversidad, la calidad, cantidad y oportunidad de agua para las diferentes actividades humanas, la pérdida de condiciones de los suelos para la producción de alimentos, la calidad de aire, entre otras condiciones que modifican sustancialmente los medios de vida de la sociedad, especialmente de comunidades vulnerables en zonas con escasa capacidad de adaptación a las nuevas condiciones del ambiente.

En sintonía con esta realidad y ante la urgente necesidad de desarrollar mecanismos y estrategias que le permitan a la sociedad y especialmente a los actores que participan en el sistema agroalimentario apropiarse del conocimiento desarrollado sobre el impacto de las actividades agropecuarias sobre el ambiente, sus técnicas de evaluación y las estrategias para su mitigación; la Universidad Nacional Abierta a y Distancia - UNAD a través del Grupo de Investigación en Sistemas Sostenibles de Producción GIGASS, presenta este documento que reúne la conceptualización teórica y el análisis de resultados de investigación de herramientas metodológicas para la determinación de la sustentabilidad agropecuarias.

En el documento titulado "Metodologías para la estimación de la sostenibilidad agropecuaria", los autores en tres capítulos presentan algunas herramientas de diagnóstico de la sustentabilidad agropecuaria, donde inicialmente se hace el abordaje conceptual de las metodologías, la descripción de su estrategia de 
aplicación en el contexto agropecuario y la explicación de los resultados obtenidos en diferentes trabajos de investigación.

En el primer capítulo del documento se presenta la Evaluación de agroecosistemas familiares campesinos mediante indicadores de sustentabilidad, usando para ello el "Marco para la Evaluación de Sistemas de Manejo de Recursos Naturales Incorporando Indicadores de Sustentabilidad (MESMIS)", que evalúa integralmente los sistemas agrarios, generando una visión dinámica de su estado de desarrollo y conservación, a la vez que permite su análisis y la generación de posibles estrategias de mejora. En el segundo capítulo se presenta la metodología para la estimación de la huella de carbono en actividades agrarias, lo cual constituye un valioso aporte para que este sector avance en el proceso de ajuste tecnológico que le permita estar dentro de parámetros normativos internacionales, se aborda desde los elementos básicos de la emisión de gases de efecto invernadero como causa antrópica del cambio climático, sus efectos sobre los agroecosistemas, los estándares internacionales de estimación de huella de carbono desde la perspectiva del ciclo de vida, para finalmente presentar experiencias de su estimación en el sector agropecuario. En el tercer capítulo se presenta la metodología para la evaluación de la huella hídrica la cual se aborda desde el enfoque del recurso hídrico como base para el desarrollo de las actividades agroalimentarias, la metodología para la evaluación de la huella hídrica como indicador de sustentabilidad, y por último el análisis de la aplicabilidad de la huella hídrica en la evaluación de la sostenibilidad agrícola.

Este documento constituye un valioso recurso de consulta para profesionales, asistentes técnicos, estudiantes de ciencias agrarias y ambientales, consultores y productores agropecuarios con interés en dar los primeros pasos en la identificación y aplicación de metodologías para determinar los niveles de sustentabilidad agropecuaria. Proceso "casi" obligatorio para las agroempresas con miras al cumplimiento de la normatividad cada vez más exigente que les permita ingresar a mercados especializados nacionales e internacionales. Esperamos que su lectura constituya la base conceptual y motivacional para profundizar en estos importantes temas agroambientales. 


\section{CAPÍTULO I}

\section{EVALUACIÓN DE AGROECOSISTEMAS FAMILIARES CAMPESINOS MEDIANTE INDICADORES DE SUSTENTABILIDAD}

Jorge Armando Fonseca Carreño

Ingeniero agrónomo, Universidad Pedagógica y Tecnológica de Colombia-UPTC. Especialista en

finanzas, Universidad Pedagógica y Tecnológica de ColombiaUPTC. Especialista en evaluación pedagógica, Universidad Católica de Manizales. Magister en Ciencias agrarias, Universidad Nacional de Colombia. Estudiante de Doctorado en Ciencias biológicas y ambientales, Universidad Pedagógica y Tecnológica de Colombia-UPTC.

Edwin Manuel Páez Barón

Médico Veterinario Zootecnista, Universidad Pedagógica y Tecnológica de Colombia-UPTC. Especialista en Sanidad animal, Universidad de Ciencias Aplicadas y Ambientales - UDCA. Magister en Ciencias Veterinarias, Universidad Pedagógica y Tecnológica de Colombia-UPTC. Magister en Educación, UNAD Florida. Doctorado en Desarrollo sostenible, Universidad Católica Santa Teresa de Jesús de Ávila, España.

Emma Sofía Corredor Camargo

Médico veterinario, Universidad Nacional de Colombia. Zootecnista, Universidad Nacional Abierta y a Distancia-UNAD. Especialista en Sanidad animal, Universidad de Ciencias Aplicadas y AmbientalesUDCA. Magister en Desarrollo sostenible y Medio ambiente, Universidad de Manizales.

\subsection{Resumen}

La sustentabilidad es un criterio de la valoración de los agroecosistemas que implica que éste conserva sus condiciones, tal que su base biológica se mantiene fortalecida, su productividad estable y su componente social satisfecho. Para cumplir esta premisa se requiere que desde la política pública se propenda por la defensa de los sistemas de producción de base campesina, que la institucionalidad gubernamental faciliten mecanismos para el acceso a recursos tecnológicos y de capital que permita su inserción en los mercados y desde la academia, la sociedad civil y las organizaciones gremiales se generen estrategias para su fortalecimiento, en tal sentido la metodología MESMIS es una estructura cíclica multiescalar y flexible, basada en un enfoque participativo con visión interdisciplinaria aplicable en diversos contextos agropecuarios para evaluar la sustentabilidad de agroecosistema en las perspectivas económica, social y ambiental. Este documento hace 
una rápida revisión de los conceptos que integran la metodología MESMIS y propone una estrategia para su implementación teniendo como punto de partida diversas experiencias de su aplicación en agroecosistemas campesinos de la región central de Boyacá (Colombia).

\subsection{Introducción}

Las actividades agropecuarias en general, tanto de producción comercial de alimentos de grandes conglomerados económicos, como la pequeña agricultura familiar campesina en sus diferentes manifestaciones, tienen como factor común y condicionante el acceso y la disponibilidad de la oferta ambiental (para otros autores Recursos naturales) los cuales constituye la base biológica sobre la cual se cimienta su desarrollo y productividad. Partiendo desde el concepto que, la oferta ambiental provee la energía suficiente para el normal desarrollo de las plantas. Dicha demanda energética aumenta considerablemente si se trata de un sistema intensivo de producción (monocultivos), tal que el medio no puede proveerla en la cantidad ni oportunidad requerida, necesitando aportes energéticos suplementarios externas y generalmente de origen sintético que procuran un importante aumento en los rendimientos del cultivo, cumpliendo temporalmente con las expectativas de productividad de los agricultores, pero con una importante carga en el aumento de los costos de producción. La frecuente incorporación de fuentes energéticas externas al sistema agrícola puede provocar desequilibrios asociados al deterioro de la condición inicial del agroecosistema, tales como: disminución de la fertilidad del suelo y compactación; contaminación de cuerpos de agua, disminución de recursos genéticos entre otros factores. Este modelo de producción agrícola emerge desde los postulados de la revolución verde, entendida, como el uso intensivo de recursos genéticos, moléculas químicas para el manejo fitosanitario de los cultivos y el desarrollo tecnológico de la mecanización de suelos y sistemas de riego; adelantos que procuraron el ostensible aumento de la producción agrícola en una de las épocas más críticas de provisión alimentaria para la humanidad (Fonseca et al., 2018).

En contraposición a este modelo de revolución verde, han surgido no pocas corrientes y movimientos que procuran el desarrollo de sistemas agroalimentarios que generen menor impacto sobre la naturaleza (oferta ambiental), procurando el equilibrio ecosistémico, privilegiando las fuentes energéticas endógenas del agroecosistema, así como el uso de saberes y tradiciones ancestrales de la 
comunidad rural, tal que se logre un balance energético que le permita ser estable y sostenible. Dichos sistemas de producción buscan la permanencia de familias rurales en actividades agropecuarias generando las condiciones básicas para su subsistencia, la seguridad alimentaria y la satisfacción de sus necesidades básicas. Pero tal vez, más que nuevas corrientes de producción agrícola, en las organizaciones sociales y académicas se ha fomentado la revalorización de los sistemas tradicionales campesinos, indígenas, raizales y afrodescendientes que por siglos han desarrollado actividades agroalimentarios bajo condiciones de sustentabilidad, tal es el caso de sistemas de producción de agricultura familiar campesina basados en conocimientos y técnicas tradicionales y/o ancestrales logran mantener el equilibrio dinámico de los sistemas agroalimentarios. Tales iniciativas han sido documentadas y sistematizadas por ciencias emergentes como la agroecología, que para algunos autores incorpora sistemas de producción, corrientes y movimientos como la agricultura orgánica, la biodinámica entre muchas otras, que tiene como elemento común el uso sostenible de los servicios de la biodiversidad y de los ecosistemas, la preservación de las especies nativas, amplia diversidad biológica, preservación de los saberes y la cultura local, el empoderamiento y la autogestión comunitaria entre otros aspectos.

Un agroecosistema sostenible posee múltiples características que lo estructuran y lo definen, y que, por supuesto le diferencia de otros agroecosistemas. Estos atributos están relacionados con la conservación de su oferta ambiental, el uso eficiente de fuentes energéticas, priorizando aquellas provenientes del mismo agroecosistema y caracterizadas por su bajo costo y bajo impacto, sin que ello implique disminuir los niveles de productividad. Igualmente, estos sistemas sostenibles privilegian el ciclaje de nutrientes, el uso de especies nativas o adaptadas al medio, aumentando la eficiencia energética y por lo tanto la rentabilidad financiera que integrada a circuitos económicos locales permite el crecimiento solidario y económico de la población. La presencia e interacción de los anteriores y otros atributos constituyen en menor o mayor grado la sustentabilidad de un agroecosistema, lo cual implica, la necesidad de identificar y evaluar dicha presencia e interacción, es decir, determinar su nivel o grado de sustentabilidad.

En el contexto agrario es necesario integrar y materializar el concepto de sustentabilidad mediante la aplicación de diversas metodologías de evaluación cuyos lineamientos permitan identificar y evaluar los factores intervinientes y su nivel de interacción, ya que algunos esfuerzos para evaluación de sustentabilidad se 
han concentrado únicamente en la construcción de grupos de indicadores, mientras que, por el contrario la tendencia es diseñar marcos metodológicos para la construcción indicadores para evaluar la sustentabilidad.

Para lo anterior, se han diseñado diversas herramientas metodológicas que permiten evaluar la sustentabilidad ambiental y socio-económica de los sistemas, lo anterior requiere de herramientas robustas que valoren su diversidad y complejidad. Para valorar la sustentabilidad de agroecosistemas y en general de los sistemas agrarios se ha usado en diversos contextos y sistemas productivos el "Marco para la Evaluación de Sistemas de Manejo de recursos naturales incorporando Indicadores de Sustentabilidad (MESMIS)", dicha herramienta permite evaluar integralmente los sistemas agrarios, pues incluye aspectos sociales, económicos y culturales, además de los eminentemente tecnológicos.

\subsection{Uso de indicadores e índices para evaluar sustentabilidad}

Tal como lo ha planteado la CEPAL para diferentes ámbitos, en especial en aspectos ambientales de américa latina, la sustentabilidad ha cobrado mayor importancia en la medida que son crecientes los efectos sociales y ecológicos de la implementación de estrategias y técnicas equivocadas que en principios buscaban ofrecer soluciones a los problemas apremiantes de sociedad. Igual situación se presenta en aspectos sociales, ecológicos y ambientales de la actividad agropecuaria, ya que los retos que se enfrentan cada vez son mayores. Lo requiere anterior además de los retos sociales y tecnológicos que ello implica, la necesidad de desarrollar herramientas y estrategias para construir y monitorear políticas públicas para el sector agropecuario que permitan atender de forma prioritaria las necesidades del sector. El éxito de dicho proceso depende entre otros factores, de contar con información veraz y oportuna, ordenada, jerarquizada y disponible de variables decisivas de determinada actividad y su interacción con dinámicas ambientales, ecológicas, productivas, sociales y económicas entre otras, medidas mediante diferentes indicadores.

En este sentido según la CEPAL (2009), los indicadores se consideran una estadística que sintetiza el comportamiento de fenómenos que son de interés y cuyo análisis resulta importante con propósitos de intervención. Dichos indicadores se construyen a partir de su necesidad y oportunidad para evaluar el comportamiento de determinado fenómeno, así como su aporte a un sistema complejo de 
indicadores, en tal sentido, el indicador pretende mostrar el estado, la evolución y la dinámica o tendencias mediante formas de agregación, proporciones, tasa de crecimiento, y contrastes entre otros; es importante garantizar la calidad y disponibilidad de la información, tal que su adecuado procesamiento (en la construcción del indicador) conforme una estadística con capacidad para mostrar el comportamiento y las interacciones de un determinado fenómeno. Lo anterior implica que un indicador representa una estadística que contiene información seleccionada que explica o muestra las particularidades del fenómeno estudiado y que su forma sintética es comprendida y aceptada por los usuarios.

En este sentido Eber y Welsch (2003), afirman que los indicadores simples están constituidos por la combinación de dos o más datos, los cuales a su vez pueden ser combinados con otros indicadores, que mediante funciones matemáticas o estadísticas de síntesis darán origen a los indicadores sintéticos o índices. Estos índices constituyen un nivel superior de análisis que a manera de herramienta cuantitativa muestra de forma simplificada los atributos de las variables que intervienen en determinado fenómeno, sin olvidar que, si bien proporciona mayor información, no da total explicación de las interacciones entre los factores que allí intervienen.

Para la construcción de los indicadores sintéticos o índices existen diversas metodologías en función al tipo de índice que se desee obtener y al contexto donde este se ha de aplicar. Domínguez et al., (2011) afirma que se puede construir mediante los siguientes métodos:

\subsubsection{Agregación de indicadores simples}

Está basado en las proyecciones lineales unidimensionales con las cuales construyen medias ponderadas, las agregaciones y ponderación se hacen vinculando una serie de variables sucesivas que constituyen los subindicadores cuya característica común es que las unidades de medida (con los cuales se conforma el índice) debe ser la misma.

La metodología comúnmente usada es asignar a los subindicadores el mismo peso, es decir el mismo valor relativo, agregándolo mediante una suma, con lo cual se crea el índice o indicador sintético. Un limitante que se debe considerar en el método de agregación de indicadores simples es que cuando los indicadores se subdividen por dimensiones para realizar las agregaciones suele ocurrir que el 
peso otorgado a cada indicador no sea igualitario. De la misma forma el método no contempla la forma de identificar las relaciones de causalidad existentes entre los subindicadores, que a la postre pueden generar inconvenientes dado que ante la incorporación de variables altamente correlacionadas se estaría contabilizando su efecto por partida doble. Así, el indicador para una unidad i se define como:

$$
I S_{t}=w . I N_{i 1}+w \cdot I N_{i 2+} \ldots+w \cdot I N_{i m}=\sum_{j=i}^{m} w \cdot I N_{i j}
$$

Donde:

w es el peso de los indicadores

$I N_{i j}$ es el valor normalizado del indicador $j$ para la unidad $i$.

\subsubsection{Construcción participativa de indicadores}

Consiste en la construcción mediante valoración cuantitativa ponderada de juicios de individuos expertos en un determinado tema quienes asignan valores subjetivos. Para la valoración de un tema, el experto cuenta con una bolsa limitada de puntos para ser distribuidos entre los indicadores que hacen parte del sistema evaluado de acuerdo con su juicio de valor, donde obtiene más puntos aquello que considera de mayor importancia. El valor del indicador es la puntuación media otorgada a cada indicador por el grupo de expertos. El indicador sintético se obtiene a partir de sumatoria de las ponderaciones de los indicadores del sistema. Las limitantes de este método refieren a la confiabilidad en las valoraciones de los expertos en razón a la disímil experticia de cada individuo lo cual le hace abordar su valoración desde una perspectiva diferente (Sajeva et al., 2005). Los métodos participativos más conocidos y de mayor uso son: el Método de opinión pública y Panel de expertos (Cottrell et al., 2004; Tsaur et al., 2006; Ugwu et al., 2006). En estos métodos las ponderaciones se obtienen a partir del promedio de la puntuación de los participantes en el panel, de tal forma que el indicador $l_{\mathrm{j}}$ está dado por:

$$
w_{j}=\frac{q_{j}}{\sum_{s=1}^{m} q_{s}}
$$

Donde:

$w_{\mathrm{j}}$ : es el peso final asignado al indicador $l_{\mathrm{j}}$

$q_{\mathrm{j}}$ : es la puntuación media del indicador $l_{\mathrm{j}}$

$q_{\mathrm{s}}$ : es la puntuación media dada al indicador $l_{\mathrm{s}}$ de la dimensión $\mathrm{s}$. 


\subsubsection{Construcción de indicadores mediante de análisis multivariante}

Está basado en la aplicación de técnicas estadísticas multivariantes para la obtención de indicadores sintéticos, es posible afirmar que entre sus múltiples fortalezas este método no hace doble valoración de información (como en los métodos anteriores) y asigna valores concretos a las ponderaciones. Dentro de este método se destacan las siguientes técnicas:

- Análisis de componentes principales.

- Análisis factorial.

- Escalamiento óptimo.

- Análisis de conjunto.

\subsubsection{Análisis de componentes principales (ACP)}

Se define como el procedimiento que se hace a un conjunto de datos para reducir su dimensionalidad, de tal forma que queden mejor representados en mediante mínimos cuadrados, es decir transforma los datos de variables correlacionadas en grupos de valores o datos de variables que no poseen correlación lineal, tratando de explicar el mayor porcentaje posible de variabilidad con menor cantidad de variables, a lo cual se le denomina Componentes principales. En este sentido el uso del ACP se usa para obtener indicadores sintéticos que contiene la máxima información posible de valores iniciales de indicadores. El uso del ACP en un indicador o un grupo de ellos, genera nuevas variables (componentes principales) no correlacionadas, de varianza máxima y media aritmética cero. Su aplicación requiere que exista correlación entre los indicadores previamente normalizados es decir que estos se expresen en las mismas unidades.

Así: la componente $h$ para $\left(Z_{h}\right)$ está definida de la siguiente forma:

Donde:

$$
Z_{h}=\sum_{j=1}^{m} \omega_{h j} . I N_{j}
$$

$\omega_{\mathrm{hj}}$ : ponderación de la componente principal $h$

\subsubsection{Análisis factorial}

Es la segunda técnica del método multivariante la cual al igual que el ACP reduce número de variables mediante las cuales se expresa o hacen parte de un determinado fenómeno. A diferencia del ACP esta técnica busca identificar relaciones matemáticas que expresan las variables iniciales a través de factores comunes y 
factores específicos. En síntesis, el Análisis factorial tiene como objetivo encontrar variables sintéticas "latentes" que no son fácilmente observables ni medibles que se sospecha existen en las variables originales. En el Análisis factorial solo parte de la varianza de las variables originales es explicada por variables cuya combinación lineal la determinan los factores comunes denominada camunalidad, así mismo, parte de la varianza que no se explica por los factores comunes se denomina unicidad, las cuales representan parte de la variabilidad de cada variable (comunalidad + unicidad $=1$ ). De tal forma que construir de un índice a partir de un sistema de indicadores puede realizarse mediante su reducción a un grupo de factores básicos o indicadores iniciales.

Sean $X_{1}, X_{2}, \ldots X_{p}$ Los subindicadores iniciales referidos a un conjunto $n$, se puede expresar en el siguiente modelo:

$$
\begin{aligned}
& X_{1}=w_{11} F_{1}+w_{12} F_{2}+\cdots+w_{1 k} F_{k}+u_{1} \\
& X_{2}=w_{21} F_{1}+w_{22} F_{2}+\cdots+w_{2 k} F_{k}+u_{2} \\
& X_{p}=w_{p 1} F_{1}+w_{p 2} F_{2}+\cdots+w_{p k} F_{k}+u_{p}
\end{aligned}
$$

Donde:

$\mathrm{F}_{1 . \mathrm{k}}$ : se definen como los factores comunes en los que quedarán representados (reducidos) los valores inicialmente planteados.

$u_{1} \ldots u_{p}$ : Características específicas de cada variable.

$\left\{w_{i j} ; i=1, \ldots, p ; j=1, \ldots, k\right\}$ : coeficientes de las cargas factoriales.

Con lo anterior es posible afirmar que el análisis de componentes principales (ACP) genera los factores comunes mediante el análisis factorial, que estarían constituidas por las componentes principales tipificadas (Domínguez et al., 2011).

\subsubsection{Escalamiento óptimo}

También llamado análisis de componentes principales categóricos por escalamiento óptimo o ACP por mínimos cuadrados alternante o no métrico. Esta técnica permite hacer un análisis de variables categóricas o cualitativas las cuales se pueden cuantificar a partir de una matriz de similaridad y disimilaridad entre los pares de $n$ objetos (Gower y Digby, 1981; Domínguez et al., 2011). El ACP no lineales transforma las variables originales asignado valores a las categorías de cada una de las variables para posteriormente analizar la estructura de sus 
datos. La técnica consiste en la valoración de las variables cualitativas, maximizando la correlación lineal entre las variables, transformado así las variables cualitativas en variables cuantitativas, determinado así la mejor combinación lineal de las variables con lo cual se facilita la construcción de modelos de regresión. La técnica genera un conjunto de cuantificaciones para las categorías de cada variable (puntuaciones óptimas) pasando de valores cualitativos a valores métricos los cuales se obtienen minimizando la distancia entre categorías relacionadas y maximizando la distancia entre las no relacionadas (Domínguez et al., 2011; Tapia, 2007).

El algoritmo de optimización para una matriz de pérdida $H$ de dimensión (nxm) se expresa de la siguiente forma:

$$
\sigma(X, A) \equiv S S Q\left(H-X H^{\prime}\right)
$$

Dónde: X es una matriz ( $\mathrm{nxp}$ ) de rango p, A es una matriz de dimensión (mxp) y SSQ(.) es la suma de cuadrados de los elementos de la matriz (.). Las matrices X y A se encuentran calculando los valores singulares de $\mathrm{H}$ por el método de mínimos cuadrados se calcula de la siguiente forma:

$$
\sigma(x, a) \equiv m^{-1} \Sigma_{j} S S Q\left(x-a_{j} h_{j}\right)=m^{-1} \Sigma_{j} \operatorname{tr}\left(\left(x-a_{j} h_{j}\right)^{\prime}\left(x-a_{j} h_{j}\right)\right.
$$

Además de las técnicas anteriormente descritas, es frecuente que se usen otras técnicas estadísticas para la construcción de indicadores e índices, tales como: (1) Indicadores basados en distancias y (2) Técnicas de análisis multicriterio, las cuales mejoran tanto el análisis de datos como la toma acertada de decisiones sobre diversos campos.

En este sentido la construcción de indicadores se ha convertido en prioridad por parte de entes gubernamentales y académicos tal que es vital analizar el desempeño y eficiencia de diversos programas de acción, el cumplimiento de los objetivos de la política pública, y la planeación del desarrollo, entre otros aspectos. Para el caso del sector agropecuarios y por los consabidos impactos generados al ambiente, han ganado importancia diversas herramientas metodológicas que dan cuenta de las externalidades del modelo de producción agropecuaria, así como sus efectos en el cumplimiento de los objetivos de sustentabilidad ecológica, social y ambiental. 
A partir de la amplia preocupación de la sociedad global y en especial de los técnicos y académicos del sector agropecuario, se ha trabajado sobre la necesidad de determinar herramientas que permitan evaluar el grado de impacto de las externalidades de la actividad agropecuaria que se manifiesta como el conjunto de condiciones que disminuyen la capacidad de los agroecosistemas por mantenerse en equilibrio, tal que esta condición es evaluada como el nivel de sustentabilidad , la cual determina de forma considerable la permanencia de los agricultores en labores del campo (Fonseca et al., 2012).

El concepto de sustentabilidad ha tenido amplia atención y su definición es diversa tanto como autores la han abordado; desde el punto de vista agropecuario se le considera como la medida de la habilidad de un agroecosistema para mantenerse productivo en el tiempo a pesar de restricciones ecológicas, climáticas y tecnológicas, entre otros aspectos (Quiroz et al., 2014). De tal forma que medir la sustentabilidad de los ecosistemas cobra especial relevancia ya que permite confirmar que un determinado modelo (sistema de producción) es una alternativa viable desde la perspectiva tecnológica, ecológica, social y financiero.

Existen diversos métodos para tal fin, el primero es la evaluación "per se” la cual busca identificar al interior de un agroecosistema si las acciones allí realizadas generan algún grado de sustentabilidad, basándose en la experiencia del examinador. Un segundo método es la Evaluación comparativa la cual se basa en un análisis ex ante y ex post comparando dos o más sistemas, identificando prácticas agrícolas y/o pecuarias pasadas versus las futuras en una dinámica retrospectiva y prospectiva.

Como se ha mencionado anteriormente los indicadores son una herramienta para comprender la dinámica de un agroecosistema y por lo tanto medir el nivel de sustentabilidad e identificar sus puntos críticos, en la medida que estos agroecosistemas son complejos la selección de indicadores debe ser tal que permita la simplificación de la realidad.

Entre otros aspectos los indicadores usados para determinar la sustentabilidad de agroecosistemas deben tener las siguientes características: Que su construcción esté relacionada y provenga de los atributos de la sustentabilidad, tal que su especificidad este dada por su facilidad de aplicación en un contexto único y determinado, y le permita registrar los cambios en el transcurso del tiempo; de la 
misma forma se deben caracterizar por ser directos, de fácil recolección, fáciles de interpretar, de características universales pero ajustados a las condiciones de un aspecto en particular.

\subsection{Evaluación de sustentabilidad de agroecosistemas familiares campesinos mediante el MESMIS}

La metodología denominada Marco para la evaluación de sistemas de manejo de recursos naturales incorporando indicadores de sustentabilidad (MESMIS), aparece en 1995 con el propósito de evaluar la sustentabilidad de proyectos productivos que integraban la red de Manejo de recursos naturales. Fue creado por un grupo interdisciplinario y multi-institucional de México, con el fin de plasmar los principios generales de la sustentabilidad en las definiciones operativas, indicadores y prácticas que pudieran aplicarse a los agroecosistemas en particular, pero a las comunidades rurales en general (López-Ridaura, Masera, y Astier, 2002).

MESMIS propone una estructura cíclica multi-escalar y flexible, con una orientación práctica basada en un enfoque participativo entre quienes intervienen en el proceso evaluativo del agroecosistema. Además, ofrece una visión amplia e interdisciplinaria sobre las potencialidades y aspectos que limitan los procesos de evaluación de sustentabilidad. Además de lo anterior establece los lineamientos para hacer la comparación entre diversos sistemas de manejo tradicionales (frecuentemente basados en técnicas de revolución verde) y sistemas agropecuarios alternativos. El método es aplicable en diversos contextos agropecuarios y muestra de manera integral, límites y oportunidades de sustentabilidad del sistema en las perspectivas económicas, sociales y ambientales (Masera, Astier, y López-Ridaura, 2000).

La evaluación de sustentabilidad de agroecosistemas requiere la identificación de los atributos generales que este posee, entendidos como el conjunto de condiciones ecológicas, ambientales, tecnológica y socio económicas que permiten su estabilidad y funcionamiento, así como aquellas que expresan los resultados de los procesos biológicos que allí se llevan a cabo. En el mismo sentido diversos autores aquí citados recomiendan estructurar un marco de referencia que permite la identificación y construcción de un grupo de indicadores con los cuales se evalúe la sustentabilidad de los agroecosistemas. Para el caso de los agroecosistemas familiares campesinos se procede de conformidad como lo establece el MESMIS, identificando los atributos a partir de sus propiedades ecosistémicas. 
Los siguientes son los atributos que son considerados por el MESMIS para la evaluación de sustentabilidad.

Figura 1. Esquema general del Mesmis.

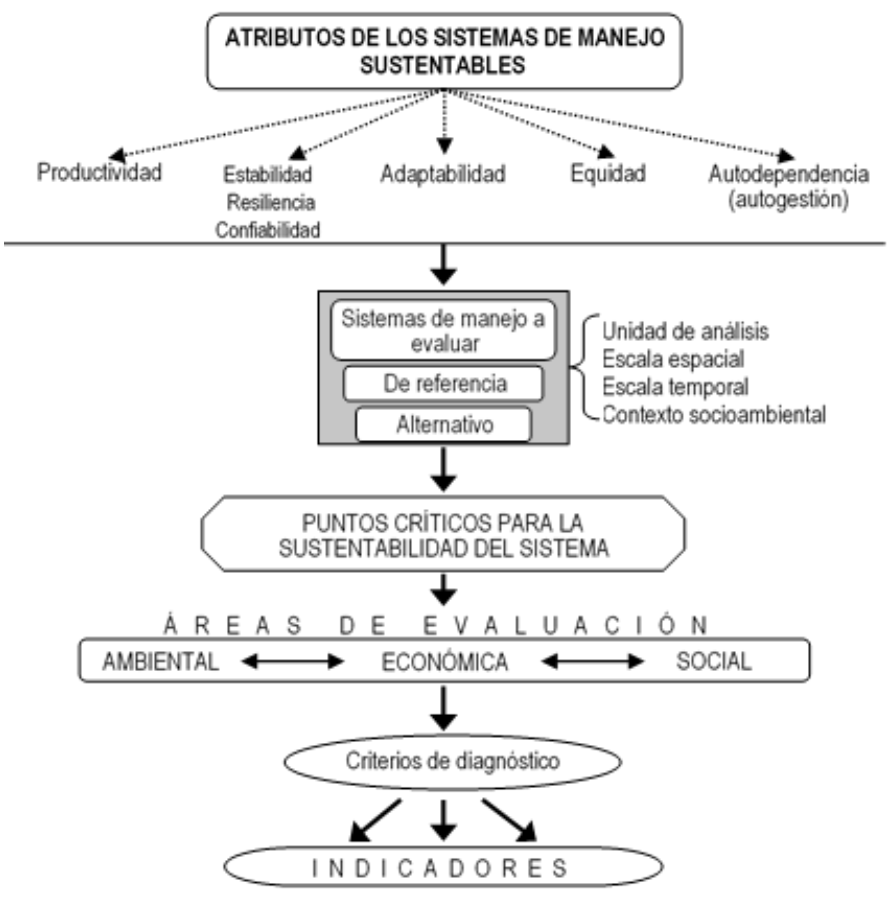

Fuente: Masera, Astier, y López-Ridaura, 2000.

1. Atributo productividad. Se considera la capacidad del agroecosistema para la provisión de bienes y servicios necesarios para mantener en condiciones adecuada a los integrantes del núcleo familiar que allí residen.

2. Atributo equidad. Se entiende como la condición que permite la participación de los integrantes del agroecosistema en la toma de decisiones, así como la distribución de responsabilidades y beneficios relacionados con el quehacer agropecuario y rural.

3. Atributo estabilidad. Refiere la capacidad del agroecosistema para mantenerse en condición productiva estable durante largos periodos a pesar de estar sometido a condiciones y factores variables, tal como condiciones climáticas, fuerzas de mercado y variaciones en la disponibilidad de recursos tanto financieros, tecnológicos y disponibilidad de mano de obra, entre otros aspectos. 
4. Atributo resiliencia. Se considera como la capacidad de origen ecosistémico que le permite retornar a un estado de equilibro inicial luego de sufrir un disturbio o perturbación de origen interno o externo, tal como variaciones drásticas en el clima, presiones originados en los precios de mercado, entre otros aspectos. De la misma forma se puede afirmar que la resiliencia es una propiedad de tipo sociocultural, definida como la capacidad que posee los integrantes del agroecosistema para adaptarse a condiciones cambiantes tanto de orden climático, social y ambiental.

5. Atributo Confiabilidad. Para los agroecosistemas se entiende la confiabilidad como la propiedad que este posee para mantener las interacciones de sus componentes tal que su capacidad de respuesta ante un evento adverso le induce a la autorregulación, en otras palabras, un agroecosistema es confiable si es poco frecuente que sea modificado por perturbaciones del ambiente, la confiabilidad es mayor cuando tanto la frecuencia como la intensidad de eventos perturbadores disminuyen. Es posible afirmar que la confiabilidad está íntimamente relacionada con la "resiliencia ingenieril" que se define como la velocidad con la cual un ecosistema vuelve a su estado de equilibrio luego de un disturbio, luego a mayor velocidad, mayor confiabilidad.

6. Atributo Adaptabilidad. Un sistema se considera adaptable cuando tiene la capacidad de hacer ajustes internos (en el sistema de producción) que le permiten buscar nuevos equilibrios luego de recibir una perturbación irreversible, luego esta capacidad de auto ajuste es frecuente en aquellos agroecosistemas que tienen amplia diversidad, ya que pueden lograr diversos equilibrios desde lo biológico, ecosistémico y socio cultural.

7. Atributo Autodependencia. Se refiere a la capacidad del agroecosistema para proveerseenaltogradolosinsumos, procesosyrecursos quelepermiten desarrollar plenamente su estructura y funcionamiento, es decir, un agroecosistema es autodependiente cuando la generación de materia y energía en alto porcentaje está soportada por las interacciones e interdependencias internas, y muy poco de fuentes energéticas externas (Astier y González, 2008).

Teniendo como base fundamental la definición e identificación de los anteriores criterios, la metodología MESMIS propone un ciclo de evaluación del agroecosistema que comprende los siguientes seis pasos a saber: 
1. Identificación y caracterización del agroecosistema: comprende entre otros aspectos las siguientes actividades: a) identificar el o los sistemas de manejo que se van a analizar; b) caracterizar el sistema de manejo de referencia; c) caracterizar el sistema alternativo. Esta caracterización se realiza identificando los aspectos del sistema de gestión y su contexto socioeconómico y ambiental.

El sistema MESMIS se basa fundamentalmente en un proceso comparativo entre agroecosistemas, es decir, la evaluación de sustentabilidad está basada en la comparación que se hace con otros agroecosistemas y/o condiciones preestablecidas en la región que le sirven como referente estándar. Dicha evaluación de sustentabilidad incluye aspectos técnicos, sociales y ecosistémicos propios de la zona de influencia. La contrastación cobra vigencia cuando dentro del agroecosistema que se desea evaluar (alternativo) se introducen innovaciones o ajustes tecnológicos, sociales etc. que se presume mejoran los indicadores de desempeño con respecto al sistema que se ha tomado como referente regional.

Para lo anterior, se realiza mediante un proceso metodológico que posteriormente se describe, la evaluación de sustentabilidad tanto para el sistema de referencia como para el sistema alternativo. En este aspecto se consideran dos tipos de evaluación de sustentabilidad a saber: Evaluación longitudinal y Evaluación transversal. Para el primer tipo se considera la comparación del agroecosistema durante un periodo de tiempo (varios años o ciclos de cosecha), para lo cual se define como el "sistema de referencia", comparando sus resultados con los obtenidos en la temporada siguiente que para este efecto se consideraría el "sistema alternativo". Un aspecto de especial atención en este primer paso es la descripción y caracterización del agroecosistema que incluyen entre otros aspectos: los cultivos, actividades pecuarias, las prácticas de manejo, insumos agropecuarios, productos que se generan dentro del agroecosistema, además de los principales aspectos socioeconómicos de la familia rural, así como su nivel de organización social.

2. Identificación de los puntos críticos del agroecosistema: se realiza mediante un análisis del desempeño de las actividades productivas, en donde se identifican aspectos que son limitantes, y cuya persistencia 
pone en riesgo su permanencia productiva, se identifican dichos aspectos mediante la valoración (cualitativa y/o cuantitativa) de diferentes variables que a juicio de los mismo agricultores y asistentes técnicos presente condiciones vulnerables, así como aquellas que representan su principal fortaleza, lo anterior resulta definitivo para obtener resultados de alto valor en la evaluación. Una vez identificados los puntos críticos del agroecosistema, se deben correlacionar con los atributos de sustentabilidad previamente identificados.

3. Identificación de criterios de diagnóstico e indicadores. Una vez identificados los atributos de sustentabilidad del agroecosistema (productividad, estabilidad, resistencia, fiabilidad, capacidad de adaptación, equidad y autogestión), a cada uno de ellos se asocia una cantidad variable de Criterios de diagnóstico, los cuales se definen como los atributos o parámetro mediante la cual se mide una determinada condición, para este caso de sustentabilidad del agroecosistema, los criterios son eminentemente descriptivos y muestran las condiciones o fortalezas (atributos) del agroecosistema, a su vez estos criterios se evalúan mediante indicadores de sustentabilidad, los cuales deben ser robusto y suficientemente amplios para cumplir con las diferentes dimensiones o áreas de evaluación: social, económica y ambiental. El siguiente cuadro muestra la relación entre los atributos de sustentabilidad, los criterios de diagnóstico y los indicadores (Astier et al., 2012). 
Tabla 1. Interacción entre Atributos de sustentabilidad, criterios de diagnóstico e indicadores.

\begin{tabular}{|c|c|c|c|}
\hline Atributo & $\begin{array}{l}\text { Criterios de } \\
\text { diagnóstice }\end{array}$ & $\begin{array}{r}\text { Areas de } \\
\text { evaluación }\end{array}$ & \\
\hline \multirow{2}{*}{ 造蛋 } & \multirow{2}{*}{ Bfieiencia } & $\begin{array}{l}\text { Rendimiento agricola, eficiencia energética del } \\
\text { agrocoosistema }\end{array}$ & $A$ \\
\hline & & $\begin{array}{l}\text { Relación beneficio/eosto, inversión financiera, } \\
\text { rentabilidad, }\end{array}$ & $\mathbf{E}$ \\
\hline \multirow{3}{*}{ 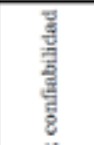 } & \multirow{3}{*}{ Diveraidad } & $\begin{array}{l}\text { Feppecies alimentarias, arreglos productivos, sistemas de } \\
\text { rotacion }\end{array}$ & A \\
\hline & & $\begin{array}{l}\text { Nùmero de eultivos; grado de integración en la } \\
\text { produccion y comercialización }\end{array}$ & $\mathbf{B}$ \\
\hline & & Nimero de etnias involucradas en el manejo de recursos & $\mathbf{S}$ \\
\hline \multirow{8}{*}{ 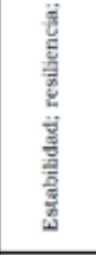 } & \multirow{4}{*}{$\begin{array}{l}\text { Conservación de } \\
\text { recuraos }\end{array}$} & Calidad de suclo $y$ agua & A \\
\hline & & Relación entre entradas y salidas de mutrientes criticos & A \\
\hline & & Número de variedades criollas utilizadas & A \\
\hline & & Capacidad de ahorro & $\mathrm{E}$ \\
\hline & \multirow{2}{*}{$\begin{array}{l}\text { Frugilidad del } \\
\text { sistemn }\end{array}$} & Incidencia de plagas y enfermedades & A \\
\hline & & Tendencias y variacion de rendimientos & $\mathbf{B}$ \\
\hline & $\begin{array}{l}\text { Distribución de } \\
\text { riesgos }\end{array}$ & Aceeso a créditos, seguros u otros mecanismos & $\mathrm{B}$ \\
\hline & Calidad de vida & Indices de calidad de vida & S \\
\hline \multirow{4}{*}{$\begin{array}{l}\frac{\mathrm{g}}{\mathrm{g}} \\
\frac{\mathrm{c}}{\mathrm{g}} \\
\frac{\mathrm{z}}{\mathrm{z}}\end{array}$} & \multirow{2}{*}{$\begin{array}{l}\text { Fortedecimiento } \\
\text { del proceso de } \\
\text { aprendizaje }\end{array}$} & Capacitación y formación de los integrantes & $\mathrm{S}$ \\
\hline & & Adaptaciones locales a los sistemas propuestos & \$ \\
\hline & \multirow{2}{*}{$\begin{array}{l}\text { Capacidad de } \\
\text { cambio e } \\
\text { innovación }\end{array}$} & Evolución del número de productores por sistemn & s \\
\hline & & Generaciôn de conocimientos y précticas & $\mathbf{s}$ \\
\hline \multirow{2}{*}{$\begin{array}{l}\text { है } \\
\text { है } \\
\text { है }\end{array}$} & $\begin{array}{l}\text { Distribución de } \\
\text { costos y } \\
\text { beneficios }\end{array}$ & $\begin{array}{l}\text { Número de beneficiarios según etnias, género o grupo } \\
\text { social }\end{array}$ & s \\
\hline & $\begin{array}{l}\text { Fvolución del } \\
\text { empleo }\end{array}$ & Demanda o desplazamiento de trabajo & $\mathrm{E}$ \\
\hline \multirow{7}{*}{ 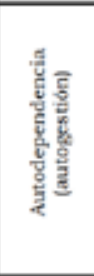 } & Participación & $\begin{array}{l}\text { Implicación de los beneficiarios en las distintas fases del } \\
\text { projocto }\end{array}$ & s \\
\hline & \multirow{2}{*}{ Autosuficiencin } & Grade de dependencis en insumos externos criticos & A \\
\hline & & Nivel de autofinanciamiento & $\mathbf{E}$ \\
\hline & \multirow{3}{*}{ Control } & $\begin{array}{l}\text { Reconocimiento de los derechos de propiedad (individuales o } \\
\text { colectivoe) }\end{array}$ & s \\
\hline & & Uso de conocimientos y habilidedes locales & S \\
\hline & & $\begin{array}{l}\text { Poder de docisión sobre aspectos criticos del } \\
\text { funcionamiento del sistema }\end{array}$ & $\mathbf{s}$ \\
\hline & Organización & Tipo, estructura, processo de toma de decisiones & S \\
\hline
\end{tabular}

Fuente: Masera, Astier, y López-Ridaura, 2000.

Para construir de forma acertada los indicadores de sustentabilidad del agroecosistema MESMIS propone seguir cinco fases metodológicas:

- Identificar los atributos generales de sustentabilidad del agroecosistema.

- Definir los puntos críticos del agroecosistema.

- Identificar los criterios de diagnóstico que permitan valorar los puntos críticos previamente definidos.

- Se construye un batería de indicadores que responde a los criterios identificados.

- Se construye el conjunto de indicadores estratégicos (ambientales, económicos y sociales). 
4. Medición y seguimiento de indicadores: Como siguiente paso en el ciclo de evaluación del agroecosistema se hace la toma y análisis de datos de los aspectos evaluados mediante los indicadores propuestos anteriormente, lo cual supone que se haga en periodos y frecuencias preestablecidas (dependiendo del ciclo biológico del cultivo, las épocas de siembra y cosecha, las temporadas de establecimiento de labores pecuarias etc.), evaluaciones repetidas de aspectos productivos, modelaje de variables, entre otros aspectos. Lo anterior se realiza haciendo uso de algunos métodos de captura de información entre los cuales se pueden mencionar los siguientes: a) Revisión bibliográfica para determinar parámetros productivos regionales y locales; b) Mediciones directas de variables productivas; c) Montaje de parcelas experimentación o monitoreo; d) Diseño de modelos de simulación de variables; e) Formularios tipo encuesta para levantamiento de información; f) Visitas de inmersión con la familia rural; g) Uso de dinámicas grupal de participación; h) Cartografía social.

5. Generación y análisis de resultados: Finalmente se procede a consolidar y analizar los resultados de los criterios de evaluación medidos con los indicadores, esta fase es vital importancia ya que de la precisión y veracidad de la información obtenida dependerá las acciones de mejora que se implementarán en el agroecosistema. Metodológicamente se debe trabaja con indicadores sintéticos que condensen información de diversos aspectos que no es fácilmente agregable. Las principales limitantes a superar en este paso es eliminar el sesgo en la elección de los criterios, o que estos tengan datos de difícil medición, igualmente es importante mantener la interrelación en la escala jerárquica y ordenada de Atributos de sustentabilidad, Criterios de diagnóstico e indicadores. Estos resultados se pueden expresar mediante técnicas o valores cualitativos, cuantitativos, gráficos descriptivos.

Las técnicas cuantitativas y cualitativas requieren una fuerte base estadística en la construcción y análisis de los indicadores, para ello se sugiere que se use el método de construcción multivariante, los cuales pueden capturar información sobre el estado actual y el desarrollo de los agroecosistemas. Las técnicas gráficas y en algunos casos las cualitativas usan esquemas de radar o ameba para presentar sus resultados, haciendo una representación de las diferencias en los aspectos evaluados mediante diferentes distancias 
respecto de un valor de referencia (López-Ridaura, Masera, Y Astier, 2000). El gráfico de radar permite representar y al mismo tiempo analizar el comportamiento de cada factor o sistema evaluado, obteniendo así una visión global del comportamiento del agroecosistema, de la misma forma de manera cuantitativa permite determinar el nivel de los indicadores evaluados y contrastarlos con los que presentan los otros agroecosistemas. A través de esta herramienta es posible visualizar los niveles de desempeño de los agroecosistemas, allí se aprecia la brecha entre los niveles de referencia internacional, nacional y local. En este trabajo se usaron los denominados radares absolutos, donde se asume la práctica ideal del sector con una puntuación de cinco (5), a partir de la cual se contrastó con la mejor práctica realizada en los agroecosistemas, sin hacer ningún tipo de modificación de los valores obtenidos y su contraste con la considerada práctica ideal (Fonseca, Cleves y Páez, 2013).

Figura 2. Esquemas de radar para la presentación de resultados.

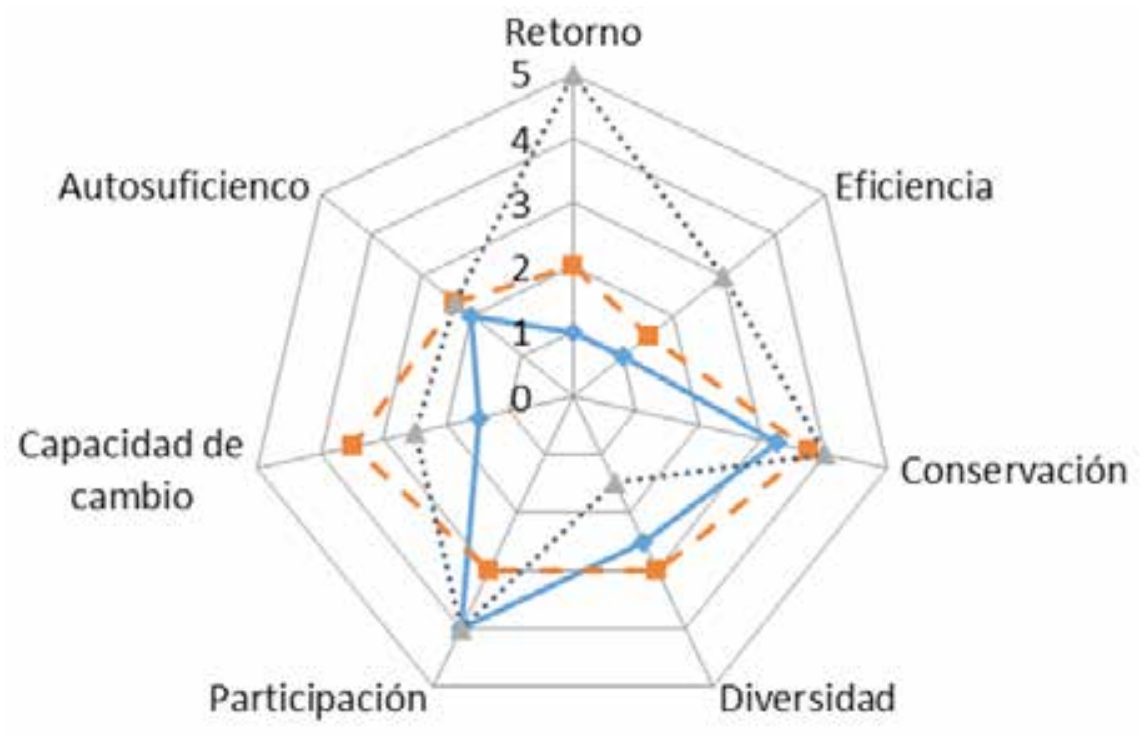

Fuente: Fonseca, Cleves y Páez, 2013. 
6. Conclusiones y recomendaciones del agroecosistema. Para finalizar el ciclo de evaluación del agroecosistema, el cual es quizá uno de los momentos más importante de este proceso, pues se evidencian los alcances logrados en la valoración del estado del agroecosistema. De la misma forma dicha valoración será primordial para planear las estrategias y recomendaciones para el sistema de manejo dentro del agroecosistema. Los expertos recomiendan que el resultado de un primer proceso de evaluación no sea más que la línea base a partir de la cual se dará inicio a un nuevo proceso que permita evidenciar la evolución en el tiempo de los ajustes planteados, es decir el modelo adquiere una nueva propiedad en la medida que permite obtener información de las dinámicas ecológicas, sociales, culturales y económicas de los agroecosistemas. Un aspecto relevante de MESMIS es que por su virtud de involucrar diversos aspectos factores y actores que intervienen en los sistemas productivos es altamente incluyente, por lo que dentro del proceso de evaluación de dichas condiciones se debe dar amplia participación de integrantes de la familia, técnicos e investigadores y todos aquellos que tengan relación con este proceso (incluyendo agentes externos como proveedores y la cadena de comercialización, entre otros). Igualmente, en esta fase de evaluación y como resultado del proceso adelantado se deberán generar las conclusiones sobre el estado de los agroecosistemas (los sistemas de manejo), como producto de la valoración de los indicadores sintéticos anteriormente mencionados. Fundamentalmente se logrará identificar el nivel o grado de sustentabilidad del "sistema alternativo" comparado con el "sistema tradicional". La valoración de las causas de dichos resultados resulta muy importante para agricultores y técnicos, ya que luego de un análisis reflexivo sobre el desempeño del agroecosistema, se lograría al menos identificar los factores y condiciones que subyacen y condicionan dicho desempeño, lo cual es el inicio de las estrategias de mejora de la sustentabilidad del sistema alternativo con respecto al de referencia (Astier et al., 2012). 
Figura 3. Ciclo de evaluación en MESMIS.

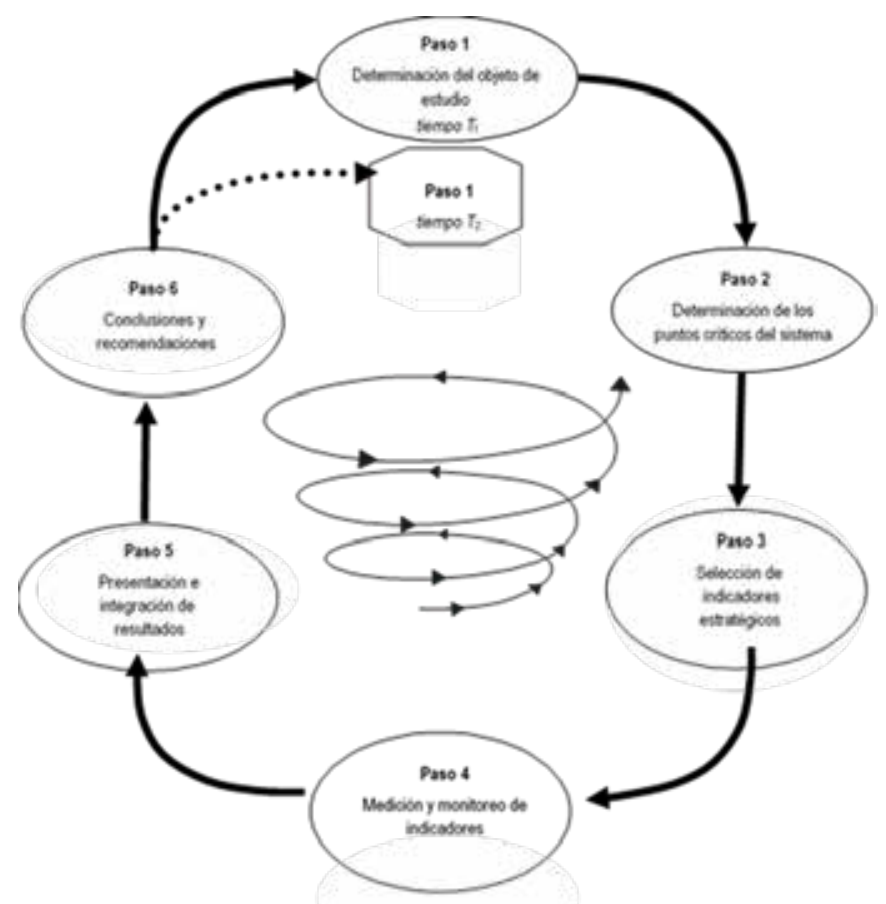

Fuente: Masera, Astier, y López-Ridaura, 2000.

\subsection{Evaluación de la sustentabilidad de agroecosistemas familiares campesinos mediante MESMIS}

A continuación, se presenta el proceso metodológico para la implementación de la evaluación de sustentabilidad de agroecosistemas campesinos mediante la metodología MESMIS, este capítulo es el resultado de la experiencia del grupo de investigación en sistemas sostenibles de producción GIGASS de la Universidad Nacional Abierta y a Distancia - UNAD de Colombia.

En los siguientes apartes se integran algunos resultados de la evaluación de sustentabilidad de agroecosistemas campesinos y de páramo de la zona central del departamento de Boyacá. Si bien el objetivo no es mostrar la totalidad de los resultados obtenidos en estos trabajos, el documento se centrará en el proceso metodológico de la selección de los agroecosistemas, la estructuración de los indicadores, captura, procesamiento y análisis de la información mediante indicadores sintéticos o índices. 
La primera actividad fue la identificación de las organizaciones de campesinos en tres municipios del Departamento de Boyacá, en cada uno de los cuales se seleccionó por conveniencia diez agroecosistemas (fincas campesinas) con las cuales se realizó una caracterización inicial de aspectos tecnológicos, sociales y ambientales. La caracterización permitió identificar los agroecosistemas “tipo”, es decir aquellos que por mayor similitud en aspectos ecológicos, sociales, ambientales y tecnológicos con otros agroecosistemas pueden ser identificados como un grupo homogéneo. Para la identificación de estos agroecosistemas "tipo" se evaluaron indicadores relacionados con la calidad de vida, biodiversidad del agroecosistema y cohesión familiar. Para el primer indicador se abordaron los siguientes aspectos:

- Tipo de tenencia de la tierra (propietario, arrendatario, aparcero etc.).

- Disponibilidad de servicios públicos.

- Disponibilidad y calidad de vías de acceso.

- Disponibilidad y calidad de agua para consumo humano.

- Condiciones y materiales de la vivienda.

- Dotación de electrodomésticos.

Para el indicador biodiversidad se realizó un inventario de la cantidad de especies tanto agrícolas, pecuarias y forestales, con lo cual se construye el indicador de nivel de biodiversidad de los agroecosistemas. Es importante mencionar que esta actividad se realiza junto con los integrantes del núcleo familiar campesino mediante la herramienta metodológica denominado "Mapa de biodiversidad" que propone Geilfus, 1997.

Para identificar el nivel de cohesión familiar se construye un indicador que involucra características del núcleo familiar, sus integrantes, roles y actividades que desempeñan y su permanencia en las actividades agropecuarias, el indicador contempla los siguientes aspectos.

- Rurales entre las cuales se destacan:

- Organización del núcleo familiar.

- Roles en la actividad agropecuaria.

- Percepción de la estabilidad financiera.

- Niveles migratorios de integrantes del núcleo familiar (últimos 10 años). 
Para la estimación de los indicadores se construyó una escala de valoración donde uno (1) representa la condición menos deseable o perjudicial y (5) cinco la mejor condición posible o mejor práctica realizada, con esta escala se estableció el desempeño de los indicadores para los 30 agroecosistemas evaluados. Luego del proceso de caracterización se hace a manera de tipificación la organización de tres grupos, cada uno con características similares de desempeño. De cada grupo "tipificado" se seleccionó un agroecosistema representativo "agroecosistema tipo", con el cual se continúa el desarrollo de la investigación. Una vez identificados los "agroecosistemas tipo" se inicia la aplicación del MISMIS siguiendo los pasos metodológicos propuestos por Astier, Masera y otros autores (Masera et al., 1999).

El segundo paso consiste en la Identificación de los puntos críticos de los "agroecosistemas tipo" los cuales surgen desde la interacción y el consenso del núcleo familiar en cada agroecosistema, los asistentes técnicos presentes en la zona y el equipo de investigación. La metodología para su identificación consistió en la realización de sendos talleres para la identificación de fortalezas y debilidades (a manera de matriz DOFA) y la valoración de impactos que fueron identificados como los de mayor incidencia al sistema de producción como a la estabilidad financiera de la familia rural. Es importante mencionar que en estos talleres participativos se aplica la metodología de la "Matriz de valoración de problemas" propuesto por Geilfus, 1997. En el siguiente cuadro se muestra el resultado del proceso anterior en tres agroecosistemas, este cuadro es meramente ilustrativo de las posibilidades que es este paso se tienen. 
Tabla 2. Puntos críticos en agroecosistemas campesinos.

\begin{tabular}{|c|c|c|c|}
\hline $\begin{array}{c}\text { Atributo de } \\
\text { sustentabilidad }\end{array}$ & $\begin{array}{l}\text { Criterio de } \\
\text { diagnostico }\end{array}$ & Agroecosistema 1 & Agroccosistema 2 \\
\hline \multirow{20}{*}{ 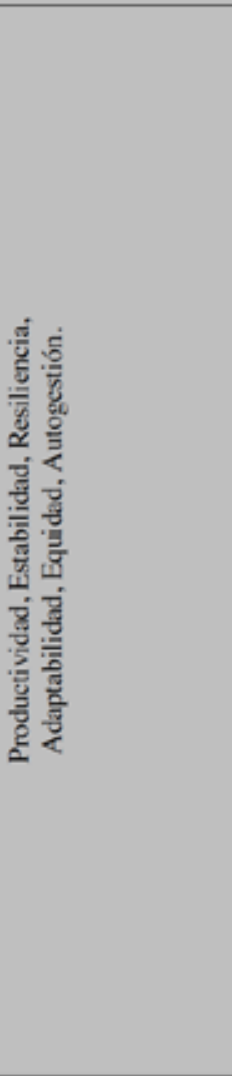 } & \multirow[t]{2}{*}{ Retornos } & $\begin{array}{l}\text { Rendimientos agrícolas } \\
\text { inferiores al promedio de la } \\
\text { región. }\end{array}$ & $\begin{array}{l}\text { Rendimientos agrícolas } \\
\text { inferiores al promedio de la } \\
\text { región. }\end{array}$ \\
\hline & & $\begin{array}{l}\text { Ingresos insuficientes para } \\
\text { atender necesidades básicas }\end{array}$ & $\begin{array}{l}\text { Ingresos insuficientes para } \\
\text { atender necesidades básicas }\end{array}$ \\
\hline & Eficiencia & $\begin{array}{l}\text { Escasa rentabilidad del } \\
\text { ejercicio agrícola. }\end{array}$ & Adecuada rentabilidad \\
\hline & \multirow[t]{5}{*}{ Conservación } & $\begin{array}{l}\text { Alta dependencia de insumos } \\
\text { químicos. }\end{array}$ & $\begin{array}{l}\text { Frecuente uso de insumos } \\
\text { químicos }\end{array}$ \\
\hline & & Escasa cobertura del suelo. & \\
\hline & & $\begin{array}{l}\text { Frecuentes ataques de plagas y } \\
\text { enfermedades }\end{array}$ & $\begin{array}{l}\text { Frecuentes ataques de plagas y } \\
\text { enfermedades }\end{array}$ \\
\hline & & Fuentes de agua & \\
\hline & & Dependencia de fertilizantes. & Dependencia de fertilizantes. \\
\hline & \multirow[t]{4}{*}{ Diversidad } & Monocultivos & Escasa rotación de cultivos \\
\hline & & Protección de áreas de bosque & Protección de áreas de bosque \\
\hline & & Pérdida de semillas locales & Escaso uso de semillas locales \\
\hline & & Biodiversidad & \\
\hline & \multirow[t]{3}{*}{ Participación } & Relevo generacional $^{1}$ & Relevo generacional \\
\hline & & Mano de obra familiar. & Mano de obra familiar. \\
\hline & & $\begin{array}{l}\text { Activa participación en } \\
\text { organizaciones }\end{array}$ & $\begin{array}{l}\text { Activa participación } \\
\text { organizaciones }\end{array}$ \\
\hline & \multirow{4}{*}{$\begin{array}{l}\text { Capacidad de } \\
\text { cambio e } \\
\text { innovación }\end{array}$} & $\begin{array}{l}\text { Sistema de ricgo de alto } \\
\text { consumo. }\end{array}$ & $\begin{array}{l}\text { Sistema de ricgo de alto } \\
\text { consumo. }\end{array}$ \\
\hline & & Acceso a tecnologia & Acceso a tecnología \\
\hline & & $\begin{array}{l}\text { Infracstructura tecnológica y } \\
\text { financiera }\end{array}$ & \\
\hline & & Acceso a capacitación & Acceso a capacitación \\
\hline & Autosuficiencia & $\begin{array}{l}\text { Dependencia de insumos } \\
\text { externos }\end{array}$ & \\
\hline
\end{tabular}

Fuente: Fonseca, Cleves y León 2016.

En los pasos 3 y 4 referente a la formulación y estandarización de indicadores es importante mencionar que la metodología MESMIS propone que en los agroecosistemas se identifiquen los atributos de sustentabilidad que este posee: Productividad, Estabilidad, Resiliencia, Adaptabilidad, Equidad, Autogestión; a partir de los cuales se derivan los criterios de diagnóstico (Retorno, Eficiencia, Conservación, Diversidad, Participación, Capacidad de cambio e innovación y Autosuficiencia), cada uno de los cuales están conformados por diversos indicadores (Ver cuadro 2). La estructuración del conjunto de indicadores está basada en la identificación de los puntos críticos previamente identificados en cada agroecosistema y correlacionados con los atributos de sustentabilidad. La sustentabilidad 
del agroecosistema es la resultante de la valoración de estos criterios a partir del desempeño del conjunto de indicadores, los cuales se expresan en función de un juicio de valorativo sobre lo considerado como un desempeño adecuado de prácticas agrícolas, arreglos productivos, y gestión de aspectos ambientales en la región. Para la estandarización de los indicadores se propone una escala de valoración de uno (1) a cinco (5), donde el nivel de desempeño más bajo o práctica inadecuada se valora con 1 y la mejor condición posible o mejor práctica se valora con 5 (Fonseca, Cleves y León 2016). Los criterios evaluados fueron los siguientes:

\subsubsection{Criterio Retorno}

Este criterio se define como la sumatoria de los ingresos tanto de tipo financiero como los beneficios de tipo ambiental y social percibidos por los integrantes del núcleo familiar como rentabilidad monetaria del ejercicio agropecuario del agroecosistema, en ella se deben contabilizar tanto las inversiones en forma de mano de obra de los integrantes de núcleo familiar, su participación en otras actividades no agropecuarias propias del entorno rural. Este criterio está conformado por el siguiente indicador.

\section{a. Indicador Valor Presente Neto (VPN)}

Este indicador mide el grado en el cual el agroecosistema tiene la capacidad para que las inversiones allí ejecutadas tendrán un retorno financiero en términos de rentabilidad y ganancia esperada. Se estima teniendo en cuenta los ingresos totales por actividades agropecuarias ( $\Sigma \mathrm{BT})$, menos los costos en los cuales se ha incurrido $(\Sigma C T)$, dividido por la tasa de descuento ( $r$ ) en un periodo de tiempo que generalmente es un año (t). Para la construcción de la escala valorativa de este indicador se tiene como premisa (en la región) que el porcentaje del VPN con lo cual se recupera la inversión (cubre los costos de producción) y se genera un excedente de rentabilidad, el VPN debe ser superior al $30 \%{ }^{2}$ del valor presente neto sobre la inversión (Alves et al., 2015). El VPN se estima mediante la siguiente expresión:

$V P N=\Sigma B T-\Sigma C T /(1+r)^{t}$

\subsubsection{Criterio Eficiencia del agroecosistema}

Este criterio evalúa la proporción entre el retorno o beneficio financiero y la inversión de tipo financiero que en la cual se ha incurrido para el funcionamiento 
del agroecosistema, con este criterio se busca medir la eficiencia del sistema mediante el siguiente indicador.

\section{a. Indicador Beneficio Costo B/C}

Este indicador da cuenta de la relación entre los ingresos totales por concepto de ventas (beneficios) y el total de los costos de producción en los agroecosistemas. Para su cálculo se tiene en cuenta la tasa de interés promedio en la región que es de $9,4 \%^{3}(r)$ anual $(t)$. El juicio de valor en la escala propuesta se considera que la relación beneficio/costo $(B / C)$ que es atractiva por su rentabilidad es aquella cercana a 1,3; pues además de recuperar la inversión se obtiene la utilidad ${ }^{4}$ adicional con la cual las actividades agropecuarias se consideran óptimas dentro de la dinámica económica.

Formula indicador beneficio - costo (B/C)

Tabla 3. Escala de VPN y B/C.

$$
B C=\left(\frac{\Sigma B T /(1+r)^{t}}{\Sigma C T /(1+r)^{t}}\right)^{1} \quad(\text { Astier et al., 2012) }
$$

\begin{tabular}{c|c|c}
\hline Valoración & VPN (\%) & B/C \\
\hline $\mathbf{1}$ & $<5$ & $<1$ \\
\hline $\mathbf{2}$ & $5-10$ & $1-1,1$ \\
\hline $\mathbf{3}$ & $10-20$ & $1,1-1,25$ \\
\hline $\mathbf{4}$ & $20-30$ & $1,25-1,33$ \\
\hline $\mathbf{5}$ & $>30$ & $>1,33$ \\
\hline
\end{tabular}

Fuente: Fonseca, Cleves y León 2016Criterio de Conservación

\subsubsection{Criterio de Conservación}

En este criterio se condesa importante información que da cuenta de la base ecológica y la estabilidad del agroecosistema, los indicadores que constituyen el criterio muestran el grado con el cual se mantiene tanto la estructura del agroecosistema como de su funcionamiento, igualmente se evalúa el estado de conservación de la oferta ambiental (también denominado recursos naturales) que los soporta. Este criterio está conformado por los siguientes indicadores a saber: 
cobertura vegetal, calidad del suelo, disponibilidad de agua, presión de insectos plaga y enfermedades.

\section{a. Indicador Cobertura Vegetal}

En los agroecosistemas analizados se desarrollan principalmente actividades agrícolas, pecuarias, forestales, además de zonas de conservación), la cobertura vegetal se evalúo a través de la realización de monitoreos frecuentes con el fin de obtener el promedio ponderado en los diferentes usos del suelo. Dentro de la escala valorativa propuesta (de 0 a 5) este indicador asume un supuesto ideal de completa cobertura del suelo (incluye coberturas nobles, mulch y praderas). La determinación se obtuvo mediante la siguiente expresión:

$$
I C V T=\dot{\mathrm{X} C A}+\dot{\mathrm{X} C P}+\dot{\mathrm{X} C F}
$$

Con esta expresión se determina la cobertura vegetal del agroecosistema (CVT); la cual es la resultante de la sumatoria de los promedios ponderados de las coberturas de las áreas de uso agrícola (XCA); uso pecuario (XCP) y uso forestal o de conservación (XCF).

\section{b. Incidencia de insectos plagas y enfermedades}

En los agroecosistemas familiares campesinos es frecuente el uso de productos de síntesis química, pero en algunos casos estos son usados abundantemente, yendo en contravía de sus prácticas tradicionales de manejo donde se privilegian las agroecológicas y/o conservacionistas. Este indicador surge en la medida que se quiere establecer su grado de aplicabilidad y su incidencia en la sustentabilidad del agroecosistema. Para lo anterior en cada agroecosistema se evaluó la incidencia de insectos plaga y las enfermedades de importancia económica en los cultivos, para lo anterior se establecieron en campo un sistema de trampas específicas para cada especie en las cuales se realizó conteo de individuos capturados en intervalos homogéneos y/o evaluación de daño según fuera el caso. El nivel de incidencia de estos agentes biológicos se obtuvo promediando las capturas de los insectos plaga, para este caso de polilla guatemalteca (Tecia solanivora) y de gusano blanco (Premnotrypes vorax), capturados mediante trampas. Es importante mencionar que para su ponderación en la escala valorativa se tienen en cuenta el umbral de daño económico de estos insectos plaga que para tal efecto tiene el Instituto Colombiano Agropecuario ICA y el Centro internacional de la 
papa (ICA, 2011; CIP, 2005; Quiroz et al., 2014). Bajo este modelo se realizó la evaluación de los demás insectos plaga y las enfermedades de mayor importancia en los cultivos. Se logra mediante la siguiente expresión:

$$
\begin{aligned}
& P P E=\frac{X p 1+X p 2+X p 3 \ldots \ldots n}{n} \\
& X p n=\frac{X m 1+X m 2+X m 3 \ldots \ldots n}{n}
\end{aligned}
$$

La presión de insectos plaga de importancia económica y las enfermedades (PPE) se obtiene del promedio de la sumatoria de la incidencia de estas especies (Xpn). Para determinar este promedio de cada una de las especies evaluadas (Xmn) se recomienda realizar varias lecturas o muestreos (n).

\begin{tabular}{|c|c|c|c|c|c|c|c|}
\hline $\begin{array}{c}\text { Plaga/ } \\
\text { Enfermedad }\end{array}$ & Monitoreo & $\begin{array}{c}\text { Base } \\
\text { para Escala }\end{array}$ & \multicolumn{5}{|c|}{ Desempeño } \\
\hline \multicolumn{3}{|c|}{ PAPA } & 1 & 2 & 3 & 4 & 5 \\
\hline Polillas & Trampa & $\begin{array}{l}50 \text { Adultos/ } \\
\text { Trampa/8 días }\end{array}$ & $>50$ & $50-40$ & $40-20$ & $20-10$ & $<10$ \\
\hline Gusanos & Trampa & $\begin{array}{l}200 \text { Adultos / } \\
\text { trampa/15 días }\end{array}$ & $>200$ & $200-150$ & $150-100$ & $100-50$ & $<50$ \\
\hline Minador & Trampa & $\begin{array}{l}300 \text { Adultos/ } \\
\text { Trampa/8 días }\end{array}$ & $>300$ & $300-200$ & $200-100$ & $100-50$ & $<50$ \\
\hline Gotas & Observación & $\begin{array}{l}\text { \% de severidad/ } \\
15 \text { días }\end{array}$ & $>50 \%$ & $50-35 \%$ & $35-25 \%$ & $25-15 \%$ & $\begin{array}{c}0 \\
-15 \%\end{array}$ \\
\hline
\end{tabular}

Tabla 4. Escala indicador plagas y enfermedades.

Fuente: Fonseca, Cleves y León 2016

\section{c. Cantidad de agua por unidad de superficie}

Un indicador de importancia para la sustentabilidad de los agroecosistemas es el acceso y capacidad de almacenamiento de recurso hídrico, para determinar la disponibilidad (acceso directo y almacenamiento) se evaluó las fuentes para el acceso directo (ríos, quebradas, nacimientos) y la infraestructura para almacenamiento y distribución (reservorios). Es importante destacar que además de evaluar la provisión de agua por unidad de superficie (hectáreas), se cuantifica su capacidad de recarga, entendida como el tiempo que la fuente requiere para recuperar su nivel inicial, para lo anterior se establecen aforos periódicos; se 
recomienda hacer la evaluación en dos épocas, una seca y otra de lluvias. El valor del indicador se obtiene del promedio de las evaluaciones de las dos épocas, tanto de la disponibilidad de agua (litros/hectárea) como de la velocidad de recarga. Para su valoración en la escala propuesta se estima que la provisión de agua necesaria para el desarrollo de actividades agrícolas en esta zona es de $250 \mathrm{~m}^{3}$ por hectárea/año y capacidad de recarga de 30 litros/segundo como condición ideal para los agroecosistemas (Quiroz et al., 2014). Para determinar estos valores se usa la siguiente expresión:

$$
D A=\frac{X V 1+X V 2+X V 3 \ldots \ldots X V n}{A T}
$$

La disponibilidad de agua (DA) está dada por el promedio del agua almacenada en las fuentes $(\mathrm{XVn})$ sobre el área agropecuaria total (AT).

Tabla 5. Escala de valoración cobertura vegetal y disponibilidad de agua.

\begin{tabular}{c|c|c|c} 
Desempeño & $\begin{array}{c}\text { \% Cobertura } \\
\text { vegetal }\end{array}$ & $\begin{array}{c}\text { Disponibilidad } \\
\text { de agua (m) }\end{array}$ & $\begin{array}{c}\text { Capacidad } \\
\text { de recarga (L/S) }\end{array}$ \\
\hline 1 & $<10$ & $0-62$ & $0-8$ \\
\hline 2 & $10-30$ & $62-125$ & $8-17$ \\
\hline 3 & $30-50$ & $125-187$ & $17-25$ \\
\hline 4 & $70-50$ & $187-250$ & $25-35$ \\
\hline 5 & $>70$ & $>250$ & $>35$ \\
\hline
\end{tabular}

Fuente: Fonseca, Cleves y León 2016

\section{d. Indicador Calidad del Suelo}

Este cuarto indicador se construye teniendo como insumo principal los resultados del análisis físico- químico del suelo, el indicador apunta a determinar el desempeño de las condiciones productivas del suelo frente a un patrón de referencia considerado como óptimo para las condiciones regionales. El indicador mide el desempeño de las características físico-químicas del análisis de suelo, en la escala valorativa propuesta el juicio de valor más alto está dado por la mejor condición de cada aspecto contenido en dicho análisis, y va descendiendo cuando este aspecto es menos favorable. Para lo anterior se usa la siguiente expresión.

$$
\mathrm{CS}=\frac{\mathrm{P} 1+\mathrm{P} 2++\mathrm{P} 3+\cdots \mathrm{Pn}}{\mathrm{n}}
$$


El valor del indicador calidad del suelo (CS) se obtiene del promedio de los valores obtenidos en la escala de valoración propuesta de cada parámetro físico- químico evaluado $(\mathrm{Pn})$.

Tabla 6. Escala valoración del suelo.

\begin{tabular}{|c|c|c|c|c|c|c|}
\hline \multirow{2}{*}{ Factor } & \multirow{2}{*}{$\begin{array}{l}\text { Rango } \\
\text { óptimo }\end{array}$} & \multicolumn{5}{|c|}{ Desempeño } \\
\hline & & 1 & 2 & 3 & 4 & 5 \\
\hline $\mathrm{pH}$ & $5,6-7,3$ & $2,6-1$ & 2,6 A 3,6 & $3,6-4,6$ & $4,6-5,6$ & $5,6-7,3$ \\
\hline MO (FRIO) & Frio: 5-10 & $<\operatorname{de} 2$ & $2-4$ & $5-4$ & $5-8$ & $80>$ \\
\hline$P(p p m)$ & $20-40$ & $<5$ & $5-10$ & $10-15$ & $15-25$ & $25-40$ \\
\hline Al & $1-2$ & $>2$ & $2-1,7$ & $1,7-1,5$ & $1,5-1$ & $<1$ \\
\hline $\mathrm{Ca}$ & $3-6$ & $<3$ & $2-3$ & $3-4$ & $4-5$ & $>6$ \\
\hline $\mathbf{M g}$ & $1,5-2,5$ & $<0,5$ & $0,5-1$ & $1-1,5$ & $1,5-2$ & $2-2,5$ \\
\hline
\end{tabular}

\subsubsection{Criterio Diversidad}

Este criterio identifica y valora la riqueza biológica que posee el agroecosistema en determinado momento, el cual además de mostrar la fortaleza que este posee, es de importancia para el funcionamiento del mismo y de su capacidad de soporte (ecosistémico) que en últimas es la base de la resiliencia y la sustentabilidad, está constituido por los siguientes indicadores.

\section{a. Indicador Riqueza y Diversidad de Especies}

El indicador mide la biodiversidad específica la cual se refiere a la cantidad de especies que cohabitan dentro del agroecosistema (riqueza de especies) y la distribución de esta abundancia dentro del mismo (equitabilidad). Por ejemplo, si dentro del agroecosistema se identifican 10 especies, pero el $90 \%$ de los individuos son de la misma especie, la equitabilidad será baja; por el contrario, si cada una de las 10 especies poseen un individuo (10\%) esta será máxima. Estos dos componentes son frecuentemente evaluados a través del índice de biodiversidad de Shannon (1987) este puede provenir de distintas combinaciones de riqueza especíica y equitabilidad. Dentro de la escala valorativa el indicador toma valor de 0 cuando el agroecosistema posee pocas especie y un valor de 5 cuando allí existe amplia diversidad de especies (Golicher, 2005). En los agroecosistemas 
se realiza la cuantificación de las diferentes especies tanto de interés agrícola, forestal y de conservación (especies nativas de bosque propias de la zona). Este índice se determina mediante la siguiente expresión:

$$
H=-\sum_{i=1}^{S}\left(p_{i} \log _{2} p_{i}\right)
$$

Para el cálculo de este índice se tienen en cuanta los siguientes aspectos: la riqueza de especies (número de especies) dentro del agroecosistema (S); la abundancia relativa de la especie $i$ ( ), es decir la proporción de individuos de la especie con respecto al total de los individuos (); el número de individuos de la especie $i$ (); y la población total de individuos de todas las especies $(N)$.

\section{b. Indicador Uso de Semillas Locales}

El indicador busca determinar el nivel seguridad alimentaria al interior del núcleo familiar rural mediante la cuantificación del uso de semillas locales (entendidas como aquellas que son base de su alimentación y que por su uso ancestral y frecuente, así como la posibilidad de almacenarlas, multiplicarlas e intercambiarlas, se han convertido en patrimonio de la sociedad rural), para lo anterior indicador de uso de semillas locales (USL) se expresa como el cociente de las semillas locales (SL) sobre aquellas semillas que son adquiridas en establecimientos comerciales o que no tiene las condiciones anteriormente descritas (SC). La valoración del indicador se hace formularios tipo encuesta aplicados a integrantes del núcleo familiar. La valoración en la escala propuesta de 0 a 5 se hace teniendo como mejor condición posible que el $70 \%$ de los alimentos de la familia provengan de este tipo de semillas. La siguiente expresión permite calcular el indicador uso de semillas locales.

$$
U S L=S L / S C
$$

\subsubsection{Criterio Participación}

Este criterio da cuenta del grado de interacción social del núcleo familiar con la comunidad vecina y con otros actores directamente relacionados con actividades económicas, sociales y culturales en su entorno inmediato. Se evalúa la capacidad de los integrantes del agroecosistema para involucrarse y participar en procesos de autogestión y desarrollo de proyectos de interés general. Para lo anterior, este criterio evalúa los siguientes indicadores: 


\section{a. Cantidad y calidad de empleos requeridos}

El indicador evalúa la cantidad de empleos que el agroecosistema genera, tanto para los integrantes del núcleo familiar (empleo interno) como para integrantes de la comunidad aledaña (empleo externo). Es importante tener en cuenta que la dinámica migratoria de las familias rurales está dada entre otros aspectos, en función del acceso a empleo suficiente, estable y de calidad; lo implica que tanto el núcleo familiar como la comunidad rural son altamente sensibles a variaciones de este tipo. Por lo tanto, se asume como condición ideal en la escala valorativa propuesta que los agroecosistemas generen empleos suficientes para los integrantes del núcleo familiar como también empleo externo para dinamizar la actividad económica local. Se estimó mediante consenso con los agricultores que la proporción ideal es que el $60 \%{ }^{5}$ de los empleos requeridos sea cubierto con mano de obra familiar (empleo interno) y el restante empleo externo (Quiroz et al., 2014). La siguiente expresión permite calcular este indicador:

$$
\begin{aligned}
E E & =\frac{T E(\% E E)}{100 \%} \\
E F & =T E-E E \\
\% E F & =\frac{\sum E F * 100}{T E}
\end{aligned}
$$

El cálculo requiere cuantificar el empleo externo (EE); El empleo familiar (EF) y la totalidad de los empleos demandados en el agroecosistema (TE).

\section{b. Participación en organizaciones locales}

Para verificar la capacidad de interacción efectiva de la familia rural se establece la vinculación existente con organizaciones locales, para lo cual se identificaron las organizaciones de origen campesino o comunal presentes en la región y que responden al interés del quehacer de los integrantes del núcleo familiar. En la escala valorativa se estima como óptimo que exista participación en el $70 \%$ de las organizaciones locales, para su cálculo se usa la siguiente expresión.

$$
\% P O L=\frac{A S P * 100}{A L E}
$$


La participación en organizaciones locales (POL) se obtiene identificando las organizaciones donde los integrantes del núcleo familiar participan (ASP) sobre las organizaciones locales existentes (ALE).

Tabla 7. Escala valoración semillas, empleos y participación.

\begin{tabular}{c|c|c|c}
\hline Desempeño & Semillas locales (\%) & Empleos (\%) & Participación (\%) \\
\hline $\mathbf{1}$ & $<5$ & $<20$ & $<20$ \\
\hline $\mathbf{2}$ & $5-20$ & $20-40$ & $20-40$ \\
\hline $\mathbf{3}$ & $20-50$ & $40-60$ & $40-60$ \\
\hline $\mathbf{4}$ & $50-70$ & $60-80$ & $60-80$ \\
\hline $\mathbf{5}$ & $>70$ & $>80$ & $80-100$ \\
\hline
\end{tabular}

Fuente: Fonseca, Cleves y León 2016

\subsection{Criterio de capacidad de cambio e innovación}

Los agroecosistemas en general posee atributos de índole ecológico, tecnológico y socio cultural lo cual les permite adaptarse a las condiciones cambiantes del medio, para algunos autores la capacidad de auto ajuste que estos poseen está directamente relacionado con su capacidad resiliente que por las condiciones expuestas su origen es ecosistémico, pero la resiliencia además de lo anterior es de tipo socioecológica, que refiere la capacidad de los integrantes del núcleo familiar para gestionar los procesos productivos internos en medio de diversa dificultades. Este criterio, por tanto, valora dicha resiliencia sociecológica. Para lo cual el criterio está estructurado con los siguientes indicadores.

\section{a. Indicador Innovación Tecnológica}

El indicador estima el grado o nivel con la cual se hacen procesos de adopción de tecnologías y prácticas innovadoras dentro del agroecosistemas y que representan mejorar o ajustes dentro de los procesos de producción, transformación y comercialización entre otros aspectos. Para su determinación como juicio de valor en la escala propuesta se definió que la mayor cantidad de prácticas de ajuste tecnológico o innovadoras, se traduce en un mejor nivel de desempeño. La condición deseable es que se adopten al menos una práctica innovadora cada año . Este indicador se estima con la siguiente expresión.

$$
I T=\sum P
$$


La innovación tecnológica (IT) está dada por la cantidad de prácticas de innovación tecnológica $(P)$ que se implementan dentro del agroecosistema.

\section{b. Indicador Capacitación y Gestión de Conocimiento}

Otro aspecto relevante para determinar la capacidad de resiliencia socioecológica dentro del agroecosistema es la disposición efectiva para mejorar su nivel tecnológico, por lo tanto el indicador estima los procesos de capacitación y/o formación que los integrantes del núcleo familiar realizan durante un periodo determinado, es importante además tener en cuenta que los agroecosistemas poseen adelantos e innovaciones que son de interés para la comunidad, los cuales son dados a conocer mediante diferentes estrategias de extensión rural. La valoración en la escala propuesta asume como desempeño óptimo la participación en al menos 10 eventos durante el último año.

\subsubsection{Criterio de Suficiencia del Agroecosistema}

Los sistemas en general requieren para su adecuado funcionamiento la constante provisión de energía con la cual desarrolla sus procesos de generación o transformación. Desde la óptica de la teoría general de los sistemas propuesta por el biólogo alemán Ludwig Von Bertalanffy publicados entre 1950 y 1968, los agroecosistemas se comportan como "un todo organizado y complejo cuyos elementos están recíprocamente relacionados entre sí y con su medio". Allí se desarrollan interacciones entre los diferentes elementos que le constituyen y donde se evidencia el cumplimiento de principios termodinámico, tal es así que este requiere de diversas fuentes energéticas para el cumplimiento de su función, las hay de tipo ecológico (la energía lumínica como base de los procesos fotosintéticos) y la energía cultural (generada por humanos) para la producción de biomasa en los agroecosistemas (Gliessman, 2001). Para los sistemas con principios de sustentabilidad se busca que la energía provenga en alto grado de procesos tróficos internos y en menor grado de fuentes energéticas externas. Este criterio está conformado por los siguientes indicadores.

\section{a. Indicador Dependencia a Insumos Externos}

Como se mencionó anteriormente los agroecosistemas requieren de fuentes energéticas, entendidos como aquellos insumos necesarios para el proceso productivo de los cuales se busca que provengan principalmente de su interior. Para calcular el grado o dependencia de insumos externos se cuantifica el costo total de los insumos provenientes del exterior, adquiridos mediante transacción 
comercial en relación con los costos totales para cada actividad o ciclo de cultivo. El indicador dependencia de insumos externos (DIE) se obtiene del cociente entre los costos de los insumos (CTi) sobre el costo de estos insumos adquiridos comercialmente (CTie). El escenario ideal es ideal es que el $70 \%$ sean insumos internos. La siguiente expresión muestra el cálculo del indicador

$$
\begin{gathered}
\text { DIE }=\text { CTie } / \text { CTi } \\
\text { CTie }=\% \text { CTie } * C T
\end{gathered}
$$

\section{b. Indicador Ahorro Interno (Al)}

Entre las múltiples dificultades que posee el sistema de producción agropecuaria nacional, especialmente de los pequeños productores rurales es su limitada capacidad de ahorro y por tanto el escaso músculo financiero para emprender proyectos productivos de mediano y largo plazo, prefiriendo así emprender actividades de bajo costo y bajo riesgo que les permita mantener funcionando su sistema de producción sin afectar la seguridad alimentaria de su familia. En tal sentido, la cuando los agroecosistemas no poseen recursos financieros suficientes para el establecimiento de los diferentes procesos productivos, quedan expuestos a las condiciones del mercado financiero, que desde la perspectiva de los productores rurales es una desventaja, ya que generalmente no cumplen con los requisitos para acceder a los créditos del sistema bancario, prefiriendo obtener estos recursos mediante un sistema de créditos informales que resulta ser más oneroso. El indicador evalúa la capacidad que tiene el agroecosistema para soportar los costos de establecimiento y manejo del proceso productivo con recursos propios y sin depender de créditos (es importante mencionar que este indicador se aplica para actividades productivas tradicionales, es decir no incluye cambios notables en sistema de producción productos de procesos de innovación). Su cálculo se hace mediante la determinación de los costos de producción cubierto con fuentes financieras externas, determinando el cociente entre los costos de producción (CT) sobre el costo asumido con préstamos (CP).

Este indicador ahorro interno (Al) evalúa los costos totales de producción que son cubiertos con préstamos (fuentes externas), para tal fin se realizó el cociente entre el costo total (CT) de producción y el costo total cubierto con préstamo (CP). En la escala valorativa se asume como condición ideal que el $20 \%$ de los costos de producción sean asumidos con crédito, dando la posibilidad de incluir ajustes tecnológicos o de innovación. La siguiente expresión se usa para su cálculo. 


$$
\begin{gathered}
A I=\frac{C T}{C P} \\
C P=\% C P * C T
\end{gathered}
$$

\section{c. Indicador Seguridad Alimentaria}

El principio de seguridad alimentaria dentro del núcleo familiar rural se tiende como la condición mediante la cual el agroecosistema provee alimentos en calidad y cantidad suficiente para atender las necesidades de los integrantes de la familia, esta condición está se puede dar por los alimentos que allí se producen o por la generación de recursos financieros suficientes para su adquisición. Tanto por calidad, cantidad y oportunidad se prefiere que sean alimentos generados al interior del agroecosistema, por lo tanto, para el cálculo del indicador se estimó el costo mensual de los alimentos consumidos por la familia y el costo de los alimentos que se proveen desde el agroecosistema. El cálculo de seguridad alimentaria (SA) se obtiene del cociente entre el costo total de alimentos (CTA) y el costo de alimentos proveniente del agroecosistema (CAa) Para la escala valorativa se estima como condición ideal que al menos el $50 \%$ de los alimentos provengan del interior del agroecosistema. La siguiente expresión permite determinar el nivel de seguridad alimentaria.

$$
\begin{gathered}
S A=\frac{C T A}{C A a} \\
C T A=\% C T A * C A a
\end{gathered}
$$

Tabla 8. Escala valorativa indicadores capacidad de cambio y autosuficiencia.

\begin{tabular}{c|c|c|c|c|c}
\hline Desempeño & $\begin{array}{c}\text { Innovación } \\
\text { Tecnológica }\end{array}$ & $\begin{array}{c}\text { Gestión del } \\
\text { conocimiento }\end{array}$ & $\begin{array}{c}\text { Dependencia } \\
\text { (\%) }\end{array}$ & $\begin{array}{c}\text { Ahorro } \\
\text { interno\% }\end{array}$ & $\begin{array}{c}\text { Seguridad } \\
\text { alimentaria } \\
\text { (\%) }\end{array}$ \\
\hline 1 & $<1$ & $1-3$ & $>80$ & $>80$ & $<20$ \\
\hline 2 & $1-3$ & $3-5$ & $80-60$ & $80-60$ & $20-30$ \\
\hline 3 & $3-5$ & $5-7$ & $60-40$ & $60-40$ & $30-40$ \\
\hline 4 & $5-7$ & $7-10$ & $40-20$ & $40-20$ & $40-60$ \\
\hline 5 & $>7$ & $>10$ & $<20$ & $<20$ & $>60$ \\
\hline
\end{tabular}




\subsection{Conclusiones}

Este documento recoge la interpretación y ajustes realizados para la evaluación de sustentabilidad de agroecosistemas, el cual constituye un proceso complejo que requiere la mirada desde diversas disciplinas y áreas del conocimiento que pueden ser integradas en el MESMIS, la cual constituye una valiosa herramienta para la valoración de los aspectos sociales, culturales, tecnológicos y ambientales de los agroecosistemas.

La caracterización permite evidenciar las diferentes tipologías de agroecosistemas existentes que están diferenciados fundamentalmente por el manejo de la oferta ambiental (recursos naturales), el nivel tecnológico y la capacidad de innovación dentro del proceso productivo. En el mismo sentido existen evidentes diferencias en la adopción de modelos tecnológicos de altos insumos químicos que posiblemente incidan en las evidentes limitantes de productividad por el deterioro de suelos, que aunado a escases y escasa gestión del recurso hídrico posee como resultante la baja rentabilidad de la actividad agropecuaria. Muy distinto para otros agroecosistemas donde el enfoque está centrado en la preservación de los componentes de oferta ambiental (gestión de suelos, agua y biodiversidad).

La caracterización permitió identificar la problemática tanto de tipo ambiental, tecnológico y socioeconómica con lo cual es posible identificar los atributos de sustentabilidad, los criterios de diagnóstico y para cada uno de ellos la batería de indicadores. La estandarización de estos indicadores se realiza mediante una escala de valoración que va desde cero (0) hasta cinco (5), donde el mejor desempeño posible del indicador es valorado con la máxima puntuación, y el desempeño bajo o inadecuado recibe la valoración más baja.

Los resultados obtenidos en los agroecosistemas evaluados sugieren que existe una interdependencia entre las prácticas agrícolas, las condiciones ecológicas y socioeconómicas del núcleo familia. Tal es así, que los indicadores que evalúan prácticas agrícolas poseen bajo desempeño (en la escala propuesta) lo que posiblemente ha disminuido la disponibilidad de recursos naturales, afectando ostensiblemente su capacidad productiva. Lo anterior permite inferir que el nivel de sustentabilidad de los agroecosistemas viene fundado por el nivel o condición de resiliencia sociocultural del núcleo familia rural, lo cual les procura un diferencial productivo agropecuario, de beneficios ambientales y financieros que definen su 
permanencia dentro del ámbito rural en actividades agropecuarias, o por el contrario el inicio de un proceso migratorio.

La metodología MESMIS propone un último paso de recomendaciones para fortalecer la sustentabilidad de los sistemas de manejo. Para el presente trabajo de investigación y a la luz de los resultados obtenidos, es recomendable aumentar la diversificación de los agroecosistemas, es decir aumentar la cantidad de especies (agrícolas y pecuarias) para, por un lado, mejorar la condición de seguridad alimentaria del núcleo familiar, y por otro, aumentar la oferta de productos agropecuarios con miras a soportar con mayor eficiencia las fluctuaciones de precios tanto en los mercados locales como nacionales. Es importante que los agroecosistemas emprendan acciones para una efectiva gestión del recurso hídrico, implementando acciones para aumentar su capacidad de almacenamiento, mejorar su calidad y disponibilidad, aumentar las estrategias para mantener la cobertura del suelo, entre otros aspectos que permiten hacer planeación de actividades de acuerdo a las condiciones climáticas y los requerimientos de los mercados.

\section{Bibliografía}

Aguilar-Jiménez, Carlos E., Tolón-Becerra, Alfredo, \& Lastra-Bravo, Xavier. (2011). Evaluación integrada de la sustentabilidad ambiental, económica y social del cultivo de maíz en Chiapas, México. Revista de la Facultad de Ciencias Agrarias. Universidad Nacional de Cuyo, 43(1), 155-174. Recuperado en 22 de agosto de 2016, de http://www.scielo.org.ar/scielo. php?script=sci_arttext\&pid=S1853-86652011000100011\&lng=es\&tlng=es.

Albicette, M., Brasesco, R, \& Chiappe, M. (2009). Propuesta de indicadores para evaluar la sustentabilidad predial en agroecosistemas agrícola-ganaderos del litoral del Uruguay. Agrociencia Uruguay, 13(1), 48-68. Recuperado en 22 de agosto de 2016, de http://www. scielo.edu.uy/scielo.php?script=sci_arttext\&pid=S2301-15482009000100007\&lng=es \&tlng=es.

Altieri M. 2013. "Construyendo resiliencia socio-ecológica en agroecosistemas: algunas consideraciones conceptuales y metodológicas”, en: Nicholls C, Ríos L, Altieri M. (ed.) Agroecología y resiliencia ecológica: adaptándose al cambio climático. Medellín: Legis: 94104. Alves EP., L. Silva, N. Oliveira, T. Barrella, H. Santos. 2015. "Economic analysis of a coffee-banana system of a family-based agriculture at the atlantic forest zone, Brazil”, Ciência E Agrotecnologia, vol. 39 (3): 232-239.

Astier, M., and C. González. 2008. Formulación de indicadores socio-ambientales para evaluaciones de sistemas de manejo complejos, en M. Astier, Y. Galván-Miyoshi, and O. R. Masera, (ed.), Evaluación de sustentabilidad. Un enfoque dinámico y multidimensional. Valencia: MundiPrensa. 
Astier, M., L. García, Y, Galván-Miyoshi, C, González, O, Masera. 2012. “Assessing the Sustainability of Small Farmer Natural Resource Management Systems. A Critical Analysis of the MESMIS Program”. Ecology and society, vol. 17(3): 25-34.

Cândido, Gesinaldo de Ataíde, Nóbrega, Mariana Moura, Figueiredo, Marilia Taynah Martins de, \& Souto Maior, Mônica Maria. (2015). Avaliação da sustentabilidade de unidades de produção agroecológicas: um estudo comparativo dos métodos idea e Mesmis. Ambiente \& Sociedade, 18(3), 99-120. https://dx.doi.org/10.1590/1809-4422ASOC756V1832015v

Cottrell, S.P., van der Duim, R., Ankersmid, P. y Kelder, L. (2004): “Measuring the Sustainability of Tourism in Manuel Antonio and Texel: A Tourist Perspective". Journal of Sustainable Tourism, 12, 5, pp. 409-431.

Domínguez Serrano, M., \& Blancas Peral, F., \& Guerrero Casas, F., \& González Lozano, M. (2011). Una revisión crítica para la construcción de indicadores sintéticos. Revista de Métodos Cuantitativos para la Economía y la Empresa, 11, 41-70.

Ebert U. y H. Welsch (2003). "Meaningful environmental indices: a social choice approach". Journal Environmental Economics and Management, 47: 270-283.

Fonseca, J.A., Pita, Y.X. y Botía, B.Y. (2018). Caracterización y Tipificación de los Atributos Ecosistémicos de la Agricultura Familiar Campesina en la Microcuenca del Rio Cormechoque (Boyacá). Revista de Investigación agraria y ambiental, 9(2), 49-62.

Fonseca, JA., Cleves, J.A., León, T.E. (2016). Evaluación de la sustentabilidad de agroecosistemas familiares campesinos en la cuenca del rio Cormechoque. Revista Ciencia y agricultura, 13(1), 29-47.

Fonseca, D. M. S. \& Fonseca, J. A. (2011). Producción sostenible de pollo de engorde y gallina ponedora campesina: revisión bibliográfica y propuesta de un modelo para pequeños productores. RIAA, 2(1), 29-43. 11.

Fonseca, J. A., Muñóz, N. A. \& Cleves, J. A. (2011). El sistema de gestión de calidad: elemento para la competitividad y la sustentabilidad de la producción agropecuaria colombiana. RIAA. 2(1): 9-22.

Fonseca Carreño, J. (2013). Integración de microempresas lácteas del corredor central del departamento de Boyacá (Colombia). Revista De Investigación Agraria Y Ambiental, 4(2), 117133. doi:http://dx.doi.org/10.22490/21456453.986

Fonseca, J., Cleves-Leguizamo. 2015. “Agroecología y variaciones climáticas: dos retos urgentes para la humanidad, en: R. Giraldo (ed.) Ciudadanía ambiental, crisis de la agricultura convencional y desafíos para una agroecología orientada hacia el desarrollo rural: 85-103.

Fonseca, J.A., Corredor, E.S. y Páez, E.M. (2012). Los servicios ecosistémicos de regulación: tendencias e impacto en el bienestar humano. Revista de Investigación agraria y ambiental, 3(1), 77 - 83

Geilfus, F. 1997. 80 Herramientas para el Desarrollo Participativo. Diagnóstico, Planificación, Monitoreo y Evaluación. IICA-GTZ. 208 p.

Instituto Colombiano Agropecuario ICA. 2011. "Manejo fitosanitario del cultivo de la papa". pdf. (en línea); Fecha de acceso 22 de noviembre de 2017; Disponible en: http://www.ica. gov.co/getattachment/b2645c33-d4b4-4d9d-84ac-97c55e7d3d0/Manejo-fitosanitariodel-cultiva-de-la-papa-nbsp;-.aspx

International Potato Center. 2015. "Manejo de gusano blanco". (en línea); fecha de acceso 22 de noviembre de 2017; Disponible en: http://cipotato.org/region-quito/informacion/inventario-de-tecnologias/manejo-de-gusano-blanco-de-la-papa 
Masera, O. R., M. Astier, y S. López-Ridaura. 1999. Sustentabilidad y manejo de recursos naturales: el marco MESMIS. México. Mundiprensa.

Neri-Ramírez, Efraín, Rubiños-Panta, J. Enrique, Palacios-Velez, Oscar L., Oropeza-Mot, José L., Flores-Magdaleno, Héctor, \& Ocampo-Fletes, Ignacio. (2013). Evaluación de la sustentabilidad del acuífero Cuautitlán-Pachuca mediante el uso de la Metodología MESMIS. Revista Chapingo. Serie ciencias forestales y del ambiente, 19(2), 273-286. Recuperado en 22 de agosto de 2016, de http://www.scielo.org.mx/scielo.php?script=sci_arttext\&pid=S0186$32312013000200009 \& \operatorname{lng}=e s \& t \operatorname{lng}=e s$

Priego-Castillo, GA, Galmiche-Tejeda, A, Castelán-Estrada, M, Ruiz-Rosado, O, \& Ortiz-Ceballos, Al. (2009). Evaluación de la sustentabilidad de dos sistemas de producción de cacao: estudios de caso de unidades de producción rural en Comalcalco, Tabasco. Universidad y ciencia, 25(1), 39-57. Recuperado en 22 de agosto de 2016, de http://www.scielo.org.mx/ scielo.php?script=sci_arttext\&pid=S0186-29792009000100003\&lng=es\&tlng=es

Quiroga, R. 2009. “Guía metodológica para desarrollar indicadores ambientales y de desarrollo sostenible en países de América Latina y el Caribe”. División de Manuales, CEPAL, (61), 129p.

Quiroz, Elsy., Tibatá, Adriana., y Villamil, Claudia. (2014). Evaluación de la sostenibilidad de unidades productivas agropecuarias en los municipios de Chivatá, Soracá y Tinjacá departamento de Boyacá. Tesis de grado. Universidad Nacional Abierta y a Distancia. Tunja.

Sajeva, M., Gatelli, D., Tarantola, S. y Hollanders, H. (2005): Methodology Report on European Innovation Scoreboard 2005. A discussion paper from the Innovation/SMEs Programme, European Commission.

Tapia, J.E. (2007). "El escalamiento optimo con base en el análisis de componentes principales no lineales para la construcción de índices de condiciones de vida y socioeconómico". Tesis ingeniero matemático. Facultad de ciencias, Ingeniería matemática. Escuela Politécnica Nacional. pp 1-15 Quito. Ecuador. Recuperado de: http://bibdigital.epn.edu.ec/handle/15000/537

Tsaur, H.S., Lin, Y.C. y Lin, J.H. (2006): “Evaluating Ecotourism Sustainability from the Integrated Perspective of Resource, Community and Tourism”. Tourism Management, 27, pp. 640-653.

Ugwu, O.O., Kumaraswamy, M.M., Wong, A. y Ng, S.T. (2006): "Sustainability Appraisal in Infrastructure Projects (SUSAIP) Part 1. Development of Indicators and Computational Methods". Automation and Construction, 15, pp. 244-256. 


\section{CAPÍTULO 2}

\section{Huella de Carbono}

\subsection{Resumen}

La huella de carbono, corresponde a la sumatoria total de gases efecto invernadero-GEl, que emite a nivel directo o indirecto por parte de un individuo, producto, evento u organización. Constituye una de las herramientas para estimar el impacto ambiental generado por procesos o servicios y puede ser implementado en diversos niveles. En el presente capitulo se brinda una revisión de los aspectos generales que fundamentan la huella de carbono, y las metodologías existentes para su estimación, haciendo especial énfasis en el análisis de ciclo de vida como mecanismo de estimación de la huella a nivel de los procesos productivos de tipo agropecuario.

La huella de carbono puede constituirse en una herramienta de gran utilidad para la toma de decisiones en la unidad agropecuaria, constituyendo un elemento que permite evaluar la sostenibilidad ambiental y con ello poder implementar medidas tendientes a disminuir el impacto negativo que puede tener el desarrollo de actividades de tipo agropecuario sobre el medio ambiente. Una de las metodologías más utilizadas para la estimación de la huella de carbono es el Análisis de Ciclo de vida-ACV, el cual permite identificar las entradas y salidas del proceso y con ello cuantificar los impactos ambientales expresados en kilogramos o toneladas de dióxido de carbono.

\subsection{Introducción}

A nivel mundial, existe una preocupación generalizada por el creciente impacto ambiental generado por actividades de tipo antropogénico, una de ellas está representada por la producción agropecuaria, necesaria para la producción de alimentos por parte de una población creciente y con una demanda cada vez mayor. Producto de estas actividades se ha observado un incremento progresivo de los 
gases de efecto invernadero-GEl, que han contribuido en el proceso de cambio climático, con las diferentes implicaciones que representa para los individuos y sistemas agropecuarios. En el marco de lo anterior, los sistemas de producción están desarrollando diversas actividades tendientes a generar procesos de producción más sostenibles y amigables con el medio, producto de ello, se han realizado investigaciones en la búsqueda de herramientas que contribuyan a disminuir el daño que se está causando sobre los recursos naturales.

El presente capitulo, pretende realizar una revisión de los aspectos generales del cambio climático, los gases efecto invernadero, la huella de carbono, las metodologías para su estimación y algunas experiencias de su estimación en actividades agropecuarias a nivel mundial.

Se pretende desarrollar un documento de tipo académico en donde se analice la utilidad de la estimación de la huella de carbono como herramienta en la toma de decisiones para las unidades agropecuarias con el fin de poder implementar acciones tendientes a mitigar el impacto ambiental negativo que pueden llegar a tener los sistemas productivos.

\subsection{Aspectos Generales del Cambio Climático}

\subsubsection{Cambio climático y calentamiento global}

El cambio climático es una realidad actual, se define como: "Todo cambio que ocurre en el clima a través del tiempo resultado de la variabilidad natural o de las actividades humanas" (SEMARNAT, 2009). Investigaciones científicas muestran como desde 1750 el planeta ha experimentado un proceso de calentamiento progresivo, el cual continuará en los próximos años como consecuencia directa del efecto de los GEI (Kumar et al., 2013; Rodríguez y Mance, 2009).

El planeta ha experimentado un proceso de permanente transformación, lo cual ha generado diversos cambios en la conformación y dinámica del planeta, lo cual ha transcurrido de la mano con la evolución de las diversas especies desde que la vida apareció en la Tierra (Rodríguez y Mance, 2009). Sin embargo, durante los últimos años ha ocurrido un fenómeno que conlleva a un rápido proceso de cambio climático generado en su mayor parte por actividades humanas (Escultura, 2014). En este marco, el Intergovernmental Panel on Climate Change-IPCC (2008) afirmó que el 
origen del cambio climático y su rápido avance tiene como base las actividades de tipo antropogénico, señalando como principal causa el consumo de combustibles fósiles, y la emisión de dióxido de carbono $\left(\mathrm{CO}_{2}\right)$ que produce (Kirkinen et al., 2008) contribuyendo de gran manera al denominado efecto invernadero.

El cambio climático es una consecuencia directa del calentamiento global, el cual genera un incremento de la temperatura a nivel terrestre y marina en una escala global, trae consigo múltiples desafíos para los individuos y sistemas, como lo señala el Programa de las Naciones Unidas para el Medio Ambiente-PNUMA, que menciona al cambio climático es uno de los principales desafíos en la actualidad generando procesos de estrés a las sociedades y el medio ambiente (PNUMA, 2010).

\subsubsection{Efecto invernadero}

El efecto invernadero es un fenómeno ocurrido de manera natural, y que es necesario para la vida en la tierra, a través de este, algunos gases presentes en la atmósfera realizan la retención de una parte de la energía emitida por la tropósfera tras haber sido calentada por la radiación solar, esto desencadena un efecto de calentamiento parecido al que ocurre en un invernadero (por ello recibe ese nombre), provocando la elevación de la temperatura ambiental (CGIAR, 2014). Este fenómeno es necesario para que se pueda desarrollar la vida en el planeta, sin él, la tierra sería una gran masa de hielo y no se tendrían las condiciones actuales para la producción. Sin embargo, este proceso natural ha incrementado su potencia en las últimas décadas, por actividades de tipo antropogénico a través de la emisión de GEI producto de las diversas actividades que desarrolla (Alexiadis, 2007). Según el IPPC (2007), las emisiones de GEl se han venido incrementando de manera progresiva y potencialmente durante los últimos años, aumentando un 70\% entre los años 1970 y 2004 (CGIAR, 2014), lo anterior denota, el gran incremento ocurrido durante los últimos años con las implicaciones que ello representa.

Cerca del $50 \%$ de la radiación solar que llega a la atmósfera y la atraviesa penetra la tropósfera y se encarga de calentar el suelo continental y los océanos, liberando al mismo tiempo calor en forma de radiación infrarroja (Ming, 2014; Rodríguez y Mance, 2009). Los GEI presentes en la atmósfera, se encargan de absorber parte de esta radiación emitida por la Tierra y la reflejan en diversas direcciones produciendo el calentamiento de la superficie del planeta para dar lugar a la temperatura actual. A mayor concentración de GEI mayor es la captura del calor y viceversa (Rodríguez y Mance, 2009). 


\subsubsection{Gases de efecto invernadero (GEI)}

La mayoría de los GEl se producen de manera natural, sin embargo, las actividades de tipo antropogénico, que han ido incrementándose acorde al crecimiento de la población, han dado lugar a un aumento de su concentración a nivel de la atmósfera durante los últimos años. La concentración actual de GEl en la atmósfera es el resultado de sus emisiones actuales y de las eliminaciones pasadas de la atmósfera (IPPC, 2008).

Los GEl pueden clasificarse en dos grupos: el primero, los GEl de larga vida (GEILV), el segundo, los GEI de corta vida (GEICV). En el primero, los GEILV, están el dióxido de carbono $\left(\mathrm{CO}_{2}\right)$ el metano $\left(\mathrm{CH}_{4}\right)$ y el óxido nitroso $\left(\mathrm{N}_{2} \mathrm{O}\right)$, estos gases son químicamente estables y pueden persistir en la atmósfera durante grandes espacios de tiempo, llegando a permanecer siglos o tiempos mayores, en este sentido, las emisiones de un GEI pueden ejercer efecto sobre el clima a largo plazo. Los GEILV tienen larga vida y por ello se mezclan bien en la atmósfera, y los datos de sus concentraciones mundiales se pueden calcular con exactitud en algunas localidades. En el segundo grupo, los GEICV, están algunos como el dióxido de azufre (SO2), y el monóxido de carbono (CO), son eliminados por lo general mediante procesos naturales de oxidación en la atmósfera, siendo muy variables sus concentraciones (IPPC, 2008). Los principales GEl que se pueden encontrar en la atmósfera son (Tabla 9):

- Dióxido de carbono $\left(\mathrm{CO}_{2}\right)$.

- Metano $\left(\mathrm{CH}_{4}\right)$.

- Óxido nitroso $\left(\mathrm{N}_{2} \mathrm{O}\right)$.

- Hidrofluorocarbonados (HFC).

- Perfluorocarbonos (PFC).

- Hexafluoruro de azufre $\left(\mathrm{SF}_{6}\right)$

- Vapor de agua.

Cada GEI tiene capacidad variable de atrapar el calor producto de la radiación solar, que es reflejado a la tropósfera como radiación infrarroja. El vapor de agua es el GEl de mayor potencia, pudiendo llegar a ser el responsable de hasta el 65\% del efecto invernadero. $\mathrm{El} \mathrm{CO}_{2}$ es luego del vapor de agua, uno de los mayores causantes del efecto invernadero, representando aproximadamente el $25 \%$ del efecto invernadero. Un aspecto importante a señalar es que algunos $\mathrm{GEl}$ tienen la capacidad de capturar la radiación, en mayor medida en relación con otros, como los Hidrofluorocarbonados y los Perfluorocarbonos, que se encuentran en baja 
concentración en la atmósfera, pero poseen un poder de calentamiento mayor a otros GEI. Las concentraciones de los principales GEI (dióxido de carbono, metano y óxido nitroso) se han incrementado de manera considerable desde la época de inicio de la revolución industrial (Rodríguez y Mance, 2009).

Tabla 9. Gases de Efecto Invernadero-GEI.

\begin{tabular}{|c|c|c|c|c|}
\hline Origen & Gases & Fuentes & $\begin{array}{l}\text { Vida media } \\
\text { en años }\end{array}$ & $\begin{array}{l}\text { Potencial de } \\
\text { calentamiento }\end{array}$ \\
\hline \multirow{3}{*}{$\begin{array}{l}\text { Gases } \\
\text { de origen } \\
\text { natural }\end{array}$} & $\begin{array}{l}\text { Dióxido de } \\
\text { carbono } \\
\left(\mathrm{CO}_{2}\right)\end{array}$ & $\begin{array}{l}\text { Quema de combustibles } \\
\text { fósiles (derivados del petróleo, } \\
\text { carbón y gas), procesos } \\
\text { industriales, cambios en el uso } \\
\text { del suelo (deforestación). }\end{array}$ & 50 a 200 & 1 \\
\hline & $\begin{array}{l}\text { Metano } \\
\left(\mathrm{CH}_{4}\right)\end{array}$ & $\begin{array}{l}\text { Procesos de descomposición } \\
\text { anaerobia (rellenos sanitarios, } \\
\text { descomposición del estiércol, } \\
\text { cultivos), minería y pozos } \\
\text { petroleros. }\end{array}$ & $12 \pm 3$ & 32 \\
\hline & $\begin{array}{l}\text { Óxido nitroso } \\
\left(\mathrm{N}_{2} \mathrm{O}\right)\end{array}$ & $\begin{array}{l}\text { Fertilizantes sintéticos } \\
\text { nitrogenados, combustibles } \\
\text { fósiles }\end{array}$ & 120 & 310 \\
\hline \multirow{3}{*}{$\begin{array}{l}\text { Gases } \\
\text { antropo- } \\
\text { génicos }\end{array}$} & $\begin{array}{l}\text { Hidrofluorocar- } \\
\text { bonos } \\
\text { (HFCs) }\end{array}$ & Refrigerantes. & 1,5 a 264 & $140-11.700$ \\
\hline & $\begin{array}{l}\text { Perfluorocarbonos } \\
\text { (PFCs) }\end{array}$ & $\begin{array}{l}\text { Solventes, espumas, } \\
\text { refrigeración fija. }\end{array}$ & $\begin{array}{l}2.600 \mathrm{a} \\
50.000\end{array}$ & $6.500-9.200$ \\
\hline & $\begin{array}{l}\text { Hexafluoruro } \\
\text { de azufre (HFCs) }\end{array}$ & $\begin{array}{l}\text { Producción de magnesio } \\
\text { y aluminio. }\end{array}$ & 3.200 & 23.900 \\
\hline
\end{tabular}

Fuente: IECC, 2014, basado en el segundo Informe de Evaluación del IPCC.

El $\mathrm{CO}_{2}$ es el GEl producto de actividades humanas con mayor contribución al calentamiento global, y se produce, en su mayor parte por las actividades de tipo industrial con elevado consumo de los combustibles fósiles y los procesos de deforestación que ocurren (Ghannadi, Moghiseh y Heidari, 2013). Las emisiones de metano $(\mathrm{CH} 4)$ son producto principal de las actividades agropecuarias, como el cultivo del arroz y la producción ganadera. Las emisiones de óxido nitroso (N2O) ocurren especialmente con el uso de agroquímicos en la agricultura. Un aspecto importante, es que, aunque el $\mathrm{CO}_{2}$ es un $\mathrm{GEl}$ de menor potencia que el metano, el óxido de nitrógeno o los fluorocarbonados, durante los últimos años 
ha aumentado su concentración a nivel atmosférico creciendo exponencialmente con el crecimiento poblacional, este constituye el principal responsable del incremento de la temperatura ambiental (Rodríguez y Mance, 2009) y por ende uno de los principales GEl a tener en cuenta en los procesos de mitigación de impacto ambiental.

Los GEl que representan mayor importancia a nivel del sector agropecuario (Tabla 10), son el $\mathrm{CO}_{2}, \mathrm{CH}_{4}$ y $\mathrm{N}_{2} \mathrm{O}$, provenientes de la diversidad de actividades desarrolladas al interior de la unidad de producción (Falloon y Betts, 2010).

Tabla 10. Principales GEI derivados de actividades agropecuarias.

\begin{tabular}{|c|c|c|c|c|c|c|c|}
\hline \multirow{2}{*}{$\begin{array}{c}\text { SECTOR } \\
\text { PRODUCTIVO }\end{array}$} & \multirow{2}{*}{$\begin{array}{c}\text { FUENTE DE EMISIÓN } \\
\text { DE GEI }\end{array}$} & \multicolumn{6}{|c|}{ GEI } \\
\hline & & $\mathrm{CO}_{2}$ & $\mathrm{CH}_{4}$ & $\mathrm{~N}_{2} \mathrm{O}$ & HFC & PFC & $\mathrm{SF}_{6}$ \\
\hline \multirow{7}{*}{ Agropecuario } & Consumo de combustibles fósiles & $x$ & $x$ & $x$ & & & \\
\hline & Consumo de refrigerantes & & & & $x$ & & \\
\hline & Consumo de energía eléctrica & $x$ & $x$ & $x$ & & & \\
\hline & Fermentación entérica & & $x$ & $x$ & & & \\
\hline & Manejo de estiércol & & $x$ & & & & \\
\hline & Uso de fertilizante sintético & & & $x$ & & & \\
\hline & Quemas de residuos agrícolas & & $x$ & $x$ & & & \\
\hline \multirow{2}{*}{$\begin{array}{l}\text { Uso de Suelo, } \\
\text { Cambio de Uso } \\
\text { de Suelo } \\
\text { y Silvicultura }\end{array}$} & Consumo de combustibles fósiles & $x$ & $\mathrm{x}$ & $x$ & & & \\
\hline & Quema de biomasa & $x$ & $x$ & $x$ & & & \\
\hline
\end{tabular}

Algunos autores señalan que la agricultura y la ganadería han incrementado su aporte de GEl durante los últimos años, por esta razón es posible que a mediano plazo puedan ser incluidas como actividades sometidas a obligaciones de reducción de GEl, cuyas emisiones de metano y óxido de nitrógeno representan, respectivamente, el $47 \%$ y $58 \%$ de las emisiones totales. En este sentido, los países en vías de desarrollo deben analizar su $\mathrm{HdC}$ y plantear estrategias para disminuir la generación de los $\mathrm{GEI}$, con miras a conservar los mercados de su producción y explorar nuevas alternativas comerciales. (Tan, Tan, y Khoo, 2014; Viglizzo, 2010). 


\subsubsection{Impacto ambiental de la ganadería bovina}

La producción agropecuaria constituye uno de los principales sectores que mayores impactos causa a nivel ambiental, bien sea por acciones directas relacionadas con un mal uso o contaminación de los recursos naturales o acciones indirectas mediante la emisión de GEl que contribuyen con el fenómeno de calentamiento global (Páez, 2016).

De acuerdo con información de la Organización de las Naciones Unidas para la Agricultura y la Alimentación-FAO (FAO, 2006), la ganadería genera una mayor cantidad de GEl (el 18\%) en su equivalente en dióxido de carbono $\left(\mathrm{CO}_{2}\right)$ en comparación con el sector del transporte (De Vries y De Boer, 2010), sumado a esto, en muchos sistemas de explotación ganadera se observa una degradación del suelo y de los recursos hídricos como consecuencia de malas prácticas en el proceso productivo. Otro aspecto de gran importancia, es que el sector pecuario y en especial la ganadería bovina, constituyen uno de los sectores de mayor crecimiento a nivel mundial, representando la fuente económica principal para muchas personas en diversas regiones, constituyendo la base económica de ingreso y en ocasiones la única fuente de subsistencia, esto es observado en mayor frecuencia a nivel de los denominado países en desarrollo, donde el ganado bovino es el principal elemento de sustento y de otros servicios como fuerza de trabajo y proveedor de fertilizante de tipo orgánico para los cultivos agrícolas (De Vries y De Boer, 2010). Sadeghian (1998) señala que la ganadería utiliza gran parte del territorio cultivable, llegando a abarcar una cuarta parte de las mismas, con un área cercana a los 3,4 billones de hectáreas, su expansión a diversas áreas con vocación y otras que no, han generado problemáticas de diversa índole en donde se pueden resaltar: deforestación de grandes áreas de bosques, procesos de erosión y perdida de la estructura de los suelos, emisión de GEl, contaminación del recurso hídrico, eutrofización de zonas costeras y aguas continentales, alteración y cambios en la flora natural, pérdida de biodiversidad, y elevado uso de combustibles y fertilizantes (Vergé et al., 2008). De acuerdo con la FAO, la producción ganadera aporta muchos elementos contaminantes, entre los que se encuentran las deyecciones, insumos, fertilizantes, antibióticos y productos hormonales, y todos los productos utilizados para la producción forrajera (FAO, 2006).

\subsection{Huella de Carbono}

La Huella de Carbono ( $\mathrm{HdC}$ ) constituye un indicador ambiental, que indica la sumatoria de todas las emisiones de GEl emitidas de manera directa o indirecta por 
un individuo, una organización, un evento, un producto o un servicio. En otras palabras, se constituye en la marca que cada una de las actividades que emiten GEI realizadas, deja sobre el medio ambiente. La HdC es expresada en unidades de carbono equivalente $\left(\mathrm{CO}_{2 \mathrm{eq}}\right)$, esta es la unidad utilizada debido a que se realiza la medición de los diversos GEl que contribuyen en el calentamiento global, pero se hace su equivalencia a unidades de $\mathrm{CO}_{2}$ con el fin de facilitar la presentación de resultados, facilitar la comunicación y la implementación de programas y estrategias a seguir (CGIAR, 2014).

El cálculo de la HdC, está basado en los principios establecidos en el protocolo de emisiones de gases de efecto invernadero o aquellos establecidos en la norma ISO 14064 (Schneider y Samaniego, 2009) y también las normas ISO 14040, 14044 y 14067 como referentes internacionales. La HdC constituye un indicador reconocido a nivel internacional, utilizado a nivel de muchas empresas y entidades como mecanismo de comprensión, medición y comunicación de la dinámica de emisión de GEl, facilitando la toma de decisiones en los procesos de mitigación de impacto ambiental. El consumidor es la base del enfoque para la estimación de este indicador, y se busca conocer el impacto de las actividades antrópicas, a través de la medición de emisiones totales de GEl y su relación o aporte al cambio climático (Ferraro, Galeis y Zulaica, 2013).

En la medición de la $\mathrm{HdC}$, se brinda un estimado de la cantidad total de GEl emitidos durante el ciclo de vida de un bien o servicio, para el caso de un producto de origen agropecuario, estaría representado por la obtención de materias primas, transporte de estas, producción o industrialización, transporte, almacenamiento, utilización y disposición de los productos finales (Molina et al., 2013).

En el proceso de estimación o medición de los GEl se han propuesto diversas metodologías, como se ha mencionado, la $\mathrm{HdC}$ se expresa en unidades de carbono equivalente ( $\mathrm{CO} 2 \mathrm{eq}$ ) como parte del proceso de estandarización de los principales GEl a través del denominado: Poder de Calentamiento Global"-, el cual constituye una medida de la capacidad que tiene el gas de atrapar energía calórica, medida en un periodo de tiempo. $\mathrm{El} \mathrm{CO}_{2}$ es el GEI que se ha utilizado como medida estándar para 100 años a nivel de la atmósfera, y es equivalente a 1, lo que equivale a metano 25 y óxido de nitrógeno 298, esto representa que una (1) tonelada de metano equivale a 25 toneladas de dióxido de carbono equivalentes en la atmosfera (Guerra, 2013; Soussana et al., 2007). 
La HdC, involucra la medición de las emisiones de GEl dadas a lo largo de la cadena de producción, desde la extracción u obtención de materias primas hasta el tratamiento o disposición final de residuos (AEC, sf).

Las emisiones de GEl se dividen en dos tipos: emisiones directas y emisiones indirectas (CAR, 2013):

- Emisiones Directas: Aquellas emitidas directamente en la fuente, son controladas.

- Emisiones Indirectas: Aquellas derivadas de las actividades, son emitidas desde fuente que no pueden ser controladas.

La CAR (2015), establece que el cálculo de las emisiones de GEI dependerá de la disponibilidad de datos y acorde a ella se realizará la estimación. Lo ideal sería determinar las emisiones a través de mediciones directas de los GEl emitidos en cada fase de un proceso, pero la mayoría de las ocasiones no es posible contar con esa información, por lo anterior, se debe estimar la emisión a través de los denominados factores de emisión, que varían de una región a otra (CAR, 2013).

\subsubsection{Factores de emisión}

Un factor de emisión es un valor representativo que establece la relación entre la cantidad de contaminante que se emite a la atmósfera y una actividad asociada a la emisión del mismo. Se pueden clasificar en dos tipos: los basados en procesos y los basados en censos (SEMARNAT, 2005). Los que se basan en procesos, se utilizan para estimar emisiones de fuentes determinadas y con frecuencia se utilizan en conjunto con datos de encuestas o registros. El factor de emisión, permite estimar la cantidad de emisiones de un determinado contaminante, es una herramienta de gran utilidad en los procesos de estimación de los GEI de un producto (CAR, 2013).

\subsubsection{Factores de emisión para combustibles}

Los factores de emisión de los combustibles, son variables, y dependen del tipo de combustible, la actividad en la que es utilizado, los procesos de uso y el nivel de tecnología empleado. Estos factores difieren de una región a otra. La Unidad de Planeación Minero Energética-UPME establece unos factores de emisión para combustibles líquidos, sólidos y gaseosos propios para Colombia (Tabla 11) (CAR, 2013). 
Tabla 11. Factores de emisión para los combustibles colombianos.

\begin{tabular}{|c|c|c|c|}
\hline \multirow{2}{*}{$\begin{array}{c}\text { TIPO DE } \\
\text { COMBUSTIBLE }\end{array}$} & \multirow{2}{*}{ COMBUSTIBLE } & \multicolumn{2}{|c|}{ FACTOR DE EMISIÓN } \\
\hline & & CANTIDAD & UNIDAD \\
\hline \multirow{10}{*}{ LÍOQUIDO } & ACPM & 10,15 & $\mathrm{kgCO}_{2} \mathrm{e} / \mathrm{gal}$ \\
\hline & Combustóleo & 11,76 & $\mathrm{kgCO}_{2} \mathrm{e} / \mathrm{gal}$ \\
\hline & Crudo de Castilla & 11,72 & $\mathrm{kgCO}_{2} \mathrm{e} / \mathrm{gal}$ \\
\hline & Diésel Genérico & 10,15 & $\mathrm{kgCO}_{2} \mathrm{e} / \mathrm{gal}$ \\
\hline & Gasolina Genérico & 8,15 & $\mathrm{kgCO}_{2} \mathrm{e} / \mathrm{gal}$ \\
\hline & Kerosene Col. & 9,71 & $\mathrm{kgCO}_{2} \mathrm{e} / \mathrm{gal}$ \\
\hline & Kerosene Genérico & 9,72 & $\mathrm{kgCO}_{2} \mathrm{e} / \mathrm{gal}$ \\
\hline & Oil Crude & 11,54 & $\mathrm{kgCO}_{2} \mathrm{e} / \mathrm{gal}$ \\
\hline & Biodiesel Genérico & 9,44 & $\mathrm{kgCO}_{2} \mathrm{e} / \mathrm{gal}$ \\
\hline & Biogasolina Genérica & 7,17 & $\mathrm{kgCO}_{2} \mathrm{e} / \mathrm{gal}$ \\
\hline \multirow{5}{*}{ SÓLIDO } & Bagazo & 1,68 & $\mathrm{kgCO}_{2} \mathrm{e} / \mathrm{kg}$ \\
\hline & Carbón Genérico & 2,45 & $\mathrm{kgCO}_{2} \mathrm{e} / \mathrm{kg}$ \\
\hline & Fibra Palma de Aceite & 1,93 & $\mathrm{kgCO}_{2} \mathrm{e} / \mathrm{kg}$ \\
\hline & Leña & 1,84 & $\mathrm{kgCO}_{2} \mathrm{e} / \mathrm{kg}$ \\
\hline & Madera-Genérico & 1,15 & $\mathrm{kgCO}_{2} \mathrm{e} / \mathrm{kg}$ \\
\hline \multirow{9}{*}{ GASEOSO } & Biogás Central & 1,97 & $\mathrm{kgCO}_{2} \mathrm{e} / \mathrm{Nm}^{3}$ \\
\hline & Coke Gas D & 0,77 & $\mathrm{kgCO}_{2} \mathrm{e} / \mathrm{Nm}^{3}$ \\
\hline & Gas Domaci & 1,86 & $\mathrm{kgCO}_{2} \mathrm{e} / \mathrm{Nm}^{3}$ \\
\hline & Gas Líquido D & 7,11 & $\mathrm{kgCO}_{2} \mathrm{e} / \mathrm{Nm}^{3}$ \\
\hline & Gas Natural Genérico & 1,86 & $\mathrm{kgCO}_{2} \mathrm{e} / \mathrm{Nm}^{3}$ \\
\hline & LNG Genérico & 1,86 & $\mathrm{kgCO}_{2} \mathrm{e} / \mathrm{Nm}^{3}$ \\
\hline & LPG Genérico & 7,11 & $\mathrm{kgCO}_{2} \mathrm{e} / \mathrm{Nm}^{3}$ \\
\hline & LPG Propano & 8,21 & $\mathrm{kgCO}_{2} \mathrm{e} / \mathrm{Nm}^{3}$ \\
\hline & Gasoil & 2,68 & $\mathrm{kgCO}_{2} \mathrm{e} / \mathrm{Nm}^{3}$ \\
\hline
\end{tabular}

Fuente: CAR, 2013, adaptado de Factores de Emisión de los Combustibles Colombianos. www.siame.gov.co

\subsubsection{Factores de emisión para energía eléctrica}

El factor de emisión para la energía eléctrica varía de acuerdo a la participación de las fuentes de generación de energía, encontrándose la hidroeléctrica y 
termoeléctrica, como las más comunes. En Colombia, la energía eléctrica consumida a nivel del sector productivo es adquirida del Sistema Interconectado Nacional-SIN. No existe un factor de emisión asociado al consumo de energía eléctrica adquirida para el país, por lo anterior, se utiliza el factor de emisión definido por la Agencia Internacional de Energía-IEA, el cual es el promedio de 2007 al 2009, equivalente a $0,136 \mathrm{kgCO}_{2} \mathrm{e} / \mathrm{kWh}$ (CAR, 2013).

Tabla 12. Factor de emisión para la energía eléctrica adquirida.

\begin{tabular}{c|c} 
AÑO & $\begin{array}{c}\text { FACTOR DE EMISIÓN } \\
\left(\mathbf{k g C O} \mathbf{~}_{\mathbf{2}} \mathbf{e} \mathbf{k W h}\right)\end{array}$ \\
\hline 2007 & 0,127 \\
\hline 2008 & 0,107 \\
\hline 2009 & 0,175 \\
\hline 2010 & 0,176 \\
\hline 2011 & 0,108 \\
\hline Promedio & $\mathbf{0 , 1 3 8}$ \\
\hline
\end{tabular}

Fuente: CAR, 2013, adaptado de Agencia Internacional de Energía. www.iea.org

\subsubsection{Factores de emisión para actividades agropecuarias}

El IPCC establece diversas fuentes de emisión de GEI en las actividades agropecuarias: la fermentación entérica, la disposición del estiércol y la quema de residuos de cosecha, entre otros. En la Tabla 13, se presentan los factores de emisión para las actividades agropecuarias (CAR, 2013).

Para el determinar el factor de emisión para la fermentación entérica se utiliza la siguiente fórmula de cálculo (CAR, 2013):

\section{$\mathrm{FE}_{\mathrm{fe}}=\mathrm{FECH}_{4} * \mathrm{PCG}_{\mathrm{CH} 4}$}

Donde:

- $\mathrm{FE}_{\mathrm{fe}}$ : Factor de emisión para la fermentación entérica.

- $\mathrm{FE}_{\mathrm{CH} 4}$ : Factor de emisión para $\mathrm{CH}_{4}$ procedente de la fermentación entérica del ganado en $\mathrm{kgCH}_{4}$ /cabeza/año (CAR, 2013).

- $\mathrm{PCG}_{\mathrm{CH} 4}:$ Potencial de Calentamiento Global del metano, según Tabla 13.

Para el determinar el factor de emisión para el manejo del estiércol se utiliza la siguiente fórmula de cálculo:

$$
\mathrm{FE}_{\mathrm{fe}}=\mathrm{FECH}_{4} * \mathrm{PCG}_{\mathrm{CH} 4}
$$


Donde:

- $\mathrm{FE}_{\mathrm{me}}$ : Factor de emisión para el manejo del estiércol.

- $\mathrm{FECH}_{4}$ : Factor de emisión para $\mathrm{CH}_{4}$ por el manejo del estiércol en $\mathrm{kgCH}_{4}$ /cabeza/año (CAR, 2013).

- $\mathrm{PCG}_{\mathrm{CH} 4}$ : Potencial de Calentamiento Global del metano, según Tabla 13.

Para el determinar el factor de emisión para el uso de fertilizantes sintéticos se utiliza la siguiente fórmula de cálculo:

$$
\mathrm{FE}_{\mathrm{FS}}=\mathrm{N}_{\text {fert }} *\left(1-\text { Frac }_{\text {GASF }}\right) * \mathrm{FE}_{\mathrm{i}} * \mathrm{PCG}_{\mathrm{N} 2 \mathrm{O}}
$$

Donde:

- $\mathrm{FE}_{\mathrm{FS}}$ : Factor de emisión para el uso de fertilizantes sintéticos.

- $\mathrm{Frac}_{\mathrm{GASF}}$ : Fracción del fertilizante sintético que se emite como $\mathrm{NO}_{x}+\mathrm{NH}_{3}$ (el valor por defecto es $0,1 \mathrm{~kg} \mathrm{NO}+\mathrm{NH}_{3} / \mathrm{kg} \mathrm{N}$, según IPCC).

- $\mathrm{FE}_{\mathrm{i}}$ : Factor de emisión para $\mathrm{N}_{2} \mathrm{O}$ del aporte de nitrógeno (el valor por defecto es $0,0125 \mathrm{~kg} \mathrm{~N}$ O/kg N, según IPCC, (CAR, 2013).

- $\mathrm{PCG}_{\mathrm{N} 2 \mathrm{O}}$ : Potencial de Calentamiento Global del $\mathrm{N}_{2} \mathrm{O}$, según Tabla 13.

Para el determinar el factor de emisión para la quema de residuos agrícolas se utiliza la siguiente fórmula de cálculo:

$$
\begin{aligned}
& \text { FEqra }=\left(\text { Praq }^{*} \text { FO * CTL * } \text { TECH }_{4} * \mathrm{PCG}_{\mathrm{CH} 4}\right) \\
& +\left(\text { Praq } * \text { FO } * \text { CTL } * \text { NC * } \text { TEN }_{2} \mathrm{O} * \mathrm{PCG}_{\mathrm{N} 2 \mathrm{O}}\right)
\end{aligned}
$$

Donde:

- FEqra: Factor de emisión para la quema de residuos agrícolas.

- Praq: Cantidad de residuos agrícolas quemados en $\mathrm{kg}$.

- FO: Fracción oxidada (por defecto es 0,9 según IPCC).

- CTL: Carbono total liberado (por defecto es 0,5; según IPCC).

- $\mathrm{TECH}_{4}$ : Tasa de emisión para $\mathrm{CH} 4$ por la quema

- de residuos agrícolas (CAR, 2013).

- $\mathrm{PCG}_{\mathrm{CH} 4}$ : Potencial de Calentamiento Global del metano, según Tabla 13.

- NC: Relación nitrógeno carbono (por defecto es 0,015, según promedio de valores recomendados por el IPCC, CAR, 2013).

- TEN $\mathrm{T}_{4} \mathrm{O}$ : Tasa de emisión para $\mathrm{N}_{2} \mathrm{O}$ por la quema de residuos agrícolas (0,007, CAR, 2013).

- $\mathrm{PCG}_{\mathrm{N} 2 \mathrm{O}}$ : Potencial de Calentamiento Global del óxido de nitrógeno, según la Tabla 13. 
Tabla 13. Factores de emisión para actividades agropecuarias para Colombia.

\begin{tabular}{|c|c|c|c|}
\hline \multirow{2}{*}{\multicolumn{2}{|c|}{ ACTIVIDAD AGROPECUARIA }} & \multicolumn{2}{|c|}{ FACTOR DE EMISIÓN (kgCO 2 /cabeza) } \\
\hline & & \multirow{2}{*}{$\begin{array}{c}\text { IPCC } 1995 \\
1.197\end{array}$} & \multirow{2}{*}{$\begin{array}{c}\text { IPCC } 2007 \\
1.425\end{array}$} \\
\hline \multirow{8}{*}{$\begin{array}{l}\text { Fermentación } \\
\text { Entérica }\end{array}$} & Ganado bovino lechero & & \\
\hline & Ganado bovino no lechero & 1.029 & 1.225 \\
\hline & Bufalinos & 1.155 & 1.375 \\
\hline & Ovinos & 105 & 125 \\
\hline & Caprinos & 105 & 125 \\
\hline & Equinos & 378 & 450 \\
\hline & Mulares y Asnales & 210 & 250 \\
\hline & Porcinos & 21 & 25 \\
\hline \multirow{9}{*}{$\begin{array}{l}\text { Manejo de } \\
\text { Estiércol }\end{array}$} & Ganado bovino lechero & 33,5 & 33,5 \\
\hline & Ganado bovino no lechero & 0,00 & 25,00 \\
\hline & Bufalinos & 21,00 & 25,00 \\
\hline & Ovinos & 2,10 & 2,50 \\
\hline & Caprinos & 2,31 & 2,75 \\
\hline & Equinos & 22,89 & 27,25 \\
\hline & Mulares y Asnales & 12,60 & 15,00 \\
\hline & Porcinos & 0,00 & 0,00 \\
\hline & Avícola & 0,25 & 0,30 \\
\hline \multicolumn{2}{|c|}{ Fertilizantes Sintéticos } & 3,49 & 3,35 \\
\hline \multicolumn{2}{|c|}{ Quema de Residuos Agrícolas } & 0,06 & 0,07 \\
\hline
\end{tabular}

Como lo señala el INAP (2011), la industria agropecuaria es otra importante fuente de GEI, una de ellas, está representada por la utilización de fertilizantes nitrogenados, los cuales emiten GEl producto de su oxidación (Tabla 14).

Tabla 14. Factores de emisión para insumos agroquímicos.

\begin{tabular}{l|c|c}
\multicolumn{1}{c|}{ FUENTE } & \multicolumn{2}{|c}{ FACTOR DE EMISIÓN } \\
\hline Nitrógeno dispuesto en suelo & $\mathbf{0 , 0 1}$ & $\mathbf{k g ~ N} \mathrm{O} / \mathbf{k g ~ N}$ (aplicado-volatilizado) \\
\cline { 1 - 3 } & 2,98 & $\mathrm{~kg} \mathrm{CO}_{2} \mathrm{e} / \mathrm{kg} \mathrm{N}$ \\
\hline Cal - Piedra caliza & 0,12 & $\mathrm{~kg} \mathrm{CO}_{2} / \mathrm{kg}$ producto \\
\hline Cal - Dolomita & 0,14 & $\mathrm{~kg} \mathrm{CO}_{2} / \mathrm{kg}$ producto \\
\hline Urea & 0,20 & $\mathrm{~kg} \mathrm{CO}_{2} \mathrm{e} / \mathrm{kg}$ producto \\
\hline
\end{tabular}




\subsubsection{Metodologías para la estimación de la Huella de Carbono}

Para la estimación de la HdC, existen diversos protocolos y metodologías de nivel internacional, las cuales varían en función al alcance de la misma (CGIAR, 2014). A nivel regional para las comunicaciones nacionales de GEI, se utilizan las directrices y guías del IPCC; para el cálculo de la $\mathrm{HdC}$ a nivel de organizaciones o empresas se pueden usar los protocolos establecidos en las normas ISO (Organización Internacional de Estandarización), también existen otras metodologías como las desarrolladas por el Instituto de Recursos Mundiales y el Consejo Empresarial Mundial para el Desarrollo Sostenible. En el nivel productivo y empresarial, se utiliza con frecuencia las metodologías de PAS 2050, y las normas ISO.

En Colombia, en el marco de los protocolos internacionales, se tiene la Norma Técnica Colombiana-NTC 5947 denominada "Especificación para el análisis de emisiones y remociones de gases de efecto invernadero durante el ciclo de vida de bienes y servicios", fundamentada en la norma internacional PAS 2050:2011, junto con la Especificación Normativa Disponible 0069 denominada "Sistema de gestión ambiental. Huella de Carbono. Requisitos" (CGIAR, 2014).

A nivel internacional, existen diversas metodologías para el cálculo de la $\mathrm{HdC}$ en empresas, organizaciones, servicios, procesos y productos, la mayoría tienen varios aspectos en común, utilizando una metodología parecida en la mayoría de los casos para la obtención de datos, basada en el Análisis de Ciclo de Vida (ACV) del producto, siguiendo todo su proceso desde la obtención de la materia prima, el proceso de industrialización y obtención del producto, hasta su disposición final (Espíndola y Valderrama, 2012).

\subsubsection{Protocolo de Gases Efecto Invernadero-GHCH Protocol}

El Protocolo de Gases Efecto Invernadero (GHG Protocol) fue desarrollado el año 2001 por el World Business Council for Sustainable Development-WBCSD y por el Instituto de Recursos Mundiales-IRM (World Resources Institute, WRI) una alianza multipartita de empresas, organizaciones no gubernamentales (ONGs), gobiernos y otras entidades integrada por 170 empresas internacionales, con sede en Ginebra, Suiza, que tiene como meta el establecimiento de bases para la contabilización de emisiones de los GEl. El protocolo de GEl brindas la metodología para el cálculo de las emisiones de GEl por medio del uso de software, este es un protocolo con amplio uso a nivel mundial en conjunto con la normativa de los estándares ISO 14064 (Páez, 2016; Espíndola y Valderrama, 2012; PIGA, 2013). 
Este protocolo fue lanzado en el 1998, con el objetivo de desarrollar una metodología con aceptación internacional para la contabilidad y reporte en el nivel empresarial (WBCSD, 2005). El GHCH Protocol se puede aplicar desde cuatro enfoques distintos (Acción RSE, 2012):

- Estándar Corporativo de Contabilidad y Reporte del Protocolo de GEl: señala la metodología para cuantificar y reportar las emisiones de GEl a nivel de empresa.

- Estándar de Cuantificación de Proyectos de Reducción de Emisiones: brinda la base de cálculo para la reducción de emisiones de GEl en proyectos específicos.

- Estándar de Contabilidad y Reporte de la Cadena de Valor. Evalúa el impacto de la cadena de valor de la empresa y permite identificar la manera de reducirlas.

- Estándar de Contabilidad y Reporte del Ciclo de Vida de los Productos: analiza las emisiones del ciclo de vida de un producto con un enfoque tendiente a disminuir a emisión de los GEl a lo largo de la cadena de producción.

El Estándar Corporativo de Contabilidad y Reporte del Protocolo de GEI-ECCR fue diseñado especialmente para las empresas involucradas en el desarrollo de un inventario de GEI. Sin embargo, puede ser aplicable a otros tipos de organizaciones cuyas operaciones estén vinculadas a la emisión de GEl, por ejemplo, instituciones de educación, agencias, entidades gubernamentales, entre otras (WBCSD, 2005).

Este protocolo, entre otros aspectos permite (Acción RSE, 2012):

- Simplificar el inventario y reporte de emisiones de GEI.

- Estandarizar el proceso.

- Brindar credibilidad y respaldo a los reportes.

- Disminuir los costos en la gestión de los GEI.

- Facilitar la gestión de los mercados de bonos de $\mathrm{CO}_{2}$.

El GHG Protocol, permite la elaboración del inventario de GEl de las emisiones reales de la empresa, con un enfoque y principios estandarizados, lo que brinda la base para el planteamiento de estrategias efectivas de gestión y reducción de emisiones de GEI (CAR, 2013).

\subsubsection{Balance de Carbono -Bilan Carbone ${ }^{\circledR}$}

El balance de carbono o también denominado “Bilan Carbone®”, corresponde al balance o inventario de todos los $\mathrm{GEl}$ expresados en $\mathrm{CO}_{2}$ equivalente. Se realiza el cálculo de todas las fuentes de emisión y se analiza el proceso de intercambio de 
carbono (biomasa, suelo, etc.). La medición se puede realizar en diversos niveles: local, para un producto, proceso o inversión; regional: para una empresa, entidad, institución; global, para una cadena de valor o productiva, un país, continente o el planeta. Dentro del proceso dinámico, es también posible evaluar el efecto del balance global de una nueva acción, nuevo proyecto/programa, de una estrategia o de una política (Bockel et al., 2011).

Esta metodología fue desarrollada el año 2002 por la Agencia del Medio Ambiente y Energía de Francia-ADEME (Espíndola y Valderrama, 2012), es compatible con la norma ISO 14064 y la iniciativa GHG Protocol (Protocolo de GEI); adicionalmente constituye una marca registrada (Cordero, 2011). La idea de esta herramienta es realizar la transformación de los datos productivos (ejemplo: consumo de energía, transporte y distancias, adquisición de insumos, etc.) en emisiones, este proceso se realiza por medio de los factores de emisión. Se contabilizan todas las emisiones de los GEI (directas e indirectas), derivadas de las actividades de la cadena productiva. El análisis se realiza con base en una planilla de Excel, donde se plasma la clasificación de las emisiones según fuente (Espíndola y Valderrama, 2012).

Cordero (2011) menciona que el Bilan Carbone $®$, es un método que permite clasificar las emisiones según su fuente en una planilla Excel, calculando las emisiones asociadas a cada actividad de un proceso. Una característica especial es que la división de las hojas de cálculo del método en tres módulos: empresas, administraciones y territorios. Lo anterior, facilita su utilización en cualquier actividad de producción, y cualquier tipo de naturaleza de la empresa (privada o pública), entidades o gobiernos, y en diferentes niveles de organización. Es una metodología simple y operacional, su fundamentación en Excel facilita el uso de los datos de actividad disponibles a nivel de la empresa o entidad (inventario de compras, distancias recorridas, facturas de consumo energético, entre otros). Las emisiones de GEl se evalúan en toneladas de carbono equivalente, un aspecto importante, es que todas las emisiones de GEl asociadas a la actividad son tomadas en cuenta lo que permite un análisis amplio y por ende un plan de acción integral (Cordero, 2011). En la Tabla 15 se presentan las características de la metodología Bilan Carbone ${ }^{\circ}$. La estimación de las emisiones de carbono, implica tres pasos fundamentales (Cordero, 2011):

- Primera etapa: Corresponde a las emisiones internas, propias del proceso productivo. 
- Segunda etapa: Corresponde a las emisiones intermedias, representadas por las actividades necesarias para la función empresarial, tales como transporte, adquisición de energía.

- Tercera etapa: Corresponde al contenido en carbono propio de los productos y los residuos que se generan al cumplir la vida útil de los productos obtenidos en la empresa.

Tabla 15. Características de la metodología Bilan Carbone ${ }^{\circledR}$.

\begin{tabular}{l|l}
\multicolumn{1}{c|}{ Formato } & \multicolumn{1}{|c}{ Software MS Excel (con guías en formato PDF) } \\
\hline $\begin{array}{l}\text { Contabilización emisiones de GEI } \\
\begin{array}{l}\text { Recomendaciones } \\
\text { para la reducción }\end{array}\end{array}$ & Sí \\
\hline $\begin{array}{l}\text { Recomendaciones } \\
\text { para la compensación }\end{array}$ & $\begin{array}{l}\text { No. Sin embargo, la ADEME presenta recomendaciones } \\
\text { para el diseño de líneas de compensación de emisiones } \\
\text { por parte de los operadores. }\end{array}$ \\
\hline $\begin{array}{l}\text { Considera otros impactos } \\
\text { ambientales }\end{array}$ & No \\
\hline Gases considerados & Todos los GEI \\
\hline Escala & $\begin{array}{l}\text { Sitio: Sí } \\
\text { Territorio: Sí } \\
\text { Producto: Sí }\end{array}$ \\
\hline Licencia & $\begin{array}{l}\text { Gratuito. Previo proceso de capacitación, el cual se } \\
\text { desarrolla con un costo. }\end{array}$ \\
\hline Transparencia & Se explica con claridad los procesos y las fórmulas. \\
\hline
\end{tabular}

Fuente: Cordero, 2011, basado en la Comisión Económica para América Latina y el Caribe (CEPAL), 2010.

\subsubsection{Especificaciones Públicamente Disponibles, PAS 2050}

Este método fue elaborado el año 2007, denominado Especificaciones Públicamente Disponibles (Publicly Available Specification), y comúnmente conocido como norma PAS 2050. Tiene su origen en el Instituto Británico de Estandarización (British Standards Institution) (Espíndola y Valderrama, 2012; Plassmann et al., 2010), junto al Consorcio del Carbono (Carbon Trust) y el Departamento para el Ambiente, la Alimentación y Asuntos Rurales (DEFRA). El método se desarrolla en el marco de las normativas ISO 14040 referido al Análisis del Ciclo de Vida e ISO/TS 14067 de Huella de carbono para productos, así como a las recomendaciones del Protocolo GEI. La metodología PAS 2050 considera todas las emisiones 
en la estimación del ciclo de vida de bienes y servicios (Dias y Arroja, 2012; Espíndola y Valderrama, 2012). En la Figura 4 se puede visualizar los pasos establecidos por la PAS 2050 para el cálculo de la HdC.

En la elaboración de la PAS 2050, tuvo participación de representantes gubernamentales, empresariales y académicos del nivel nacional e internacional. El PAS 2050 no exime del cumplimiento de la normativa legal a aquellas empresas o entidades que lo apliquen, pero si sirve como referente para mejorar las prácticas aplicadas tendientes a disminuir la emisión de GEl. El análisis del ciclo de vida de los productos para las empresas que adopten esta metodología debe ser lo más completo posible (AEC, 2015; Tao Gao y Jianp, 2014).

En la norma PAS 2050 se establece el análisis a nivel de dos tipos de ciclos de vida, el marco del tipo de producto (AEC, 2015; Ma y Zhaob, 2012):

- Negocio a negocio: cuando solo se analiza el ciclo de vida del producto hasta donde se realiza la entrega del mismo a otra fase de producción o comercialización.

- Negocio a cliente: cuando se considera el ciclo de vida completo del producto, incluyendo aquellas postconsumo.

Figura 4. Pasos a seguir según la metodología PAS 2050:2008 para el cálculo de la HdC.

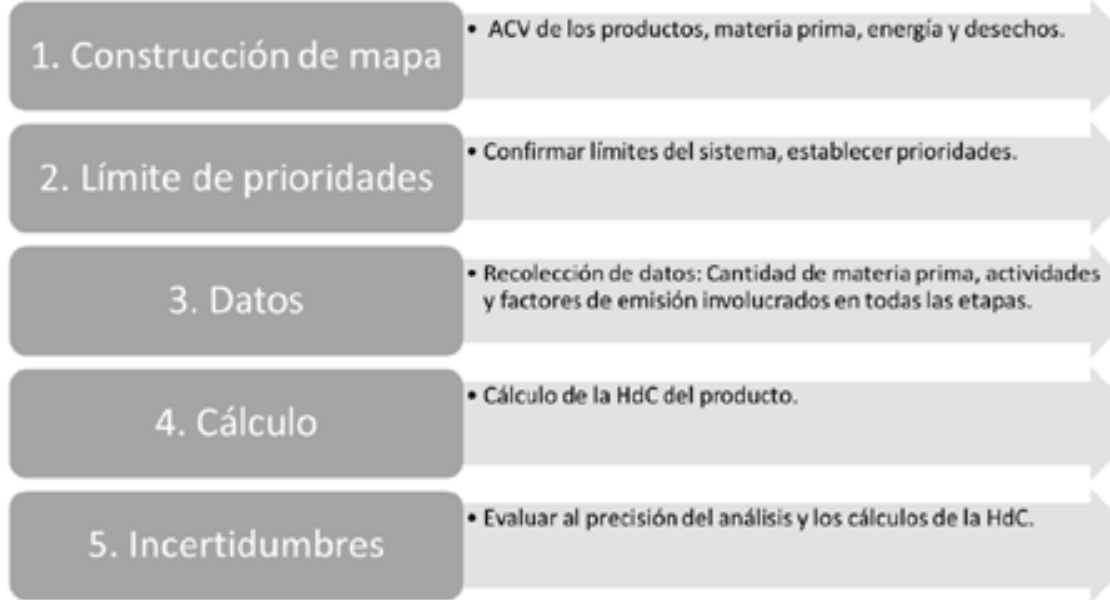

Fuente: adaptado de Ministerio de Ganadería, Agricultura y Pesca de Uruguay (2013). 


\subsubsection{Método Compuesto de las Cuentas Contables (MC3)}

El Método Compuesto de las Cuentas Contables (MC3) fue desarrollado en el año 2004 por Doménech y colaboradores (Espíndola y Valderrama, 2012). Doménech elaboró un método para el cálculo de la $\mathrm{HdC}$ de empresas y organizaciones, expresado esta huella en toneladas de $\mathrm{CO}_{2}$, mediante el uso de herramientas compatibles con la contabilidad que desarrollan las empresas (Bolea, 2011; CarbaIlo, García y Doménech, 2009). Gracias a estas herramientas de la contabilidad la información fluye de forma dinámica entre las organizaciones, y al pasar de una entidad a otra la información fluye acumulándose de manera progresiva. El MC3 únicamente analiza el alcance organizacional, ya que no tiene acceso a la información ni involucra a consumidores en el proceso de análisis (Espíndola y Valderrama, 2012; Cagiao et al., 2011).

Las principales ventajas de esta metodología son:

- Su "enfoque a la organización", favorece los procesos de ecoetiquetado, para los productos o servicios de una organización.

- El indicador se expresa en toneladas de $\mathrm{CO}_{2}$ (huella de carbono), constituyendo un indicador compatible con otras metodologías.

- Permite comparar los datos con otras empresas o productos, ya que se fundamenta en la contabilidad de la empresa.

- El ciclo de vida previo se incorpora con los productos o consumos de entrada, facilitando el uso de los datos, a la vez que no requiere de la participación de clientes o proveedores; ya que la información en la cadena de suministro fluye automáticamente (Espíndola y Valderrama, 2012).

La HdC medida a través de la MC3 incluye las emisiones directas e indirectas de $\mathrm{CO}_{2}$, obtenidas en la producción o en la prestación de los bienes y servicios obtenidos. También incorpora las emisiones del resto de GEl incluidos en el Protocolo de Kioto, para ello se emplean los coeficientes de potencial de calentamiento (GWP) planteados por el IPCC, con un horizonte de 100 años (Boela, 2011). El indicador se expresa en toneladas equivalentes de $\mathrm{CO}_{2}\left(\mathrm{tCO}_{2}\right.$ eq). La información para estimar la $\mathrm{HdC}$ por medio de la MC3 es obtenida de documentos contables de la empresa, por lo cual la información obtenida es muy fiable. También recoge el concepto de Contrahuella que son las emisiones evitadas (Bolea, 2011). 


\subsubsection{Norma ISO 14040 para el cálculo de la $\mathrm{HdC}$ de un producto}

La creciente conciencia ambiental, y la búsqueda de alternativas de mitigación del posible impacto asociado a la producción, han incrementado el interés por el desarrollo técnicas y metodologías para la comprensión y el análisis de los diversos impactos. Una de las más completas, que se ha desarrollado, es la del análisis del ciclo de vida-ACV (NTC, 2007a).

El ACV realiza la recopilación y evaluación de las entradas, salidas y los impactos ambientales potenciales de un producto a través de su ciclo de vida, es decir, realiza la trazabilidad del producto para hacer el inventario de los procesos ocurridos a lo largo de la cadena. Las normas para los procesos de certificación son la ISO 14040, ISO 14044 (Conservación y Carbono S.A.S, 2013) e ISO/TS 14067.

El ACV analiza los aspectos e impactos ambientales potenciales que pueden tener un producto en su ciclo de producción, desde la obtención o extracción de la materia prima, producción, industrialización, utilización, tratamiento final y/o reciclado, hasta que llega a su consumidor o usuario final (NTC, 2007a).

\subsubsection{Metodología del Análisis del Ciclo de Vida-ACV}

Acorde a la norma ISO 14040 el Análisis del Ciclo de Vida-ACV se define como: "una técnica para determinar los aspectos ambientales e impactos potenciales asociados con un producto, lo cual se efectúa recopilando un inventario de las entradas y salidas relevantes del sistema; evaluando los impactos ambientales potenciales asociados a esas entradas y salidas, e interpretando los resultados de las fases de inventario e impacto en relación con los objetivos del estudio" (Pryshlakivsky y Searcy, 2013; Romero, 2003; Berlín, 2002). Desde el punto de vista metodológico se establece una serie de etapas que siguen una secuencia más o menos definida, aunque es posible eliminar alguna fase, en el caso de estudios que no requieren una gran profundidad. Acorde a la ISO 14040, el ACV está conformado por cuatro etapas, las cuales se pueden visualizar en la Figura 5 (NTC, 2007a, Roy, et al, 2009; Rebitzer et al., 2004):

- Etapa 1: Definir el objetivo y el alcance del estudio.

- Etapa 2: Realización o análisis del inventario.

- Etapa 3: Evaluar el impacto ambiental.

- Etapa 4: Interpretar los resultados obtenidos. 
Figura 5. Fases de un Análisis de Ciclo de vida en el marco de ISO 14040.

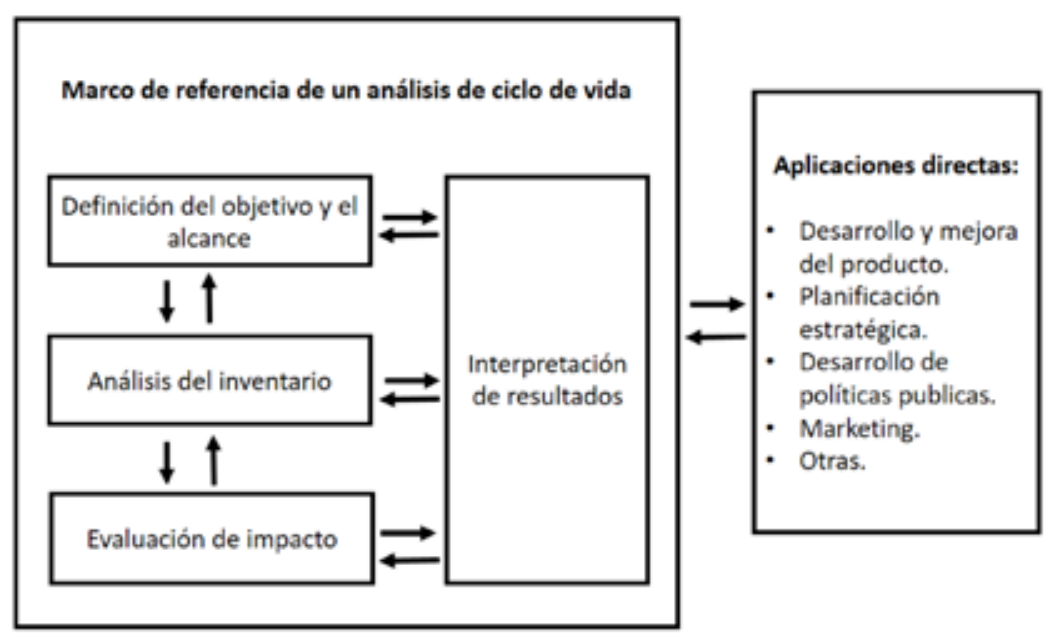

Fuente: adaptado de Conservación y Carbono S.A.S, 2013; Roy et al, 2009

La segunda y tercera fase, son dinámicas, en las que se recogen y evalúan los datos. La primera y cuarta fase son fases estáticas. Una ventaja que presenta, es que se realiza un proceso de evaluación continua, así, con base en los resultados obtenidos en una de las fases o etapas pueden reconsiderarse las hipótesis de la fase o etapa anterior y reorientarla acorde a los resultados obtenidos, en este sentido, el ACV es un proceso en permanente retroalimentación y reorientación, pudiendo dar lugar a la toma de decisiones y reconsideración de los procesos involucrados (Wang, Huo y Arora, 2011; Finnveden et al., 2009; Romero, 2003).

\subsection{Fases del ACV}

\section{Fase 1: Objetivo y alcance del estudio}

Se define el tema de estudio y se incluyen todos los motivos por los cuales debe realizarse. El objetivo puede tener diferentes proyecciones, uno podría ser la comparación de dos productos, teniendo como base la información recogida en la cadena de producción. También podría utilizarse para la introducción de mejoras a productos existentes en procesos de innovación. Un aspecto fundamental de este proceso es el establecimiento de la unidad funcional, referida como la principal función del sistema que se quiere analizar. El ACV se utiliza para evaluar servicios o cantidades de productos (Yan, Humphreys y Holden, 2011). En el caso de sistemas agrícolas, la principal función es la producción alimentaria, por lo cual la unidad funcional estaría representada por un kilo de producto acorde a 
la finalidad del sistema, esta unidad brinda una referencia respecto a la dinámica de las entradas y las salidas del sistema (ISOTools, 2015).

El alcance de un ACV estará acorde al tema específico y el uso previsto del estudio, algunos aspectos que son variables son la profundidad y amplitud del ACV, que son dependientes del objetivo del ACV (NTC, 2007a).

Se pueden establecer límites para evitar que el ACV resulte muy extenso, producto de los límites establecidos van a determinar los procesos que deben incluirse en el ACV. Existen diferentes factores que se constituyen en determinantes de los límites del sistema, entre los cuales se puede resaltar la aplicación proyectada para el ACV, las hipótesis planteadas, los datos, las limitantes económicas y el destino proyectado para el ACV (ISOTools, 2015).

En los límites del sistema los aspectos a incluir generalmente son los siguientes (ISOTools, 2015):

- La secuencia de producción principal, que abarca los procesos que implican la obtención de las materias primas hasta la eliminación del producto.

- Las operaciones de transporte (materias primas y productos finales).

- La producción y la utilización de combustibles (en sus diferentes tipologías).

- La generación de energía (en el proceso).

- La eliminación de los residuos.

- Los mecanismos de transporte.

A nivel del establecimiento de los límites del sistema, generalmente no son incluidos (ISOTools, 2015):

- Los procesos que involucran la fabricación de los equipos para la producción.

- Los procesos de mantenimiento de equipos y plantas de fabricación.

- Los elementos comunes de cada uno de los procesos en estudio que se evalúan.

\section{Fase 2: Análisis del inventario del Ciclo de Vida-ICV}

Implica el levantamiento de todos los datos de entrada y de salida de un proceso, y el análisis de su relación con el sistema que se está estudiando. Requiere una recolección exhaustiva de los datos acordes al alcance definido y que den respuesta a los objetivos del estudio (NTC, 2007a). 
En esta etapa, se realiza la cuantificación de las entradas y salidas de materia y energía correspondiente al sistema durante su ciclo de vida. Implica la obtención de datos y el desarrollo de todos los pasos necesarios para la identificación y cuantificación de los diferentes efectos e impactos ambientales asociados a la unidad funcional. Los efectos ambientales pueden denominarse "carga ambiental", que corresponden a la entrada o salida de materia y/o energía de un sistema que genera un efecto ambiental de tipo negativo. Aquí se incluyen las emisiones de gases contaminantes, efluentes de agua, residuos sólidos, consumo o impacto sobre recursos naturales, radiaciones, olores, emanaciones, etc. En caso de evaluar varios productos, se debe realizar el proceso de asignación de estos flujos de materia y energía, junto con la identificación de las emisiones al medio ambiente para cada uno de los productos (ISOTools, 2015).

\section{Fase 3: Análisis o Evaluación del impacto del Ciclo de Vida}

La evaluación del impacto del ciclo de vida brinda la información necesaria para estimar la importancia de los resultados del inventario del ciclo de vida (ICV) de un sistema del producto para facilitar la compresión de su importancia ambiental (NTC, 2007a). La estructura de esta fase se determina por la norma ISO 14042, que diferencia elementos obligatorios y elementos opcionales (ISOTools, 2015). Los elementos obligatorios corresponden a:

- Selección: Plantear los indicadores de la categoría y los modelos a utilizar.

- Clasificación: Se realiza la asignación a cada categoría de impacto de los diferentes datos que proceden del inventario acorde al tipo de efecto ambiental que se espera.

- Caracterización: es un proceso de modelización de los datos que proporciona el inventario para cada una de las categorías de impacto evaluadas.

A cada categoría de impacto, se le realiza una representación cuantitativa que se denominará indicador de categoría. En la unidad del indicador de la categoría es donde se realiza la sumatoria de todas las intervenciones ambientales para una misma categoría.

\section{Fase 4: Interpretación de los resultados}

Esta es la última fase del ACV, la cual corresponde a un resumen y la discusión de los resultados del inventario del ciclo de vida-ICV, también puede realizarse la evaluación del impacto del Ciclo de Vida-EICV como tal, o en algunos casos se 
realizan los dos procesos. Esto da lugar al desarrollo de las conclusiones, recomendaciones y la toma de decisiones acordes al objetivo y alcance definidos en la primera fase del estudio (NTC, 2007a).

\subsubsection{Normatividad asociada al Análisis de Ciclo de vida-ACV}

\subsubsection{Norma ISO $\mathbf{1 4 0 4 4}$ para cálculo de la $\mathrm{HdC}$ de un producto}

La norma ISO 14044, es de amplio uso a nivel mundial, y permite evaluar el ciclo de vida de un producto, esta norma genera los requisitos y directrices para llevar a cabo la evaluación, entre estos se incluyen (Nuevas normas ISO, 2014):

- Definición del objetivo.

- Alcance del ciclo de vida del producto.

- Analizar el inventario del ciclo de vida.

- Interpretar, informar y realizar un examen crítico del ciclo de vida.

- Las fases del ciclo de vida están relacionadas.

- Hay opciones de valor y elementos que son opcionales.

La norma ISO14044 define los objetivos y el alcance acorde a la aplicación de los resultados del análisis del ciclo de vida (Nuevas Normas ISO, 2014).

\subsubsection{Norma ISO/TS 14067 para cálculo de la HdC de un producto}

La norma ISO/TS 14067 fue publicada el 2013 (Peng, Bo y Xiangyu, 2015), establece un marco de referencia, que es reconocido a nivel internacional para calcular la HdC de un producto y está basada en la norma PAS 2050 de la BSI, esta incluye los requisitos para la comunicación. Esta norma específica los principios, requisitos y directrices para cuantificar, comunicar la $\mathrm{HdC}$ de un producto (que cubren tanto bienes como servicios) con base en las emisiones y remociones de GEl durante el ciclo de vida de los productos (Figura 6).

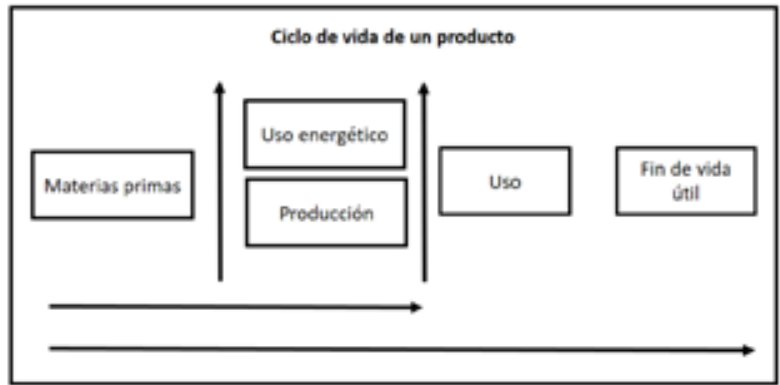

Figura 6. Ciclo de vida de un producto.

Fuente: adaptado de ISM, 2013. 
El estándar de esta norma fue desarrollado con base en las normas internacionales anteriores, relacionadas con el etiquetado y la gestión ambiental. Entre las normas que dieron soporte están (Peng, Bo y Xiangyu, 2015; García y Freire, 2014):

- ISO 14020: Etiquetas ecológicas y declaraciones. Principios generales.

- ISO 14024: Etiquetas ecológicas y declaraciones medioambientales. Etiquetado ecológico. Tipo I. Principios generales y procedimientos.

- ISO 14025: Etiquetas y declaraciones ambientales. Declaraciones ambientales tipo III. Principios y procedimientos.

- ISO 14040: Gestión ambiental. Análisis de ciclo de vida. Principios y marco de referencia.

- ISO 14044: Gestión ambiental. Análisis de ciclo de vida. Requisitos y directrices.

Esta norma tiene como objetivo homogeneizar los principios y procedimientos de cuantificación en la evaluación de la HdC, el cual debe incluir un proceso de cuantificación de la $\mathrm{HdC}$, un informe del estudio de la $\mathrm{HdC}$ a partir de los resultados de la cuantificación de la misma y, una revisión crítica sobre la base de la norma ISO 14044. Luego viene la etapa de comunicación, para lo cual se deben cumplir unos estándares en los procesos y los informes para ser puestos a disposición del público (Peng, Bo y Xiangyu, 2015).

La ISO/TS 14067 se basa el cálculo de la HdC en los principios metodológicos del ACV (Imagen No. ), lo que permite determinar la fase en la cual se produce una mayor emisión de GEI, facilitando información para identificar las oportunidades de mejora y permite aplicar los esfuerzos en el lugar adecuado, con la máxima eficacia (Rinaldi, Barbanera y Lascaro, 2014; ISM, 2013). La norma, incluye los esquemas de etiquetado de carbono, en términos de permitir una comunicación de los resultados de GEl para que los mismos puedan ser comunicados de forma transparente a los usuarios de los productos, con el fin de que puedan tomar decisiones con base en una información completa (Peng, Bo y Xiangyu, 2015; Ingrao et al., 2015, DNV-GL, 2014).

Los beneficios que aporta la norma ISO/TS 14067 son (DNV-GL, 2014):

- Crear estrategias asociadas al "benchmark" del producto.

- Generar confianza a los consumidores. 
- Definir mejores objetivos y políticas de reducción de emisiones de mayor efectividad.

- Identificar oportunidades de ahorro en la organización.

- Promover la concienciación ecológica entre compradores y productores.

- Demostrar los compromisos con la responsabilidad social.

- Mejorar la credibilidad, la coherencia y la transparencia de la cuantificación, información y comunicación de la $\mathrm{HdC}$ de productos y con ello la imagen institucional.

- Proporcionar requisitos para los distintos métodos de evaluación de la Huella de Carbono.

- Facilitar el seguimiento de los resultados en la reducción de las emisiones de GEI.

Respecto a los límites del sistema (los cuales definen las etapas del ciclo de vida que deben ser incluidos en los estudios de ACV), en la norma ISO/TS 14067, se proponen cuatro opciones de límites del sistema (Peng, Bo y Xiangyu, 2015):

De la cuna a la tumba: incluye las emisiones y absorciones derivadas del ciclo de vida de los productos. Debe ser utilizado cuando se puede hacer una determinación completa de las fases finales de la vida de un producto, se debe tener acceso completo a toda la información a lo largo de la cadena.

- De la cuna a la puerta: incluye las emisiones y absorciones derivadas hasta el punto en que el producto sale de la organización, se efectúa la evaluación para la transferencia a otra parte. Son estimaciones parciales dentro de la cadena de producción.

- Puerta a puerta: incluye las emisiones y absorciones que surjan dentro de las diferentes organizaciones de la cadena de suministro del producto. Esta medición puede ser adoptada cuando las emisiones procedentes de la cuna a la puerta sean difíciles de obtener o cuantificar. Permite la toma de decisiones en alguna parte de la cadena de producción.

- Huella parcial de carbono: incluye las emisiones y absorciones de un número limitado de etapas aisladas dentro del proceso de un producto. Son mediciones más limitadas y sirven como referente o indicador para el desarrollo de mediciones más amplias. 
En la norma ISO/TS 14067, la Unidad funcional, puede estar representada por un producto o un servicio. La unidad de medida en la norma ISO/TS 14067 es el dióxido de carbono equivalente $\left(\mathrm{CO}_{2 \mathrm{e}}\right)$ (Peng, Bo y Xiangyu, 2015).

\subsubsection{Experiencias y aplicación de la metodología de estimación de la $\mathrm{HdC}$ en el sector agropecuario}

La agricultura es una fuente importante de GEI, aportando directamente el $14 \%$ de las emisiones totales globales (Bockel et al., 2011; Muñoz et al., 2010). Otros elementos de la agricultura que aportan a los GEl incluyen los cambios con el uso de la tierra y la deforestación, llegando a contribuir con cerca de un tercio de las emisiones de GEl. A nivel mundial la producción agropecuaria es responsable de la mayoría de las emisiones de metano (cultivos, ganadería) y de óxido nitroso (fertilizantes sintéticos). El sector agropecuario es uno de los que puede generar más acciones para mitigar ese impacto, especialmente en países en desarrollo como Colombia (Páez, 2016).

A nivel de mitigación, existen diversas opciones: reducir las emisiones de $\mathrm{CO}_{2}$ a través de la utilización de prácticas de labranza mínima, aumentar la reforestación y reducir la deforestación, protección de recursos naturales, mejoramiento de la eficiencia de la nutrición animal para una menor disposición de gases tipo metano, gestión integral de los residuos del ganado (estiércol, biogás), gestión hídrica en cultivos, plantaciones forestales para secuestro de carbono e implementación de sistemas silvopastoriles, entre otros aspectos (Bockel et al., 2011). Todo lo anterior, debe estar fundamentado en estudios que permitan visualizar el impacto que causan las prácticas tradicionales de producción, con el objetivo de crear conciencia y dar lugar a la generación de prácticas que mitiguen ese impacto y sean amigables con el medio ambiente (Páez, 2016).

América ocupa el segundo lugar a nivel mundial entre los continentes que más emisiones de GEl derivados de actividades agropecuarias con un total del $25 \%$ de las mismas (Figura 7). 
Figura 7. Emisiones por Continente de GEI derivadas de la agricultura.

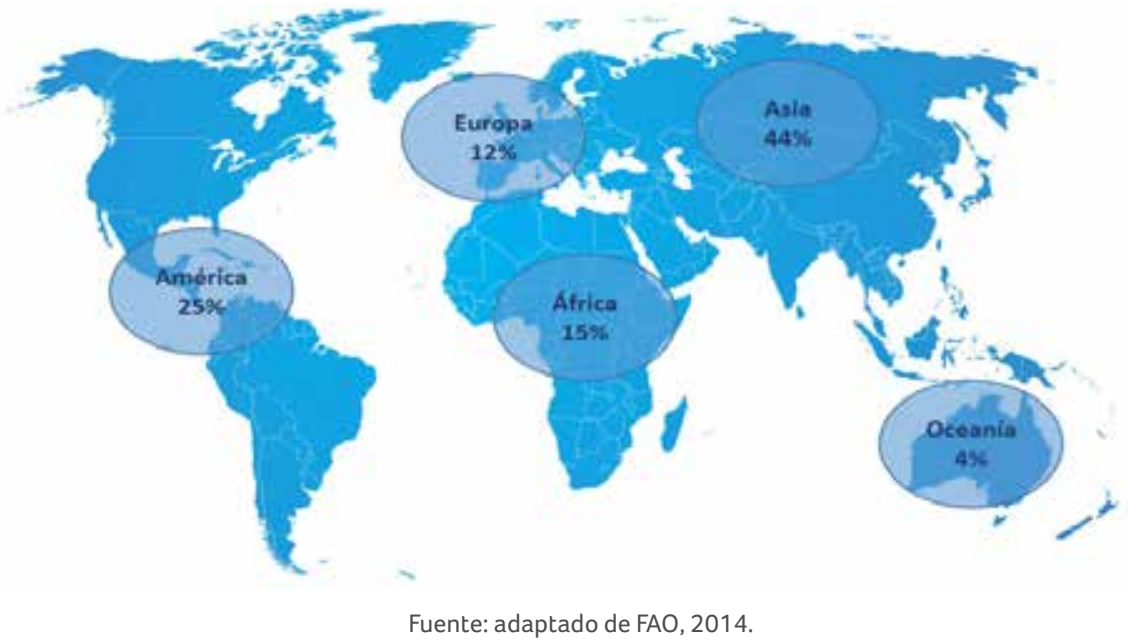

A nivel global las emisiones provenientes de la producción agropecuaria casi se han duplicado entre 1961 y 2011 (Figura 8) (CGIAR, 2014; Zervas y Tsiplakou, 2012). En el promedio mundial el sector agropecuario realiza un aporte significativo $(13,5 \%)$ como fuente de GEl, sin embargo, el primer lugar lo siguen ocupando los procesos de producción energética (Figura 9).

Figura 8. Incremento de emisiones de GEI derivadas de la agricultura.

\section{Emisiones globales de la agricultura en los últimos $\mathbf{5 0}$ años \\ = $1961=2011$}

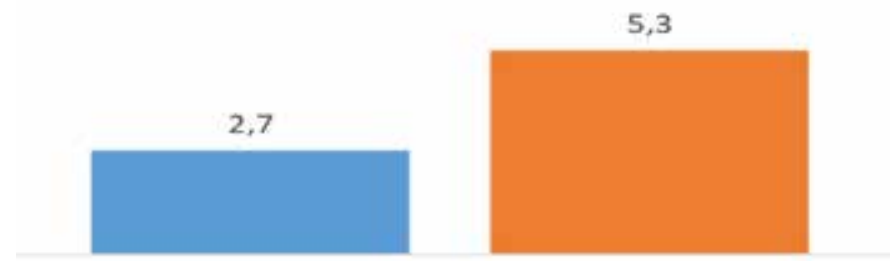

Billones de toneladas de $\mathrm{CO} 2$ eq

Fuente: adaptado de CGIAR, 2014 basado en FAO, 2011.

Las emisiones de GEl han aumentado de manera directamente proporcional al crecimiento poblacional, esto como consecuencia directa del incremento de los bienes y servicios producidos (Figura 9). 
Figura 9. Emisiones mundiales de GEl de origen antropogénico entre 1970 y 2004.

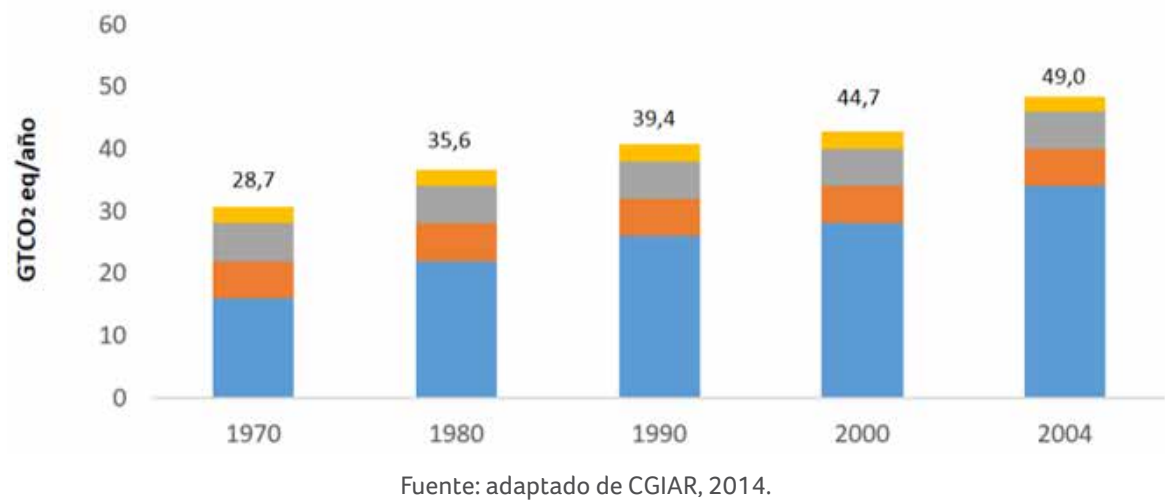

Según datos del Inventario Nacional de GEl para Colombia (2004), uno de los mayores aportantes en el país, está representado por el sector agropecuario, contribuyendo con cerca del 38,1\% en las emisiones nacionales totales de GEl (Figura 10), siendo la mayor fuente de emisión (CGIAR, 2014), esto es acorde a lo observado a nivel mundial en donde los países en desarrollo tienen como principal fuente de GEl los procesos de producción primaria. En el sector agropecuario, la ganadería es la que representa el mayor nivel de aporte con 48,51\% (producto de emisiones de GEI pro fermentación de las actividades digestivas de la ganadería) seguida de un $47,54 \%$ de aportes agrícolas, por prácticas de adecuación de suelos (fertilizantes nitrogenados sintéticos) (CGIAR, 2014) (Figura 11).

Figura 10. Inventario de emisiones de GEl clasificadas por sectores en Colombia.

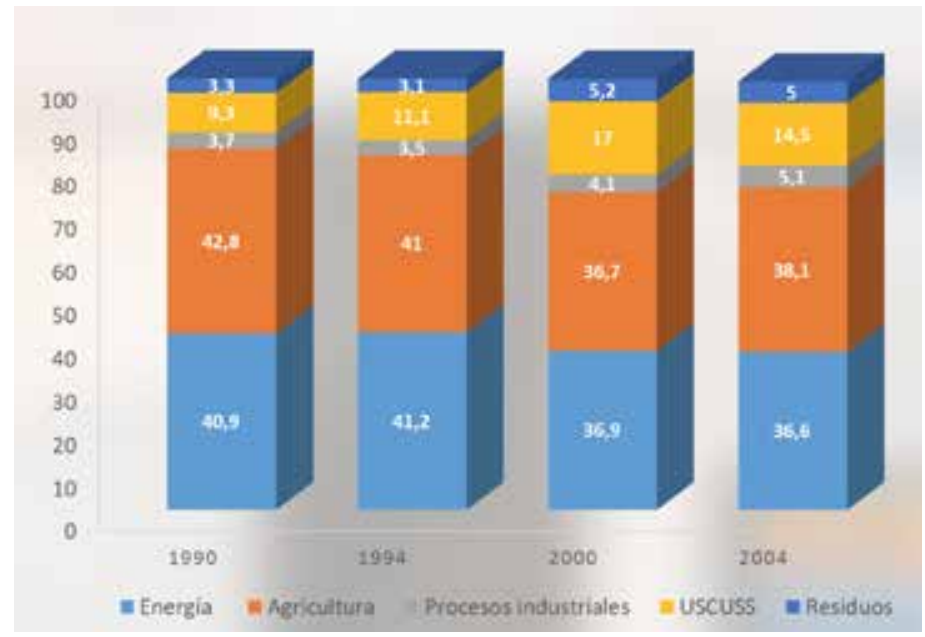

Fuente: adaptado de CGIAR, 2014. 
Figura 11. Inventario de emisiones de GEl por categoría en Agricultura en Colombia.
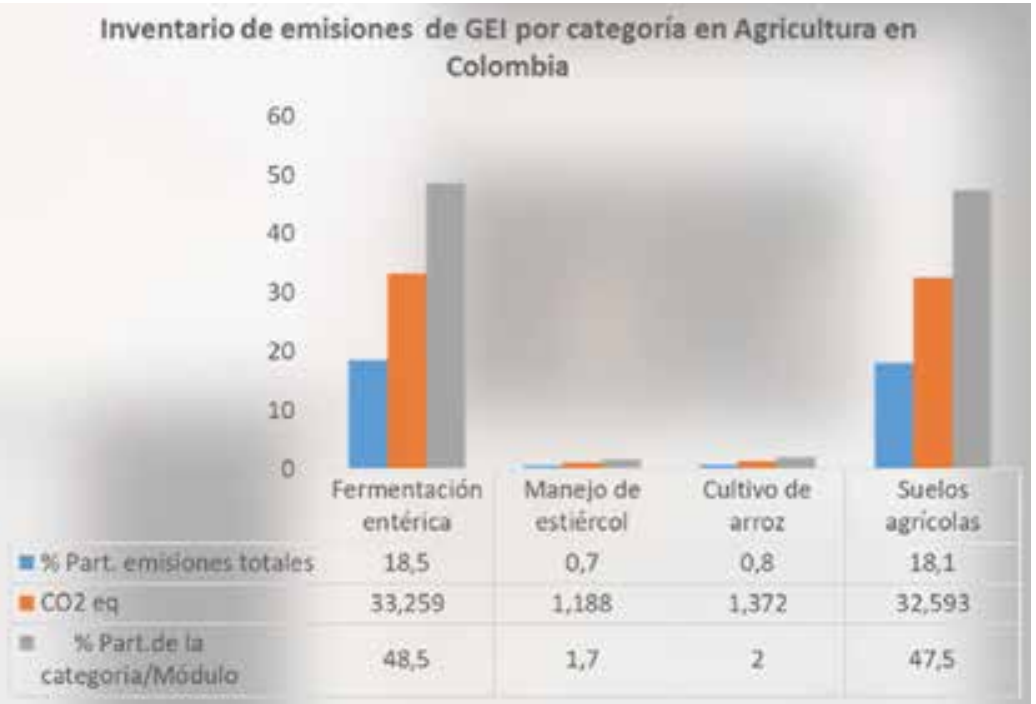

Fuente: adaptado de CGIAR, 2014.

\subsubsection{Investigación de la Huella de Carbono en sectores agropecuarios $\mathrm{o}$ asociados}

Steinfeld et al. (2009) señalan que el $18 \%$ de las emisiones globales de GEl provienen del ganado, lo cual lo convierte en uno de los sectores objeto de investigación para implementar acciones de mitigación. Sumado a esto, en los últimos años, se ha incrementado la preocupación por los impactos adversos del cambio climático, lo cual ha motivado a diversas organizaciones a la investigación respecto a las emisiones de GEl y su mitigación (Ministerio de Ganadería, Agricultura y Pesca de Uruguay, 2013).

El Ministerio de Ganadería, Agricultura y Pesca de Uruguay (2013) señala, que una de las principales preocupaciones se ha centrado en los impactos ambientales de las actividades agropecuarias, como consecuencia del aporte de residuos y metabolitos a los cuerpos de agua subterránea y superficial y el aporte de GEl como el metano y el óxido nitroso al proceso de calentamiento global y cambio climático. Aquí la $\mathrm{HdC}$, puede ser una herramienta útil poder identificar el impacto real causado por los sistemas productivos y poder implementar acciones que permitan disminuir la producción y emisión de estos GEl.

Guerra (2013) señala, que las fuentes de emisión de GEl en la cadena productiva bovina están representadas por: procesos fisiológicos de los animales con 
emisión de metano y óxido nitroso $\left(\mathrm{CH}_{4}\right.$ y $\left.\mathrm{N}_{2} \mathrm{O}\right)$, prácticas de fertilización nitrogenada (N2O), cambios en el uso de suelo, deforestación, elevado consumo de combustibles derivados del petróleo dentro de la finca para máquinas y vehículos $\left(\mathrm{CO}_{2}\right)$. Las prácticas de manejo de la finca, el nivel de incorporación tecnológica y la variabilidad climática son las determinantes de la intensidad de emisiones.

La FAO (2014) estima la HdC para ganaderías lecheras en un 2,4 $\mathrm{kg} \mathrm{CO}_{2 \mathrm{eq}}$ por $\mathrm{kg}$ de leche corregida en grasa y proteína (FPCM por sus siglas en inglés: fat and protein corrected milk) a la puerta de la finca. La mayor emisión se da en países con bajo nivel de desarrollo, como aquellos localizados en África, Asia Meridional y Medio Oriente, los cuales aportan 7,5; 4,6 y 3,7 kg CO 2 / $/ \mathrm{kg}$ FPCM respectivamente. Es de anotar que los países desarrollados tienen una menor emisión de GEl frente los países en desarrollo (Guerra, 2013). El tipo de manejo de los sistemas: convencionales, silvopastoriles y mixtos, son los que van a determinar la cantidad de emisiones (Guerra, 2013). Debido al alto grado de variabilidad de las condiciones y manejo de las unidades productivas, inclusive dentro de una misma región, es difícil la estandarización de unidades de medición comparables y estandarizadas por lo que se requiere contar con procedimientos, metodologías y protocolos adaptados a las condiciones de cada país (Guerra, 2013).

En Costa Rica se realizó un estudio sobre huella de carbono a través del ACV en producción lechera el año 2011. El estudio permitió determinar que se tiene un promedio de emisión de 1,2 kg CO $\mathrm{Ceq}_{2} / \mathrm{kg}$ FPCM, existiendo gran variabilidad en los sistemas de producción y las diferentes regiones (Guerra, 2013).

De acuerdo con lo planteado por Guerra (2013), existen tres herramientas metodológicas para calcular las emisiones de GEI en bovinos: CAR livestock, Greenhouse in Agriculture: Dairy and Beef Greenhouse Accounting V4 y V6, junto a estas se encuentran algunas guías y protocolos y guías que permiten identificar y cuantificar las fuentes de emisión: AOS-Beef Feeding, Beef Lifecycle, AOS Dairy, FAO Dairy. Es importante mencionar que como lo señala Guerra (2013), en Latinoamérica no existen herramientas estandarizadas y deben ser aplicados modelos de países industrializados.

Las anteriores herramientas se basan en los tres métodos definidos por el IPCC para la cuantificación: El primero, se basa en emisiones que se estiman a partir de factores de emisión establecidos; el segundo, tiene en cuenta además de los 
anteriores, otros parámetros como la característica del hato en conformación, la disposición de residuos, los parámetros productivos, entre otros; el tercero, está fundamentado en factores de emisión con base en las condiciones propias del área de estudio y del sistema productivo que este bajo estudio(Guerra, 2013).

A partir del 2001 se emitió la norma ISO 14040, que toma el Análisis de Ciclo de Vida (ACV) como herramienta de decisión, que permite realizar un inventario de entradas, salidas y evaluación del impacto ambiental.

A nivel internacional, existen algunas herramientas aplicadas para la medición o estimación de la huella de carbono, una de las herramientas utilizadas en ganadería de tipo lechero es el Modelo de GEl de producción lechera (DairyGHG), representado por un software para la estimación de las emisiones de GEI y la HdC de los sistemas de producción lechera. DairyGHG se fundamenta en factores de emisión y análisis de procesos para hacer una estimación de las emisiones de GEI de la unidad de producción, basadas en las practicas nutricionales y manejo de residuos (Bockel et al., 2011). Esta es una herramienta muy útil en ganadería en sistemas lecheros especializados, sobre todos aquellos localizados en países desarrollados donde es fácil llevar registro y control total de los elementos del sistema, sin embargo, su utilidad práctica en sistemas ganaderos de países en vía desarrollo es aún muy limitada (Páez, 2016).

Existen otras herramientas también disponibles y aplicadas al sector agrícola principalmente, entre las cuales se pueden destacar (Bockel et al., 2011):

Holos Software: es un software creado en el año 2001 en Canadá por el departamento de agricultura, permite calcular las emisiones de GEl a partir de la modelización.

Evaluación de gestión de carbono - Informes voluntarios (COMET-VR): permite la estimación de las emisiones de GEI con base en las prácticas de suelo (cambios de vocación, uso de fertilizantes), uso de combustibles y captación de carbono. Es una herramienta de aplicación online, pero con limitación de aplicación a Estados Unidos por sus modelos de simulación dinámica.

DNDC (DesNitrificación-DesComposición): es una metodología de modelización que se utiliza en sistemas agropecuarios, se basa en la simulación del proceso del carbono y del nitrógeno. Tiene la utilidad de servir como método de predicción 
de la dinámica del cultivo, desde el crecimiento de las plantas hasta los procesos de emisión de GEl y lixiviación del nitrógeno conllevando a la contaminación de aguas subterráneas, Asimismo permite la estimación de emisiones de GEI como: óxido nitroso $\left(\mathrm{N}_{2} \mathrm{O}\right)$, óxido nítrico $(\mathrm{NO})$, dinitrógeno $\left(\mathrm{N}_{2}\right)$, amoniaco $\left(\mathrm{NH}_{3}\right)$, metano $\left(\mathrm{CH}_{4}\right)$ y dióxido de carbono $\left(\mathrm{CO}_{2}\right)$.

$\boldsymbol{E X}-\boldsymbol{A C T}$ (Balance de carbono EX-Ante): creada por la FAO, esta herramienta metodológica permite estimar el balance de carbono y el secuestro del mismo para estimar el impacto de los procesos de mitigación. Se fundamenta en el análisis de la dinámica del sistema productivo, evaluando las emisiones y existencias de carbono en la unidad de producción, dando como resultado evaluaciones que sirven para la toma de decisiones en los procesos de implementación de proyectos productivos agropecuarios o forestales (Bockel et al., 2011).

\subsubsection{Investigación de la huella de carbono en Uruguay}

El Ministerio de Ganadería, Agricultura y Pesca de Uruguay (2013), lideró el desarrollo del primer estudio sobre $\mathrm{HdC}$ de tres cadenas agroexportadoras relevantes de Uruguay se ejecutó a instancias del Ministerio de Ganadería, Agricultura y Pesca (MGAP), entre Octubre de 2010 y Septiembre 2011, denominado "Huella de Carbono de tres de los principales rubros de exportación". Se realizó en base a un trabajo interinstitucional donde participaron conjuntamente la Facultad de Agronomía de la Universidad de la República (FAGRO-UDELAR), el Instituto Nacional de Investigación Agropecuaria (INIA), la Unidad Agropecuaria de Cambio Climático (UACC-MGAP) y el Laboratorio Tecnológico del Uruguay (LATU). Además, contó con el apoyo y participación del PNUD y diversas organizaciones públicas y privadas nacionales, empresas y organizaciones de productores.

Como resultado del estudio se constató que el sistema criador registra mayores emisiones de GEl que cualquier sistema de recría o invernada. Es importante mencionar que, si bien estos últimos se miden en función de los kilos obtenidos, en el caso de la cría se expresan en función de los kilogramos de ternero destetado. Esto implica que en estos sistemas se deben incluir emisiones de animales que puntualmente no están produciendo como es el caso de reemplazos o toros, y que contribuyen en las emisiones del sistema (Ministerio de Ganadería, Agricultura y Pesca de Uruguay, 2013).

El estudio dejó en claro que, en el sistema global nacional, aproximadamente el 55 $\%$ de la $\mathrm{HdC}$ proviene de la etapa criadora. Por otra parte, las recrías más cortas, 
así como los procesos de invernada más intensivos donde se registran ganancias diarias de peso-GDP promedio mayor, verifican menores estimaciones de $\mathrm{HdC}$. Si bien los procesos de invernada de $\mathrm{P}+\mathrm{S}$, así como el $\mathrm{FL}$, incrementan las emisiones producto de la producción de alimentos y suministro, la mejora en la eficiencia productiva contrarresta a éstas. En este punto se analiza el impacto de incorporar a partir del destete del ternero, los procesos de recría e invernada. Teniendo en cuenta que la $\mathrm{HdC}$ mide emisiones por unidad de producto, se observó que el sistema en base a recría e invernada a campo natural, donde las GDP promedio son menores, presentan una mayor HdC (Tabla 16) (Ministerio de Ganadería, Agricultura y Pesca de Uruguay, 2013).

Tabla 16. Huella hídrica ganadería Uruguay.

\begin{tabular}{l|c|c|c}
\multicolumn{1}{c|}{ Sistemas } & $\begin{array}{c}\text { Emisiones } \\
\text { Sistema A CN } \\
\text { Base 100 (\%) }\end{array}$ & $\begin{array}{c}\text { \% Faena Nacional } \\
\text { Ponderado } \\
\text { Base 100 }\end{array}$ & $\begin{array}{c}\text { Participación } \\
\text { en la HC Nacional }\end{array}$ \\
\hline $\begin{array}{l}\text { Cría, recría e invernada } \\
\text { CN de novillos }\end{array}$ & 100 & 0,17 & 23,2 \\
\hline $\begin{array}{l}\text { Cría CN, recría larga } \\
\text { y Inv P+S de novillos }\end{array}$ & 86 & 0,09 & 9,9 \\
\hline $\begin{array}{l}\text { Cría CN, recría corta } \\
\text { y Inv P+S de novillos }\end{array}$ & 76 & 0,20 & 20,5 \\
\hline $\begin{array}{l}\text { Cría CN, recría larga } \\
\text { y Inv FL de novillos }\end{array}$ & 83 & 0,03 & 3,2 \\
\hline $\begin{array}{l}\text { Cría CN, recría corta } \\
\text { y Inv FL de novillos }\end{array}$ & 73 & 0,09 & 8,4 \\
\hline Invernada vacas & 61 & 0,42 & 34,7 \\
\hline Total & & 100 & 100 \\
\hline
\end{tabular}

Fuente: Ministerio de Ganadería, Agricultura y Pesca de Uruguay, 2013.

Lizarralde (2013) desarrolló un estudio para establecer la relación entre la HdC y las prácticas de manejo de predios lecheros de Uruguay (Figura 12). El estudio siguió las normas internacionales para cuantificar la $\mathrm{HdC}$ de la leche producida en 24 tambos o hatos de Uruguay. Las vacas pastorean todo el año y son suplementadas con concentrados. Los predios lecheros variaron en productividad 4075 ( \pm $1360 \mathrm{~kg}$ ) leche corregida por grasa y proteína (LCGP) por hectárea, producción de leche por vaca $5672( \pm 1245) \mathrm{kg}$ LCGP/año, carga animal $0,71( \pm 0,12)$ vaca masa por hectárea y porcentaje de concentrado en la dieta 36 ( $\pm 12 \%)$ materia seca, 
siendo el promedio de $\mathrm{HdC} 0,99 \mathrm{~kg} \mathrm{CO}{ }_{2 \mathrm{eq}}\left(\mathrm{CO}_{2}\right.$ equivalente) $/ \mathrm{kg} \mathrm{LCGP}( \pm 10 \%)$. La productividad de leche y la producción de leche por vaca fueron las variables que explicaron mejor la variación en la huella de carbono. Los hatos con similares producciones y manejo nutricional fueron categorizados en conglomerados. Las estrategias que resultaron en las más altas producciones basadas en alta producción de leche por vaca, baja carga animal y alta relación de vacas en ordeño en el hato fueron identificadas como algunas de las prácticas con proyección para la reducción de las emisiones de GEl por kg de leche a la puerta del predio.

Figura 12. Contribución de las distintas fuentes de emisión de GEl a la huella de carbono de cada uno de los conglomerados.

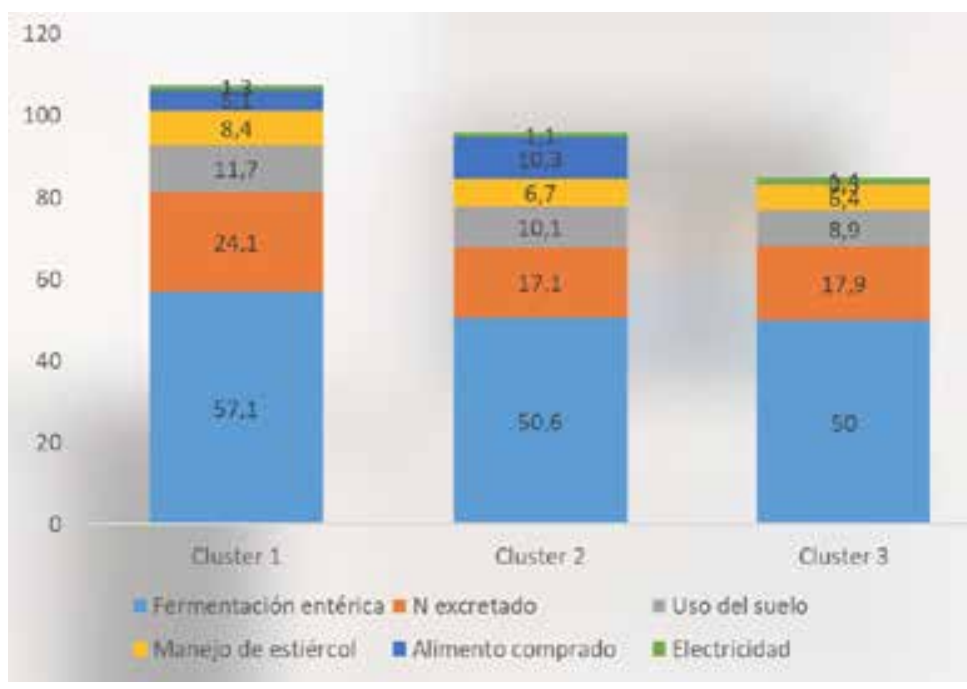

Fuente: adaptado de Lizarralde, 2013

\subsubsection{Investigación de la huella de carbono en Costa Rica}

Arguedas (2012) desarrolló un estudio durante el periodo 2007-2009 en Costa Rica, para estimar las emisiones de GEl del Instituto Tecnológico de Costa Rica (ITCR) basado el metodología y lineamientos de IPCC, los resultados demostraron un promedio de emisión de 2541 t/año de $\mathrm{CO}_{2 \text { eq }}$, con una proyección de 3741 t/año $\mathrm{CO}_{2}$ entre el 2011-2021 (Tabla 17). Se evaluaron diversas fuentes de emisión de GEl entre las que se encuentran: Producción ganadera y los procesos digestivos y fermentación entérica (40\%), disposición y manejo del estiércol (36\%), vehículos (11\%), desplazamientos aéreos (4\%), procesos de faenamiento (4\%), consumo eléctrico (4\%), consumo de combustible (1\%) y consumo de gas $(0,1 \%)$. 
Tabla 17. Promedio y porcentaje de emisiones de $\mathrm{CO} 2$ equivalente ( $(t)$ emitidas por el ITCR durante el período 2007-2009.

\begin{tabular}{l|c|c}
\multicolumn{1}{c|}{ Fuente de emisión } & Promedio $\mathrm{CO}_{\mathbf{2}}$ equivalente & Porcentaje (\%) \\
\hline Fermentación entérica & 1016,33 & 40,01 \\
\hline Gestión del estiércol & 915,33 & 36,03 \\
\hline Flotilla vehicular & 280,00 & 11,02 \\
\hline Viajes aéreos & 101,33 & 3,99 \\
\hline Gas LP institucional & 1,33 & 0,05 \\
\hline Planta de matanza & 99,33 & 3,91 \\
\hline Gasolina/diésel & 27,00 & 1,06 \\
\hline institucional & 99,67 & 3,92 \\
\hline Electricidad & $\mathbf{2 5 4 0 , 3 3}$ & $\mathbf{1 0 0}$ \\
\hline Total & & \\
\hline
\end{tabular}

Fuente: Arguedas, 2012.

\subsubsection{Investigación de la huella de carbono en ganado de carne en América y Europa}

Desjardins et al. (2012) desarrollaron un estudio para estimar la huella de carbono de ganado vacuno para Canadá, Estados Unidos, la Unión Europea, Australia y Brasil. Los valores oscilaron entre 8 y $22 \mathrm{~kg} \mathrm{CO}_{2 \mathrm{e}}$ por $\mathrm{kg}$ de peso vivo (PV), dependiendo del tipo de sistema de cultivo, la ubicación, el año, del tipo de las prácticas de gestión, la asignación, así como los límites del estudio. Este mismo estudio permitió establecer que reducciones sustanciales se han observado durante la mayor parte de estos países en los últimos treinta años. Por ejemplo, en Canadá la $\mathrm{HdC}$ de ganado de carne significa en la puerta de salida de la granja se redujo de $18,2 \mathrm{~kg} \mathrm{CO}{ }_{2 \mathrm{e}}$ por $\mathrm{kg}$ PV en 1981 a 9,5 $\mathrm{kg} \mathrm{CO}_{2 \mathrm{e}}$ por $\mathrm{kg} \mathrm{LW}$ en 2006, principalmente debido a la mejora genética, la mejor alimentación y la tierra más sostenible.

\subsubsection{Investigación de la huella de carbono en cuero en Taiwán}

Kuo, Lung y Wen (2014) realizaron un estudio para el análisis de la HdC del cuero en utilizado en la industria del calzado de Taiwan (Figura 13) el cual estuvo centrado en el análisis de ciclo de vida (ACV) del cuero y siguió la norma ISO 14044:2006 y la metodología establecida por la PAS 2050:2011.

Los resultados del estudio fueron $64,8 \mathrm{~kg} \mathrm{CO}_{2 \mathrm{e}} / \mathrm{m}^{2}$ de $1,5 \pm 0,1 \mathrm{~mm}, 74,5 \mathrm{~kg} \mathrm{CO}_{2 \mathrm{e}}$ $/ \mathrm{m}^{2}$ de $1,7 \pm 0,1 \mathrm{~mm}, 79,6 \mathrm{~kg} \mathrm{CO} 2 \mathrm{e} / \mathrm{m}^{2}$ de $1,9 \pm 0,1 \mathrm{~mm} \mathrm{y} 73 \mathrm{~kg} \mathrm{CO}_{2 \mathrm{e}} / \mathrm{m}^{2}$ de todos los espesores. 
Figura 13. Mapa de procesos del ciclo de vida del cuero.

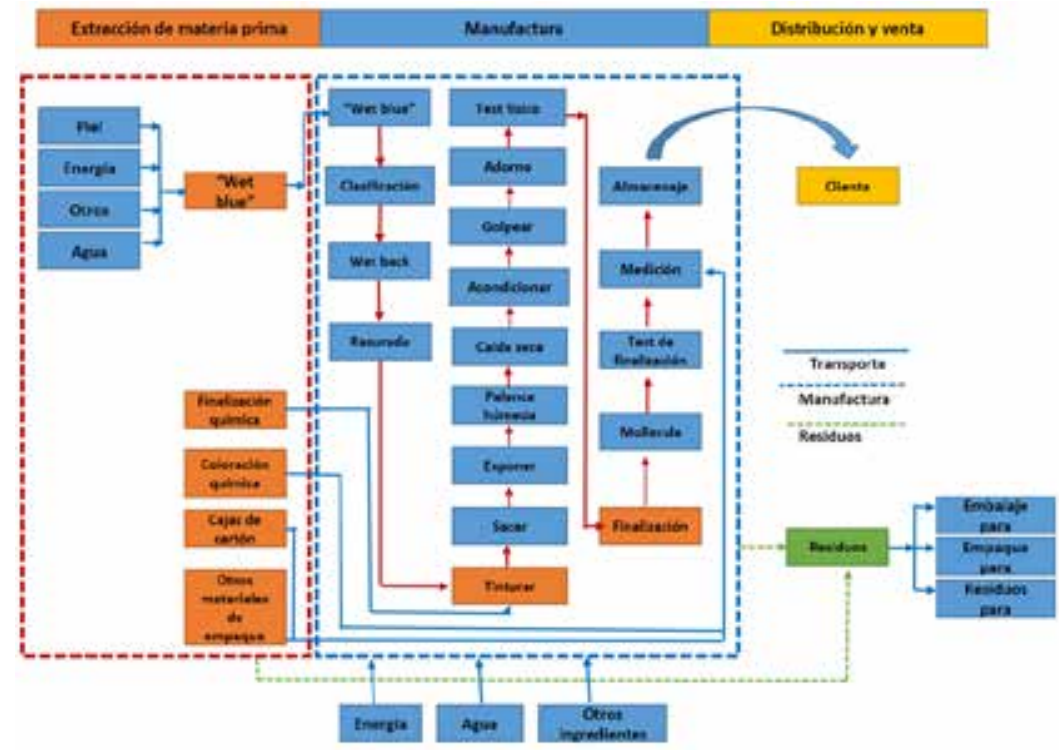

Fuente: adaptado de Kuo, Lung y Wen, 2014.

\subsubsection{Investigación de la huella de carbono en ganaderías de Alemania}

Robert, Menzel y Bahrs (2015) desarrollaron una investigación para evaluar la integración de los servicios ecosistémicos y la $\mathrm{HdC}$ en granjas lecheras localizadas en el sur de Alemania, fundamentaron su estudio en la metodología de ACV. Pudieron determinar la complejidad de la estimación de los GEI, debido a la multifuncionalidad de las granjas estudiadas, ya que no sólo se dedicaban la producción de leche sino también de carne y otros productos, asimismo pudieron identificar que algunas granjas cumplen una amplia gama de servicios que pueden ser beneficios para la sociedad, como lo son: la gestión y conservación de los recursos naturales renovables, la preservación de la biodiversidad y de los paisajes culturales, entre otros, los cuales pueden ser un potencial en el marco de los sistemas de pago por servicios ambientales.

Los resultados del estudio para un total de 113 explotaciones lecheras mostraron una $\mathrm{HdC}$ en promedio de $1,99 \mathrm{~kg} \mathrm{CO}_{2 \mathrm{e}} / \mathrm{kg}$ de leche grasa y proteína corregida (FPCM) en promedio (Robert, Menzel y Bahrs, 2015).

\subsubsection{Investigación de la huella de carbono en ganadería lechera de Australia}

Gollnow et al. (2014) desarrollaron un estudio para evaluar la $\mathrm{HdC}$ de la leche producida por vacas lecheras en Australia, la metodología se desarrolló bajo las 
directrices de aproximación de huella de carbono de la Federación Internacional de Lechería y la normativa internacional para el ACV. Los datos primarios fueron recogidos y analizados de 139 granjas que representan a las principales regiones lecheras en Australia. El alcance del estudio cubrió todas las entradas y salidas desde la "cuna a la puerta" (Figura 14) de la granja para un período de doce meses desde julio 2009 a junio de 2010 (2009/2010). La HdC de la leche australiana promedio para $2009 / 2010$ se calculó en $1,11 \mathrm{~kg} \mathrm{CO}_{2 \text { eq }} / \mathrm{kg}$ de leche grasa y proteína corregida (FPCM). La eficiencia de conversión del alimento balanceado fue identificada como el elemento más importante para contribuir a la reducción de las emisiones de metano entérico, asimismo se identificaron como potenciales de reducción, las prácticas de manejo del estiércol en las granjas.

Figura 14. Límites del sistema, subcategorías y fuentes de emisión.

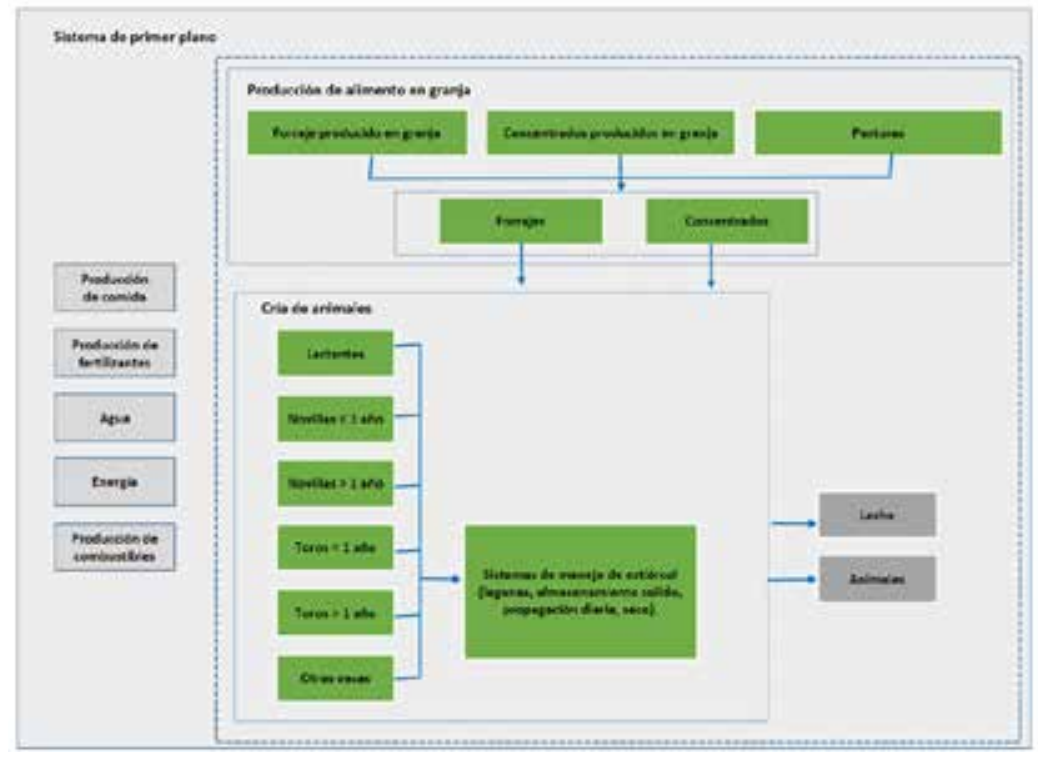

Fuente: adaptado de Gollnow et al., 2014.

O'Brien et al. (2014) desarrollaron un estudio para comparar la HdC en vacas estabuladas (confinamiento) de alto rendimiento y las vacas lecheras con alimentación a base de pasturas. Para ello utilizaron la metodología de análisis del ciclo de vida, el modelo estimó todas las fuentes de GEI dentro y fuera de la granja asociados con la producción de leche. La comparación mostró la huella de carbono de la leche del sistema productivo irlandés basado en pasturas naturales (837 $\mathrm{kg}$ de $\mathrm{CO}_{2 \mathrm{e}} / \mathrm{t}$ de ECM) fue un $5 \%$ más bajo que el sistema de confinamiento de la 
ganadería del Reino Unido ( $884 \mathrm{~kg}$ de $\mathrm{CO}_{2 \mathrm{e}} / \mathrm{t}$ de $\mathrm{ECM}$ ) y un $7 \%$ más bajo que el sistema de confinamiento de Estados Unidos ( $898 \mathrm{~kg}$ de $\mathrm{CO}_{2 \mathrm{e}} / \mathrm{t}$ de ECM). En comparación con los últimos informes que evalúan la huella de carbono de la leche de los sistemas de ganaderos lecheros de Irlanda, Reino Unido y Estados Unidos, este estudio de caso indica que los rebaños de alto rendimiento de las respectivas naciones tienen la huella de carbono de 27 a 32\% menor que los sistemas lecheros promedio. Aunque las diferencias entre los estudios se explican en parte por la inconsistencia metodológica, la comparación indica que existe potencial para reducir la huella de carbono de la leche en cada una de las naciones mediante la implementación de prácticas que mejoran la productividad.

\subsubsection{Investigación de la huella de carbono de leche producida en granjas bufalinas de Italia}

Pirlo et al. (2014) desarrollaron un estudio para estimar la HdC de la leche producida en seis granjas bufalinas de Italia, la metodología implementada fue la de un ACV simplificado. La unidad funcional del proyecto fue de $1 \mathrm{~kg}$ de leche grasa y proteína corregida (FPCM). Las explotaciones evaluadas se caracterizan por altos niveles de insumos como: alimentos concentrados balanceados, fertilizantes químicos y combustibles fósiles; la superficie media cultivada fue de 53,2 hectáreas, el suministro de forraje se basó principalmente en el ensilaje de maíz, seguido por raigrás italiano y/o ensilado de cereales. El tamaño promedio del rebaño fue de 360 animales y el promedio por FPCM búfalo lactantes era de 3563 $\mathrm{kg} /$ año con un porcentaje medio de leche grasa y proteínas corregida de 8,24 y 4,57 respectivamente. La evaluación de la $\mathrm{HdC}$ fue desde la cuna hasta la puerta de la granja. Los GEl que se tuvieron en cuenta fueron el metano $\left(\mathrm{CH}_{4}\right)$ producto de la fermentación entérica, metano $\left(\mathrm{CH}_{4}\right)$ proveniente del estiércol en el establo y en el tanque; óxido de nitrógeno $\left(\mathrm{N}_{2} \mathrm{O}\right)$ a partir de procesos de nitrificación y desnitrificación en el estiércol antes de la aplicación en el suelo y el $\mathrm{N}_{2} \mathrm{O}$ producido después de la aplicación de fertilizantes orgánicos y químicos; emisiones directas de $\mathrm{CO}_{2}$ procedentes de la combustión de combustibles fósiles en las granjas y las emisiones indirectas de $\mathrm{CO}_{2}$ derivadas de la producción de electricidad, fertilizantes químicos y otros. La HdC de $1 \mathrm{~kg}$ de FPCM fue $3,75 \mathrm{~kg} \mathrm{CO}_{2 \mathrm{e}}$. Las principales fuentes de gases de efecto invernadero son: fermentación entérica $\mathrm{CH}_{4}$ (45\%) y $\mathrm{CO}_{2 \mathrm{e}}$ indirectos (25\%). Además de la fermentación entérica $\left(\mathrm{CH}_{4}\right)$, la actividad agrícola que da la mayor contribución de carbono a la leche es la producción de piensos en las explotaciones agrícolas, con el $34 \%$ en las emisiones de gases de efecto invernadero totales. 


\section{Conclusiones}

Existen diversas metodologías para evaluar la $\mathrm{HdC}$ que varían en función del alcance que se quiere evaluar, por ejemplo: organizaciones, empresas o eventos (MC3, GHG Protocol). Para el caso de productos se han desarrollado metodologías que permiten comprender mejor y emprender acciones para tratar y disminuir esos impactos, una de las técnicas desarrolladas en este sentido y con uso y aplicación hoy en día es la del Análisis del Ciclo de Vida (ACV), la cual se encuentra muy bien articulada a la metodología establecida en la normatividad PAS: 2050 y también a la establecida en las normas ISO 14040, ISO 14044 e ISO/TS 14067 (Páez, 2016). En el ACV se realiza el inventario y evaluación de las entradas, procesos, salidas y los posibles impactos ambientales del producto a través de su ciclo de vida. La metodología establecida por la norma ISO/TS 14067 podría brindar las herramientas adecuadas para el análisis del ciclo de vida del producto y poder determinar los elementos de entrada y salida del sistema productivo, su dinámica y sus posibles efectos o impactos en el medio ambiente.

Uno de los puntos de un sistema productivo agropecuario, para el caso de condiciones de nuestro país, que causa mayor impacto está representado por el proceso nutricional de los animales, cuya base está dada por un gran porcentaje de forrajes o pastos naturales, con baja incorporación de suplementos o alimentos concentrados, dando estos forrajes y pastos lugar a la generación de una elevada carga de excretas (estiércol y orina), las cuales liberan una carga alta de GEI al medio ambiente (Páez, 2016).

La HdC puede servir como herramienta para la toma de decisiones en los sistemas productivos agropecuarios, asimismo para la implementación de alternativas de mitigación del impacto ambiental causado por estos sistemas, pudiendo llegar hasta la incorporación y obtención de beneficios por los pagos por servicios ambientales o ecosistémicos que pueden llegar a proveer los sistemas (Corredor, Fonseca, Páez, 2012). 


\section{Bibliografía}

Acción RSE (2012). Cálculo y gestión de inventario de emisiones de Gases de Efecto Invernadero y Huella de Carbono. Basado en el Protocolo GEI (GHG Protocol). Acción RSE, PWC. Chile.

AEC (2015). Norma PAS 2050. Asociación Española para la Calidad. Centro Nacional de Información de la Calidad.

AEC (sf). La huella de carbono. Asociación Española para la Calidad. Centro Nacional de Información de la Calidad.

Alexiadis, A. (2007). Global warming and human activity: A model for studying the potential instability of the carbon dioxide/temperature feedback mechanism. Ecological Modelling. Volume 203, Issues 3-4, 10 May 2007, P: 243-256.

Arguedas Marín, M. (2012). La huella de carbono del Instituto Tecnológico de Costa Rica. Revista Forestal Mesoamericana Kurú (Costa Rica) Volumen. 9, № 22, Junio, 2012.

Berlin, J. (2002). Environmental life cycle assessment (LCA) of Swedish semi-hard cheese. International Dairy Journal. Volume 12, Issue 11, 2002, P: 939-953.

Bockel, L.; Smith, G.; Bromhead, M.; Bernoux, M.; Tinlot, M. Matieu, H. Branca, G. (2011). Generalizando la evaluación del balance de carbono en Agricultura. EX-ACT: Una herramienta para medir el balance de Carbono. EASYPol. Recursos para la elaboración de políticas. Organización de las Naciones Unidas para la Agricultura y la Alimentación, FAO.

Bolea García, M. (2011). Análisis de dos metodologías de cálculo de la huella de carbono para un sistema de trigeneración optimizado. Departamento de Ingeniería, Química y Tecnologías del medio Ambiente. Universidad de Zaragoza.

Cagiao, J.; Gómez, B.; Doménech, J.L; Mainar, S.; Lanza, H. (2011). Calculation of the corporate carbon footprint of the cement industry by the application of MC3 methodology. Ecological Indicators. Volume 11, Issue 6, November 2011, P: 1526-1540.

CAR (2013). Guía metodológica para el cálculo de la huella de carbono corporativa a nivel sectorial. Corporación autónoma regional de Cundinamarca-CAR. Corporación Ambiental Empresarial-CAEM. Cámara de Comercio de Bogotá. Bogotá D.C.

Carballo Penela, A.; García Negro, M.C.; Doménech Quesada, J.L. (2009). El MC3 una alternativa metodológica para estimar la huella corporativa del carbono (HCC). Revista Desarrollo Local Sostenible. DELOS. Grupo Eumed.net y Red Académica Iberoamericana Local Global. Vol 2, No 5 (junio 2009).

CGIAR (2014). Clima y Sector Agropecuario Colombiano. Adaptación para la sostenibilidad productiva. Consorcio CGIAR: Cambio Climático, Agricultura y Seguridad Alimentaria en América Latina (CCAFS). Centro internacional de Agricultura Tropical (CIAT). Ministerio de Agricultura y Desarrollo Rural (MADR). Consultado en: http://www.aclimatecolombia.org/ acerca-del-convenio-madr-ciat/

Conservación y Carbono S.A.S. (2013). Análisis del Ciclo de Vida ISO 14040. Consultado en: http://www.conservacionycarbono.com/analisis-del-ciclo-de-vida-iso-14040

Cordero Ahimán, O.V. (2011). Cálculo de la huella de carbono según la metodología francesa Bilan Carbone $\circledast$ : aplicación a la sociedad de los transportes públicos de la ciudad Limoges S.T.C.L. en el año 2009. Universidad de Zaragoza. Centro Politécnico Superior (C.P.S). Zaragoza. España. 
Corredor, E.S.; Carreño,J.A.; Páez, E.M(2012). Los servicios ecosistémicos de regulación:tendencias e impacto en el bienestar humano. Universidad Nacional Abierta y a Distancia (UNAD); Escuela de Ciencias Agrícolas, Pecuarias y del Medio Ambiente (ECAPMA), Bogotá D.C.

De Vries, M.; De Boer, I.J.M. (2010). Comparing environmental impacts for livestock products: A review of life cycle assessments. Livestock Science. Volume 128, Issues 1-3, March 2010, P: 1-11.

Desjardins, R.L; Worth, D.E.; Vergé, X.P; Maxime, D.;Dyer, Y.; Cerkowniak, D. (2012). Carbon Footprint of Beef Cattle. Rev. Sustainability 2012, 4, P: 3279-3301.

Dias, A.C; Arroja, L (2012). Comparison of methodologies for estimating the carbon footprint case study of office paper. Journal of Cleaner Production. Volume 24, March 2012, P: 30-35.

DNV-GL (2014). Lanzamiento de la ISO 14067:2013. DNV-GL. Newsletter de Business Assurance Año 4. Edición 8.

Doménech J. L.; González A. M. (2009). La huella ecológica de las empresas: 4 años de seguimiento en el puerto de Gijón. Revista Desarrollo Local Sostenible. Vol 2, № 5.

Escultura, E. (2014). Is Human Activity Linked to Climate Change? Atmospheric and Climate Sciences, Vol 04, Iss 02, P: 305-316.

Espíndola, C.;Valderrama,J.O.(2012). Huella del Carbono. Parte 1: Conceptos, Métodos de Estimación y Complejidades Metodológicas. Información Tecnológica. Vol. 23(1), 163-176 (2012).

Falloon, P.; Betts, R. (2010). Climate impacts on European agriculture and water management in the context of adaptation and mitigation. The importance of an integrated approach. Science of The Total Environment. Volume 408, Issue 23, 1 November 2010, P: 5667-5687.

FAO (2015). AGP-Biodiversidad y servicios de ecosistema. Consultado en Julio de 2015. Disponible para descarga en: http://www.fao.org/agriculture/crops/mapa-tematica-del-sitio/ theme/biodiversity/es/

FAO (2014). Greenhouse Gas Emissions from Agriculture, Forestry and Other Land Use. Consultado en Julio de 2015. Disponible para descarga en: http://www.fao.org/resources/infographics/infographics-details/en/c/218650/

FAO (2006). La ganadería amenaza el medio ambiente. Organización de las Naciones Unidas para la Agricultura y la Alimentación.

Ferraro, R.; Gareis, M.C.; Zulaica, L. (2013). Aportes para la estimación de la huella de carbono en los grandes asentamientos urbanos de Argentina. Universidad Nacional de Mar del Plata, Argentina. Centro de Investigaciones Ambientales (CONITEC), Universidad Nacional de Mar del Plata, Argentina. Cuadernos de geografía. Rev Col de Geog. Vol. 22, N. 2, jul.-dic. P: 87-106.

Finnveden, G.; Hauschildb, M.Z.; Ekvallc, T.; Guinéed, J.; Heijungsd, R.; Hellwege, S. Koehlere, A.; Penningtonf, D.; Suhg, S. (2009). Recent developments in Life Cycle Assessment. Journal of Environmental Management. Volume 91, Issue 1, October 2009, P: 1-21.

Ghannadi, M; Moghiseh, E.; Heidari, A. (2013). Impacts of deforestation and reforestation on soil organic carbon storage and CO2 emission. Soil \& Environment, Vol 32, Iss 1, P: 1-13.

García R.; Freire, F. (2014). Carbon footprint of particleboard: a comparison between ISO/TS 14067, GHG Protocol, PAS 2050 and Climate Declaration. Journal of Cleaner Production 66, (2014) P: 199-209.

Gollnow, S.; Lundie, S.; Moore, A.; McLaren, J.; Buurenc, N.V.; Stahled, P.; Christiee, K.; Daniel 
Thylmann, D.; Rehl, T. (2014). Carbon footprint ofmilkproduction from dairy cows in Australia. International Dairy Journal. Volume 37, Issue 1, July 2014, P: 31-38.

Guerra, L. (2013). Metodología para el análisis de la huella de carbono a través del análisis de ciclo de vida Sistemas lecheros, Costa Rica. CATIE Programa GAMMA.

INAP (2011). Determinación de los factores de emisión para los Alcances 1 y 2 de la estimación de la huella de carbono. Programa de Estudios e Investigaciones en Energía para la División de Desarrollo Sustentable. Subsecretaría de Energía. Chile.

Ingrao, C.; Rana, R.; Tricase, C.; Lombardi, M. (2015). Application of Carbon Footprint to an agro-biogas supply chain in Southern Italy. Applied Energy 149 (2015). P: 75-88.

IPPC (2008). IPCC Fourth Assessment Report: Climate Change 2007. Intergovernmental Panel on Climate Change. Consultado en Julio de 2015. Disponible para descarga en: http://www. ipcc.ch/publications_and_data/ar4/syr/es/spms3.html

ISM (2013). Novedades de la ISO 14067 para Cálculo de la Huella de Carbono de un producto. Instituto Superior del Medio Ambiente. 25 de septiembre de 2013.

ISOTools (2015). ISO 14040: Análisis del ciclo de vida. Sistemas de Gestión Normalizados. Consultado en Julio de 2015. Disponible para descarga en: http://www.isotools.com.mx/iso14040-ciclo-de-vida/

Kirkinen, J.; Palosuo, T.; Holmgren, K.; Savolainen, I. (2008). Greenhouse Impact Due to the Use of Combustible Fuels: Life Cycle Viewpoint and Relative Radiative Forcing Commitment. Environmental Management, 2008, Vol. 42 (3), P: 458-469.

Kuo, W.C; Lung, C.L.; Wen, S.L. (2014). Analyzing the carbon footprint of the finished bovine leather: a case study of aniline leather. The 6th International Conference on Applied Energy, ICAE2014. Energy Procedia 61. P: $1063-1066$.

Kumar, P.; Wiltshire, A.; Mathison, C.; Asharaf, S.; Ahrens, B.; Lucas, P.; Christensen, J.; Gobiet, A.; Saeed, F.; Hagemann, S.; Jacob, D. (2013). Downscaled climate change projections with uncertainty assessment over India using a high resolution multi-model approach. Science of The Total Environment. Volumes 468-469, Supplement, 1 December 2013, P: S18-S30.

Lizarralde Piquet, C.A. (2013). Relación entre la huella de carbono y las prácticas de manejo de predios lecheros de Uruguay. Tesis de Maestría, Universidad de la República (Uruguay). Facultad de Agronomía, 2013.

Ma, A.J.; Zhaob, H.Z. (2012). Studies on Emissions and Measures of Reduction and Control of Greenhouse Gas during Lifecycle of Dairy Products. Procedia Environmental Sciences 13 (2012). P: 2310- 2315.

Ming, T.; De Richter, R.; Liu, W.; Caillol, S. (2014). Fighting global warming by climate engineering: Is the Earth radiation management and the solar radiation management any option for fighting climate change? Renewable and Sustainable Energy Reviews. Volume 31, March 2014, P: 792-834.

Ministerio de Ganadería, Agricultura y Pesca de Uruguay (2013). Primer estudio de la huella de carbono de tres cadenas agroexportadoras del Uruguay: carne vacuna, láctea y arrocera. Mayo, 2013. Universidad de la República. Uruguay.

Molina Ruiz, H.D.; Reyes Vázquez, S.G.; Castillo Gallegos, F.; Rojano Chávez, S.M. (2013). Estimación de la huella de carbono de una institución de educación media superiory superior. Universidad Autónoma del Estado de Hidalgo. Universidad Autónoma de Tlaxcala. México. 
Muñoz, C.; Paulino, L.; Monreal, C.; Zagal, E. (2010). Greenhouse Gas (CO2 AND N2O) Emissions from Soils: A Review. Chilean journal of agricultural research, 2010, Vol.70 (3), P: 485-497.

NTC (2007a). NTC-ISO Colombiana 14040. Gestión ambiental. Análisis de ciclo de vida. Principios y Marco de referencia. Norma técnica Colombiana. Adopción idéntica por traducción (IDT) a la norma ISO 14040:2006.

NTC (2007b). NTC-ISO Colombiana 14044. Gestión ambiental. Análisis de ciclo de vida. Requisitos y directrices. Requisitos del ciclo de vida. Norma técnica Colombiana. Adopción idéntica por traducción (IDT) a la norma ISO 14044:2006.

Nuevas normas ISO (2014). ISO 14044: Una norma para evaluar el ciclo de vida. Escuela Europea de Excelencia.

O’Brien, D.; Capper, J.L; Garnsworthy, P.C.; Grainger, C.; Shalloo, L. (2014). A case study of the carbon footprint of milk from high-performing confinement and grass-based dairy farms. J. Dairy Sci. 97. P: 1835-1851.

Páez, E. (2016). Medición de huellas ambientales como indicadores de sostenibilidad en unidades de producción ganadera bovina en la región centro del departamento de Boyacá, Colombia. Universidad Católica Santa Teresa de Jesús de Ávila, España.

Peng, W.; Bo, X.; Xiangyu W. (2015). The contribution ofISO 14067 to the evolution ofglobal greenhouse gas standards. A review. Renewable and Sustainable Energy Reviews. 47, (2015), P: 142-150.

PIGA (2013). Guía para la elaboración del informe de Huella de Carbono Corporativa en entidades públicas del Distrito Capital. Secretaría distrital de ambiente. Subdirección de Políticas y Planes Ambientales. Plan Institucional de Gestión Ambiental. Alcaldía mayor de Bogotá D.C.

Pirlo, G.; Terzano, G.; Pacelli, C.; Abeni, F. Carè, S. (2014). Carbon footprint of milk produced at Italian buffalo farms. Livestock Science, Volume 161, p: 176-184.

Plassmann, K.; Norton, A.; Attarzadeh, N.; Jensen, M.P.; Brenton, P.; Edwards-Jones, G. (2010). Methodological complexities of product carbon footprinting: a sensitivity analysis of key variables in a developing country context. Environmental Science \& Policy. Volume 13, Issue 5, August 2010, P: 393-404.

PNUMA (2010). Cambio climático. Programa de las Naciones Unidas para el Medio Ambiente. Paris.

Pryshlakivsky, J.; Searcy, C. (2013). Fifteen years of ISO 14040: a review. Journal of Cleaner Production, 2013, Vol.57, P: 115-123.

Rebitzer, G.; Ekvallb, T.; Frischknechtc, R.; Hunkelerd, D.; Norrise, G.; Rydbergf, T.; Schmidtg, W.P.; Suhh, S.; Weidemai, B.P.; Penningtonf, D.W. (2004). Life cycle assessment: Part 1: Framework, goal and scope definition, inventory analysis, and applications. Environment International. Volume 30, Issue 5, July 2004, P: 701-720.

Rinaldi, S.; Barbanera, M.; Lascaro, E. (2014). Assessment of carbon footprint and energy performance of the extra virgin olive oil chain in Umbria, Italy. Science of The Total Environment. Volumes 482-483, 1 June 2014, P: 71-79.

Robert, L.; Menzel, F.; y Bahrs, E. (2015). Integration of ecosystem services into the carbon footprint of milk of South German dairy farms. Journal of Environmental Management. Volume 152, 1 April 2015, P: 11-18.

Rodríguez Becerra, M.; Mance, H. (2009). Cambio climático: lo que está en juego. Foro Nacional Ambiental. Bogotá - Colombia. Foro Nacional Ambiental@. 
Romero Rodríguez, B.I. (2003). El Análisis del Ciclo de Vida y la Gestión Ambiental. Tendencias tecnológicas. Boletín IIE, julio-septiembre del 2003. P: 91-98.

Roy, P.; Nei, D., Orikasa, T.; Xu, Q.; Okadome, H.; Nakamura, N.; Shiina, T. (2009). A review of life cycle assessment (LCA) on some food products. Journal of Food Engineering. Volume 90, Issue 1, January 2009, P: 1-10.

Sadeghian K. S (1998). Impacto de la ganadería sobre el suelo. Alternativas sostenibles de manejo. Centro Nacional de Investigaciones de Café-Cenicafé. Conferencia electrónica de la FAO sobre "Agroforestería para la producción animal en Latinoamérica".

Schneider, H.; Samaniego, J. L. (2009). La huella del carbono en la producción, distribución y consumo de bienes y servicios. Comisión Económica para América Latina y el Caribe (CEPAL). Organización de las Naciones Unidas, Chile.

SEMARNAT (2009). Cambio Climático. Ciencia, evidencia y acciones. Serie ¿Y el medio ambiente? Secretaría de Medio Ambiente y Recursos Naturales-SEMARNAT. México.

SEMARNAT (2005). Guía de elaboración y usos de inventarios de emisiones. Instituto Nacional de Ecología. Secretaría de Medio Ambiente y Recursos Naturales-SEMARNAT. México.

Soussana, J.F.; Allard, V.; Pilegaard, K.; Ambus , P.; Amman , C.; Campbell, C.; Ceschia , E.; CliftonBrown, J.; Czobel, S.; Domingues, R. (2007). Full accounting of the greenhouse gas (CO2, $\mathrm{N} 2 \mathrm{O}, \mathrm{CH} 4)$ budget of nine European grassland sites. Agriculture, Ecosystems \& Environment. Volume 121, Issues 1-2, June 2007, P: 121-134.

Steinfeld, H.; Gerber, P.; Wassenaar, T.; Castel, V.; Rosales, M. Haan, C. (2009). La larga sombra del ganado. Problemas ambientales y opciones. Organización de las Naciones Unidas para la Agricultura y la Alimentación-ONU. Roma.

Tan, M.Q.B.; Tan, R.B.H.; Khoo, H.H. (2014). Prospects of carbon labelling. A life cycle point of view. Journal of Cleaner Production. Volume 72, 1 June 2014, P: 76-88.

Tao Gao, Q. L.; Jianping W. (2014). A comparative study of carbon footprint and assessment standards. Int. J. Low-Carbon Tech. 2014, 9, P: 237-243.

Vergé, X.P.C.; Dyer, J.A.; Desjardins, R.L.; Worth, D. (2008). Greenhouse gas emissions from the Canadian beefindustry. Agricultural Systems. Volume 98, Issue 2, September 2008, P: 126-134.

Viglizzo, E.F. (2010). Huella de carbono, ambiente y agricultura en el Cono Sur de Sudamérica. IICA. Instituto Interamericano de Cooperación para la Agricultura (IICA), 2010.

Wang, M.; Huo, H.; Arora, S. (2011). Methods of dealing with co-products of biofuels in life-cycle analysis and consequent results within the U.S. context. Energy Policy, 2011, Vol. 39 (10).

WBCS D (2005). Protocolo de Gases Efecto Invernadero. Estándar corporativo de contabilidad y reporte. World Business Council for Sustainable Development. World Resources Institute. Secretaría de medio ambiente y recursos naturales. Consultado en Julio de 2015. Disponible para descarga en: http://www.ghgprotocol.org/files/ghgp/public/protocolo_de_gei.pdf

Yan, M. J.; Humphreys, J.; Holden, N.M. (2011). An evaluation of life cycle assessment of European milk production. Journal of Environmental Management. Volume 92, Issue 3, March 2011, P: 372-379.

Zervas, G.; Tsiplakou, E. (2012). An assessment of GHG emissions from small ruminants in comparison with GHG emissions from large ruminants and monogastric livestock. Atmospheric Environment. Volume 49, March 2012, P: 13-2.3 


\section{CAPÍTULO 3}

\section{Huella Hídrica}

\subsection{Resumen}

La Huella Hídrica es una metodología de gran importancia que puede ser implementada como parte del análisis de la sostenibilidad de un producto, proceso, consumidor, grupo de consumidores o productor, comprendiéndose como un indicador enmarcado en la estimación del uso de agua dulce, incluyendo, además del volumen consumido o contaminado; el tiempo, el espacio y la clasificación según su fuente. Su utilidad contempla las dimensiones directa e indirecta, la evaluación de impactos generados y la toma de decisiones consecuentes. Teniendo en cuenta la relevancia de la HH este capítulo presenta la conceptualización teórica y el análisis de casos prácticos de su aplicación específicamente en sistemas de producción agropecuaria. Dicha temática se abarca en primera instancia con un compendio de la relación entre los sistemas agropecuarios y el recurso hídrico, se centra posteriormente en la descripción metodológica para la estimación de la Huella Hídrica y sus antecedentes, para finalmente recoger casos que enfatizan e ilustran su aplicabilidad dentro del sector agrícola.

\subsection{Introducción}

El agua es un recurso ecosistémico de gran importancia, de su ubicación y cantidad se desprenden los servicios de provisión o de sustento, mientras que de la calidad y temporalidad lo hacen los servicios de regulación, estos últimos dependen de patrones climáticos regionales y del balance de los componentes del ciclo hidrológico, así como de las características de la vegetación, el suelo y el subsuelo (Corredor, Fonseca y Páez, 2012).

El recurso hídrico resulta fundamental para el desarrollo social y económico, mejorar el manejo del agua es un requerimiento prioritario, así como asegurar su acceso, de lo contrario se presentarán efectos devastadores sobre las economías y se pondrá en peligro el bienestar, especialmente en las poblaciones más pobres y vulnerables (IICA, 2017). 
La demanda mundial de agua se ha estimado en alrededor de $4.600 \mathrm{~km}^{3} / \mathrm{año} \mathrm{y}$ se prevé que aumente entre un $20 \%$ y $30 \%$ (de 5.500 a 6.000 kmªño) para 2.050 (Burek et al., 2016, citado por WWDR., 2018), siendo el sector agrícola el de mayor participación en las extracciones de agua dulce a nivel global (69\%), porcentaje que varía dependiendo del clima y del lugar que ocupe la agricultura en la economía del país o región (FAO, 2016).

En consecuencia, para evaluar la sostenibilidad del recurso hídrico se requieren metodologías como la Huella Hídrica $(\mathrm{HH})$ que estimen de manera multisectorial, geográfica y temporalmente explicita tanto el volumen consumido como la contaminación del agua dulce. La HH es una herramienta de administración del agua, un índice de sostenibilidad para cualquier tipo de industria o sector productivo. Esta herramienta, permite estimar el uso del recurso en relación a una población, a un determinado producto o proceso, y actualmente es asumida como un determinante complementario a la tradicionalmente generada por los indicadores de uso del agua en los sectores productivos que pueden carecer de especificidad referente a la delimitación del espacio y el tiempo (Schneider y Samaniego, 2009).

Por ejemplo, la $\mathrm{HH}$ de un producto es la cantidad de agua dulce consumida o requerida, de forma directa e indirecta, durante la generación de dicho producto, contabilizada a lo largo de la cadena de abastecimiento y durante el proceso primario. Se trata entonces de un indicador del volumen de agua consumido, según su origen, y la contaminación en términos de la capacidad de asimilación del cuerpo receptor del efluente (Mekonnen y Hoekstra, 2011).

Con base en la participación que tiene el sector agrícola en la extracción de agua dulce resulta de gran importancia abarcar los aspectos metodológicos, así como las particularidades de los casos que evidencian la aplicabilidad de la $\mathrm{HH}$ en éste, incluyendo: la unidad de medición, expresada en volumen de agua por unidad de tiempo, de tiempo per cápita, de masa, de dinero o de energía, y el alcance del análisis, cuyos referentes a incluir son: 1) el enfoque, ya que es posible orientarla hacia el cálculo, 2) la evaluación de impactos, 3) la generación de soluciones o incluir los tres pasos. Adicionalmente, los estudios pueden variar acorde a la inclusión o no de los tres tipos de agua dulce (azul, verde y gris) clasificados por su fuente, con base en la necesidad y viabilidad, además de abarcar de forma discriminada la $\mathrm{HH}$ directa, indirecta o las incluir las dos; el nivel espacio-temporal y el límite temporal a evaluar (Hoekstra, et al. 2011). 


\subsection{Relación entre los sistemas agrícolas y el recurso hídrico}

\subsubsection{Papel del sector agrícola en la extracción del agua}

De acuerdo con los indicadores de la FAO (2016) a escala mundial, en el siglo XX la extracción de agua dulce aumentó 1.7 veces más rápido que la población y el sector agrícola enmarca el porcentaje más alto de participación en este proceso (incluyendo riego, limpieza y abrevado del ganado y acuicultura), con el $69 \%$ de las extracciones a nivel global, como se puede evidenciar en la Figura 15 el alto porcentaje correspondiente a la agricultura es seguido de lejos por la extracción industrial y municipal.

Figura 15. Población y extracción del agua.

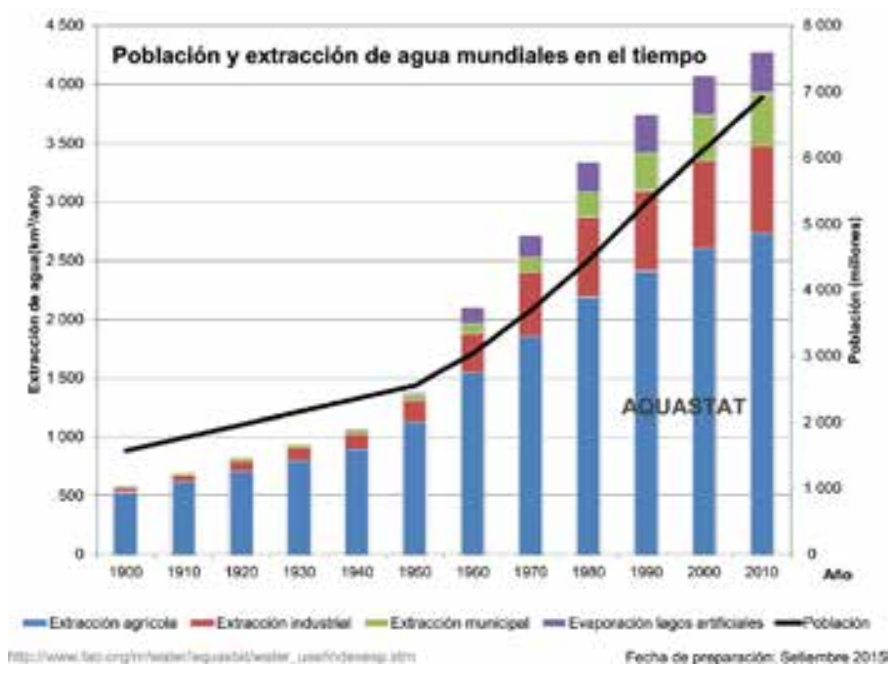

Fuente: FAO, 2016

La FAO (2016) destaca que el papel de la extracción de agua por el sector agrícola depende en gran medida del clima y del lugar que ocupe la agricultura en la economía (desde el $21 \%$ de las extracciones totales de agua en Europa, hasta el $82 \%$ en África). Existiendo un gran número de países (25) que dedican más del $90 \%$ de sus extracciones de agua dulce a la agricultura.

El crecimiento demográfico traerá como consecuencia un incremento en la necesidad de producir alimento ( $60 \%$ más de alimentos a nivel mundial, y un 100\% más en los países en desarrollo) para el año 2050 (ONU, 2015). En este contexto, las amenazas sobre los recursos hídricos se incrementan, relacionándose con el crecimiento 
demográfico y el desarrollo económico, es por esto que se han planeado retos frente a la competencia por el acceso al agua y a la calidad de la misma (UNESCO, 2003). Dichas amenazas se han relacionado con las prácticas tradicionales de la agricultura y de la ganadería enmarcadas en la revolución verde y el cambio en el uso del suelo que trae como consecuencia la expansión de su frontera, impactando el ciclo hidrológico promoviendo desequilibrio en los ecosistemas por disminución de la biodiversidad y perdida de bosques (Ardila y Vergara, (2012); Renda, (2006)), en general, el modelo de agricultura industrial resulta en eutrofización y contaminación orgánica y química del agua, transformación de los biomas terrestres, degradación de suelos que se suma a la pérdida de capacidad de retención y velocidad de infiltración de aguas lluvias.

Adicionalmente, la competencia por el recurso hídrico de calidad puede tener efectos en la salud pública, tanto en los grupos poblacionales directamente expuestos que comparten el uso del agua, como en los consumidores por enfermedades transmitidas por alimentos (RAPAL, 2010).

\subsubsection{Uso del agua en el sector agrícola}

El recurso hídrico en el sector agrícola tiene una gran importancia, enmarcada en el agua requerida dentro de la producción primaria dentro del predio y la indirecta consumida o contaminada a través de la producción de alimentos concentrados, insumos, cadena de distribución, entre otros, siendo el mayor porcentaje la ingerida por el ganado a través de los alimentos (Sánchez, Delgado, Bueno, y Román, 2014).

La mayor proporción de este recurso es destinado al riego de forrajes para alimentación de los animales o para producción de cultivos (FAO, 1998). Los requerimientos anuales de agua de riego a nivel mundial son de $1.500 \mathrm{~km}^{3}$. Para satisfacer estas necesidades, se extraen unos $2.700 \mathrm{~km}^{3}$ de fuentes de agua renovables, no renovables y no convencionales, como el uso directo de aguas residuales y aguas de drenaje agrícola y en muy pocos casos agua desalinizada (FAO, 2016). Siendo éste un uso consuntivo, ya que el agua es extraída de la fuente original y no regresa totalmente en la misma calidad o cantidad (WFN, 2012). Sin embargo, no se puede negar la relación entre la agricultura y la seguridad alimentaria, en la que la agricultura de riego tiene un papel fundamental, debido a que genera más del $40 \%$ de la producción mundial de alimentos para consumo humano (IICA, 2017).

Es necesario tener en cuenta en este sentido que el agua es el elemento esencial para los procesos fisiológicos, las reacciones químicas y el transporte de las sustancias 
y nutrientes a través de la planta, siendo vital para el metabolismo y la fotosíntesis, además en ausencia de humedad se cierran las estomas y se enrollan las hojas lo que disminuye el crecimiento de la planta, por lo tanto es un factor determinante para el rendimiento del cultivo (Sánchez, Delgado, Bueno y Román, 2014).

La evapotranspiración, comprendida como la perdida de vapor de agua a través de las hojas de la planta, más la que se evapora directamente del suelo (Sánchez, et al. 2014) es la vía más importante por la cual el riego genera el detrimento del agua. En términos generales esta pérdida lleva a una disminución en el aporte o el retorno del agua al sistema hidrográfico en el que se encontraba.

Teniendo en cuenta que el uso no solo se refiere a la extracción sino también a la contaminación, es importante destacar que en los sistemas agrícolas se producen aguas residuales, las cuales pueden generar impactos ambientales, atribuidos a la carga contaminante sobre el medio ambiente y el agua dulce. En cuanto a la contaminación directa, los residuos mayormente incluyen agroquímicos y dentro de la etapa predial de la ganadería, estos residuos están constituidos adicionalmente por la mezcla de heces, orina y agua de higiene, siendo necesario destacar el papel de las excretas, que contienen contaminantes minerales, bacterias y otros patógenos, además de residuos de medicamentos, hormonas y metales pesados, lo que resulta en un riesgo para la salud humana y animal (Pinos, García, Peña, Rendón y Tristán, 2012). En la Figura 16 (FAO, 1997) es posible identificar la diversidad y complejidad de la contaminación agrícola procedente de fuentes no localizadas.

Figura 16. Contaminación agrícola procedente de fuentes no localizadas

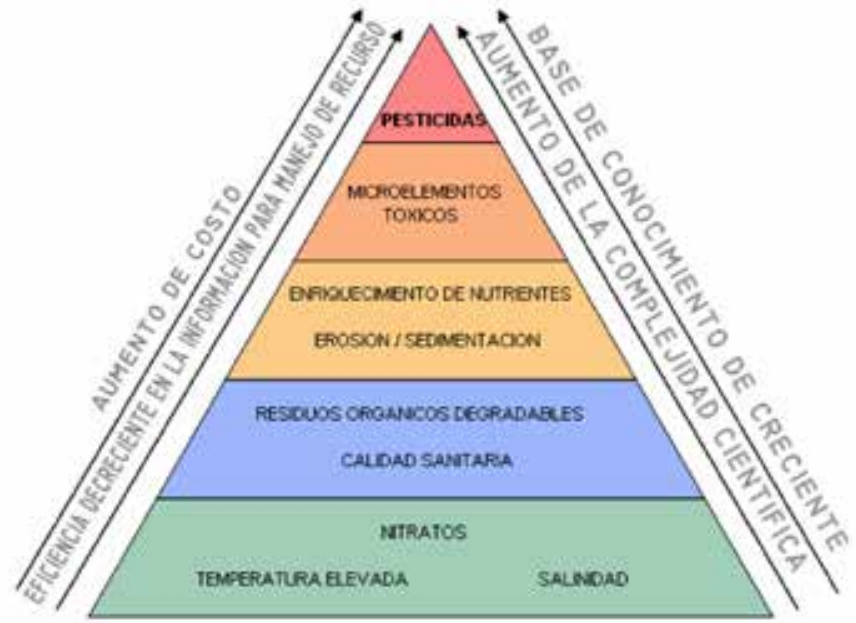

Fuente: FAO, 1997. 
Cabe mencionar que la agricultura no solamente requiere de gran cantidad de agua sino además que ésta sea de calidad, por ejemplo, que este criterio se cumpla en el agua consumida por los animales de manera directa, es un elemento fundamental para la salud, la eficiencia de los parámetros de interés zootécnico, así como para la composición de los productos finales, especialmente, alimentos de origen animal que son destinados al consumo humano lo que resulta muy importante a nivel productivo y de salud pública (Revelli, Sbodio, Tercero, y Ubert, 2002), por lo tanto no se puede dejar de identificar la doble vía que existe entre la agricultura y el recurso hídrico, participando el agua como entrada y salida del sistema productivo, lo que fundamenta la necesidad de estimar el impacto generado sobre el recurso durante el proceso de producción agrícola e identificar medidas tendientes a disminuirlo.

\subsubsection{Efectos del sector agrícola sobre el agua}

Aunque son diversos los efectos de la actividad agrícola sobre las aguas superficiales y subterráneas (Tabla 18), acorde a lo descrito por RAPAL (2010), las causas más importantes de los procesos de eutrofización relacionadas con el sector agrícola se pueden agrupar en la descarga de aguas servidas, deforestación y erosión de suelos agrícolas y finalmente la eutrofización consecuente al ciclaje de gases ambientales, especialmente óxidos de nitrógeno (NO) y óxidos de azufre (SO).

Tabla 18. Efectos de las actividades agrícolas en la calidad del agua.

\begin{tabular}{|c|c|c|}
\hline \multirow{2}{*}{$\begin{array}{l}\text { Actividad } \\
\text { agrícola }\end{array}$} & \multicolumn{2}{|l|}{ Efectos } \\
\hline & Aguas superficiales & Aguas subterráneas \\
\hline $\begin{array}{l}\text { Labranza/ } \\
\text { arado }\end{array}$ & $\begin{array}{l}\text { Sedimentos/turbidez: los sedimentos transportan } \\
\text { fósforos y plaguicidas adsorbidos a las partículas de } \\
\text { los sedimentos; entarquinamiento de los lechos de } \\
\text { los ríos y pérdida de hábitat, desovaderos, etc. }\end{array}$ & \\
\hline $\begin{array}{l}\text { Aplicación } \\
\text { de } \\
\text { fertilizantes }\end{array}$ & $\begin{array}{l}\text { Escorrentía de nutrientes, especialmente fósforo, } \\
\text { que da lugar a la eutrofización y produce mal } \\
\text { gusto y olor en el abastecimiento público de agua, } \\
\text { crecimiento excesivo de las algas que da lugar a } \\
\text { desoxigenación del agua y mortandad de peces }\end{array}$ & $\begin{array}{l}\text { Lixiviación del nitrato hacia } \\
\text { las aguas subterráneas; } \\
\text { los niveles excesivos } \\
\text { representan una amenaza } \\
\text { para la salud pública. }\end{array}$ \\
\hline $\begin{array}{l}\text { Aplicación } \\
\text { de estiércol }\end{array}$ & $\begin{array}{l}\text { Esta actividad se realiza como medio de aplicación } \\
\text { de fertilizantes; si se extiende sobre un terreno } \\
\text { congelado provoca en las aguas receptoras elevados } \\
\text { niveles de contaminación por agentes patógenos, } \\
\text { metales, fósforo y nitrógeno, lo que da lugar a la } \\
\text { eutrofización y a una posible contaminación. }\end{array}$ & $\begin{array}{l}\text { Contaminación de las } \\
\text { aguas subterráneas, } \\
\text { especialmente por el } \\
\text { nitrógeno. }\end{array}$ \\
\hline
\end{tabular}




\begin{tabular}{|c|c|c|}
\hline \multirow{2}{*}{$\begin{array}{l}\text { Actividad } \\
\text { agrícola }\end{array}$} & \multicolumn{2}{|l|}{ Efectos } \\
\hline & Aguas superficiales & Aguas subterráneas \\
\hline Plaguicidas & $\begin{array}{l}\text { La escorrentía de plaguicidas da lugar a la } \\
\text { contaminación del agua superficial y la biota; } \\
\text { disfunción del sistema ecológico en las aguas } \\
\text { superficiales por pérdida de los depredadores } \\
\text { superiores debido a la inhibición del crecimiento } \\
\text { y a los problemas reproductivos; consecuencias } \\
\text { negativas en la salud pública debido al consumo } \\
\text { de pescado contaminado. Los plaguicidas son } \\
\text { trasladados en forma de polvo por el viento hasta } \\
\text { distancias muy lejanas y contaminan sistemas } \\
\text { acuáticos que pueden encontrarse a miles de millas } \\
\text { de distancia (por ejemplo, a veces se encuentran } \\
\text { plaguicidas tropicales o subtropicales en los } \\
\text { mamíferos del Ártico). }\end{array}$ & $\begin{array}{l}\text { Algunos plaguicidas } \\
\text { pueden lixiviarse en las } \\
\text { aguas subterráneas, } \\
\text { provocando problemas } \\
\text { para la salud humana } \\
\text { a través de los pozos } \\
\text { contaminados. }\end{array}$ \\
\hline $\begin{array}{l}\text { Granjas/ } \\
\text { parcelas de } \\
\text { engorde }\end{array}$ & $\begin{array}{l}\text { Contaminación del agua superficial con numerosos } \\
\text { agentes patógenos (bacterias, virus, etc.), lo que } \\
\text { da lugar a problemas crónicos de salud pública. } \\
\text { Contaminación por metales contenidos en la orina } \\
\text { y las heces. }\end{array}$ & $\begin{array}{l}\text { Posible lixiviación de } \\
\text { nitrógeno, metales, } \\
\text { etc. hacia las aguas } \\
\text { subterráneas. }\end{array}$ \\
\hline Riego & $\begin{array}{l}\text { Escorrentía de sales, que da lugar a la salinización de } \\
\text { las aguas superficiales; escorrentía de fertilizantes } \\
\text { y plaguicidas hacia las aguas superficiales, con } \\
\text { efectos ecológicos negativos, bioacumulación en } \\
\text { especies ícticas comestibles, etc. Pueden registrarse } \\
\text { niveles elevados de oligoelementos, como el selenio, } \\
\text { con graves daños ecológicos y posibles efectos en la } \\
\text { salud humana. }\end{array}$ & $\begin{array}{l}\text { Enriquecimiento del agua } \\
\text { subterránea con sales, } \\
\text { nutrientes (especialmente } \\
\text { nitrato). }\end{array}$ \\
\hline Talas & $\begin{array}{l}\text { Erosión de la tierra, lo que da lugar a elevados } \\
\text { niveles de turbidez en los ríos, entarquinamiento } \\
\text { del hábitat de aguas profundas, etc. Perturbación y } \\
\text { cambio del régimen hidrológico, muchas veces con } \\
\text { pérdida de cursos de agua perennes; el resultado es } \\
\text { problemas de salud pública debido a la pérdida de } \\
\text { agua potable. }\end{array}$ & $\begin{array}{l}\text { Perturbación del régimen } \\
\text { hidrológico, muchas veces } \\
\text { con incremento de la esco- } \\
\text { rrentía superficial y dismi- } \\
\text { nución de la alimentación } \\
\text { de los acuíferos; influye } \\
\text { negativamente en el agua } \\
\text { superficial, ya que reduce el } \\
\text { caudal durante los períodos } \\
\text { secos y concentra los nu- } \\
\text { trientes y contaminantes en } \\
\text { el agua superficial. }\end{array}$ \\
\hline Silvicultura & $\begin{array}{l}\text { Gran variedad de efectos; escorrentía de plaguicidas } \\
\text { y contaminación del agua superficial y de los peces; } \\
\text { problemas de erosión y sedimentación. }\end{array}$ & \\
\hline Acuicultura & $\begin{array}{l}\text { Descarga de plaguicidas (por ejemplo, } \text { TBT }^{1} \text { ) y } \\
\text { altos niveles de nutrientes en el agua superficial y } \\
\text { subterránea a través de los piensos y las heces, lo } \\
\text { que da lugar a fenómenos graves de eutrofización. }\end{array}$ & \\
\hline
\end{tabular}


Destacándose que el efecto del uso de productos químicos que se ha incrementado en todo el mundo hasta aproximadamente 2 millones de toneladas al año (WWDR, 2018). Siendo la agricultura la fuente predominante de nitrógeno reactivo vertido en el medio ambiente y una fuente importante de fósforo como se puede evidenciar en la Figura 17:

Figura 17. Porcentaje de participación de la agricultura en las emisiones totales de nitratos y fosforo en los países de la OCDE, 2000-2009.

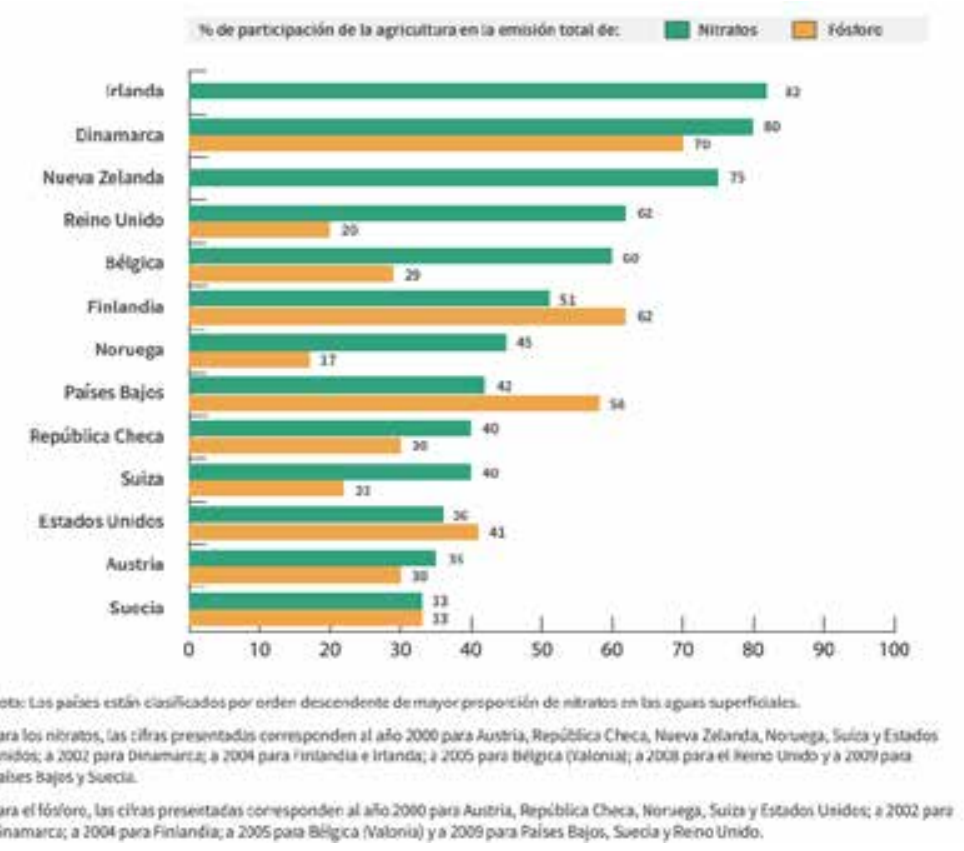

Fuente: OCDE (2013, fig. 9.1, pág. 122) modificado por WWDR, 2018.

Es así como el nivel de contaminación del agua dependerá del uso y manejo que se les da a los residuos tanto biológicos como químicos, a las aguas servidas, a los fertilizantes, al componente arbóreo y en general a la estructura e interacción de los componentes bióticos y abióticos de los sistemas agrícolas (Pinos, et al. 2012, RAPAL, 2010).

\subsection{Descripción metodológica para la estimación de la huella hídrica}

$\mathrm{La} \mathrm{HH}$ ha sido propuesta por diversos investigadores como un indicador adecuado para cuantificar el impacto de los productos y servicios sobre el agua dulce, su escasez y su calidad (Mekonnen y Hoekstra, 2011). Indicador que promueve el análisis 
del uso eficiente y la productividad del agua, comprendiendo la eficiencia como la realización de un proceso o generación de un producto o servicio con el uso de la mínima cantidad de recurso (Lt/unidad de producto), mientras que la productividad se entiende como la relación existente entre la cantidad de producto o servicio, con el volumen de agua utilizada (unidad de producto/Lt). En busca de un uso sostenible del recurso hídrico se hace evidente la necesidad de producir mayor cantidad de bienes y servicios con menos volumen de agua y procesos ajustados a menguar su contaminación (Hoekstra y Chapagain, (2008); Zarate (2013)). La metodología estándar descrita por la Water Footprint Network (Hoekstra, et al. 2011) y el Análisis del Ciclo de Vida-ACV: son dos técnicas de gran relevancia en la estimación de la $\mathrm{HH}$ que han venido evolucionando y cada vez tienen una mayor fundamentación teórica.

\subsubsection{Metodología estándar de Water Footprint Network (WFN)}

El concepto de $\mathrm{HH}$ descrito por la WFN tiene en cuenta además del volumen; el tiempo, el espacio y los tipos de agua dulce consumida, extraída y/o contaminada. Incluyendo en la estimación indicadores que permitan calcular de forma directa o indirecta la cantidad de agua consumida y contaminada; la evaluación de impactos que genera y la toma de decisión con respecto a estos impactos (Hoekstra, et al. 2011). Siendo un indicador temporalmente y espacialmente explicito permite analizar los resultados acordes a los requerimientos del recurso en la región. La relación entre los usos y los colores del agua acorde a su fuente fueros definidos por Hoekstra y Chapagain (2008) de la siguiente manera (Figura 18):

HH Azul: uso consuntivo de agua dulce disponible en la superficie o subterránea, que se evapora, no retorna a la misma cuenca o se incorpora al producto, al hacer el análisis dentro de la estimación se debe relacionar con la escasez y competencia por recurso hídrico (Hoekstra, et al. 2011; CGIAR, 2014).

HH Gris: especifica la cantidad de agua dulce que se requiere para asimilar o diluir la carga de contaminantes dadas las concentraciones naturales y estándares ambientales de calidad de agua en el cuerpo receptor, hasta el punto en que esté sobre los estándares aceptables de calidad (Hoekstra, et al. 2011).

HH Verde: referente al volumen de agua de lluvia que no se convierte en escorrentía, sino que se incorpora en productos agrícolas. Esta $\mathrm{HH}$ verde corresponde a la cantidad de agua precipitada que es evaporada durante todo el proceso productivo (Hoekstra, et al. 2011). 
Figura 18. Metodología estándar de Water Footprint Network (WFN).

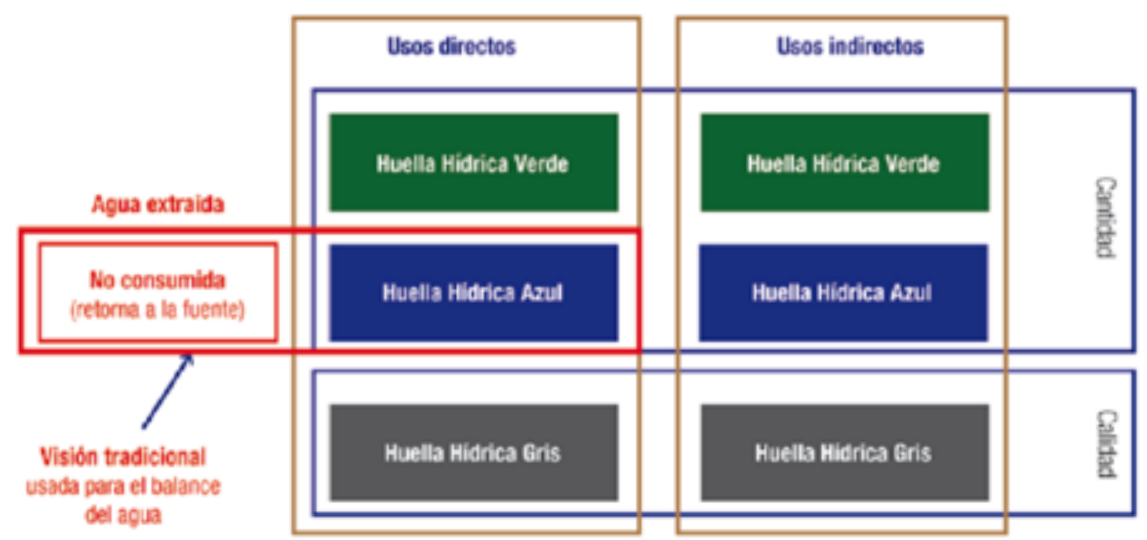

Fuente: modificado de Hoekstra, et al. (2011).

La metodología incluye las siguientes fases:

I. Establecimiento de objetivos y alcance del estudio.

II. Cuantificación de la huella hídrica por unidad de estudio.

III. Evaluación de la sustentabilidad de la huella hídrica.

IV. Formulación de estrategias de respuesta frente a los resultados de huella hídrica (Hoekstra, et al. 2011).

\subsubsection{Análisis del Ciclo de Vida-ACV y Norma ISO 14066:2014 para cálculo de la $\mathrm{HH}$}

A la metodología del Análisis del Ciclo de Vida-ACV acorde a la normas ISO 14040 e ISO 14044 tratadas en el capítulo anterior se le suma el marco de referencia de la norma ISO 14046 incluyendo en el análisis de ciclo de vida para la HH las siguientes fases (Figura 19):

I. Definición del objetivo y del alcance.

11. Análisis del inventario de la huella de agua.

III. Evaluación del impacto de la huella de agua.

IV. Interpretación de resultados. 
Figura 19. Evaluación de la huella hídrica.

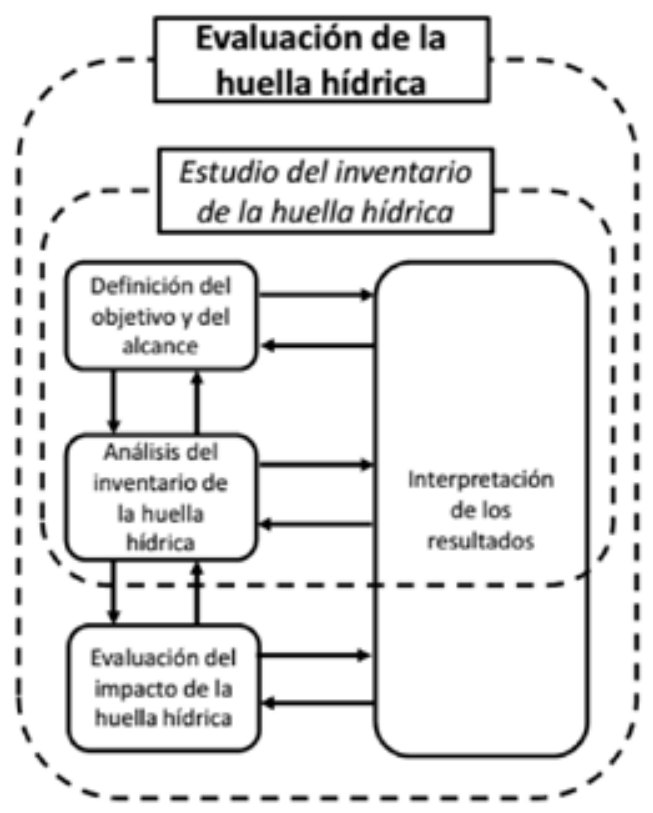

Fuente: ISO, (2014).

Junto con estas fases se establecen los principios, requisitos y directrices para la evaluación de la huella de hídrica de productos, procesos y organizaciones, con base en cada una de las etapas del ciclo de vida, desde el origen en la adquisición de materias primas, hasta el final de la vida del producto, servicio u organización, para realizar e informar de una evaluación de huella de agua única o individual, o como parte de una evaluación ambiental más integral (ISO, 2014)

De acuerdo con CONAMA (2014) la norma ISO 14046 centra su aporte en una armonización consensuada a nivel mundial de conceptos, principios y metodologías, con una base científica, lo que promueve una mayor transparencia, facilita la comprensión y uso de los resultados de una $\mathrm{HH}$, sin caer en simplificaciones, por las partes interesadas, incluyendo clientes, proveedores e inversores.

\subsection{Aplicabilidad de la HH para evaluación de la sostenibilidad agrícola}

Para determinar la importancia ambiental, social y económica de la $\mathrm{HH}$, los países han estimado tanto la correspondiente al consumo interno, como al externo, este último concepto tiene gran importancia en los bienes con una $\mathrm{HH}$ elevada, 
que son comercializados al exterior del país, algo muy común en la actualidad debido a la apertura del comercio y los mercados internacionales, la exportación de agua virtual hace referencia al desplazamiento de ese recurso de manera indirecta, desde el país de origen hasta el país consumidor, es de esta forma, como muchos países que son grandes consumidores, externalizan su $\mathrm{HH}$ (Chapagain y Hoekstra, 2003).

Hoekstra y Mekonnen (2012) estimaron la huella hídrica por nación tanto desde una perspectiva de producción como de consumo, encontrando que el promedio de la $\mathrm{HH}$ anual global en el período entre 1996-2005 fue de 9,087 Gm3 / y (74\% verde, $11 \%$ azul, $15 \%$ gris). Representando la producción agrícola el mayor aporte con el $92 \%$ y dentro de este sector los cereales tienen la mayor contribución, (27\%), seguido de la carne (22\%) y productos lácteos (7\%), en la Figura 20 se puede evidenciar la $\mathrm{HH}$ de la producción agrícola en las naciones.

Figura 20. HH de la producción agrícola en el período 1996-2005.

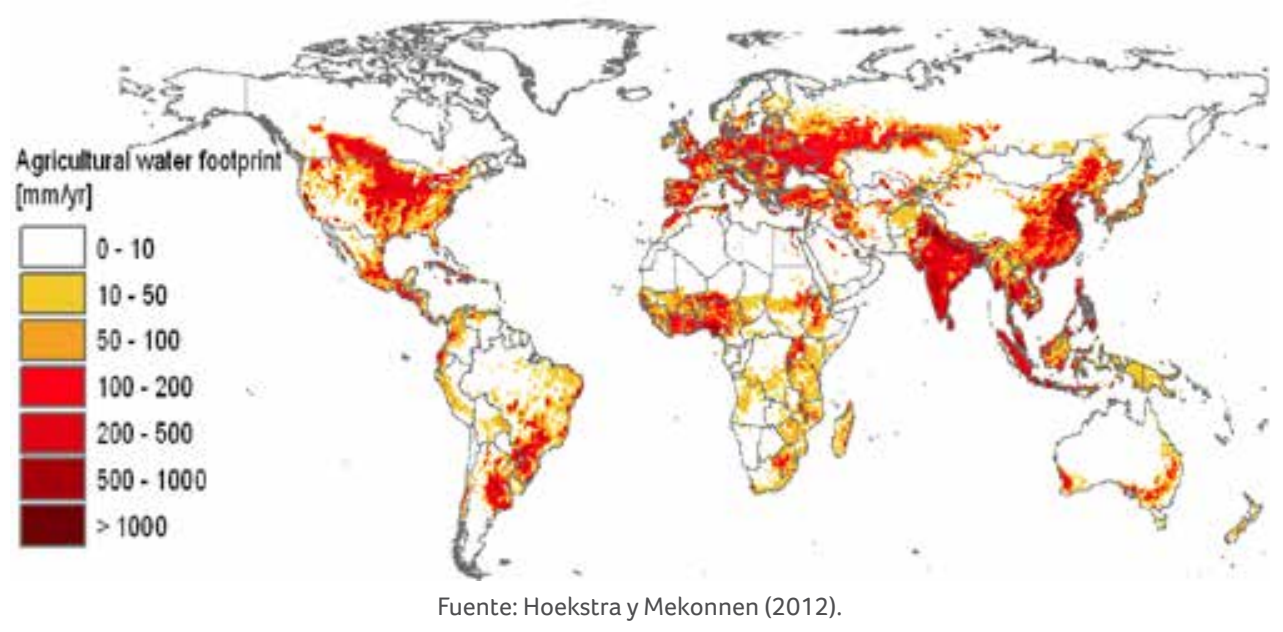

De acuerdo con Hoekstra (2012), la HH de consumo nacional se calcula con la sumatoria de las correspondientes a la completitud de los procesos llevados a cabo dentro del país, incluyendo la HH de consumo nacional, la exportación y el presupuesto de agua. Los factores que determinan la HH de un país o de una región, involucran por supuesto el sector agrícola, el industrial y el grado de tecnificación, entre otros (Hoekstra, et al. 2011). 
La HH mundial promedio en el periodo comprendido entre los años 1996 y 2005 fue de $1.385 \mathrm{~m}^{3} /$ per cápita/año y el $16 \%$ del total se utiliza para producir bienes que se exportan. Indicadores globales para el uso sostenible del recurso hídrico se han enfocado en estimaciones para grupos de poblaciones o países con el fin de analizar el consumo de sus habitantes frente a la capacidad biológica del medio (Mahamud y Suárez, 2007; Mekonnen y Hoekstra 2012). Los cálculos de $\mathrm{HH}$ de producción y consumo se realizaron con base en la metodología de The Water Footprint Assessment Manual, utilizando fórmulas como: $\mathrm{HH}$ de Consumo Nacional, HH de Consumo per cápita, y HH de Producción Nacional (Hoekstra y Mekonnen, 2012).

La HH de un producto se mide sobre los consumos directos e indirectos de agua que se realizan a lo largo del proceso. Los directos son aquellos en los que el agua se consume durante el proceso productivo, los indirectos son aquellos en los que el agua se utiliza a lo largo de la cadena de producción de los insumos (Hoekstra et al., 2011). Específicamente, para la caracterización del sector agrícola la información básica a tener en cuenta incluye tres grupos de variables, el clima y el suelo son las dos primeras, basadas en el conocimiento del entorno, y la tercera se relaciona con el recurso productivo (Arévalo y Campuzano, 2013).

\subsubsection{Estimación de la HH en un cultivo}

\subsubsection{Información requerida para la estimación de la $\mathrm{HH}$ en el un cultivo}

El uso de agua del cultivo depende tanto de las necesidades como de la cantidad real del recurso hídrico disponible en el suelo, la cantidad de agua que las plantas transpiran es mucho mayor que la utiliza para crecimiento y fotosíntesis. Diversas metodologías se han propuesto para su determinación, debiendo considerarse siempre que la evapotranspiración depende, entre otros aspectos, de las condiciones climáticas, tipo y estado de desarrollo del cultivo, así como de la disponibilidad de agua del suelo.

El requerimiento de agua de los cultivos, se dividen en directos e indirectos. Los métodos directos proporcionan el valor del consumo total del agua requerida por las plantas, para lo que se utilizan instrumentos en su determinación directa, los métodos indirectos proporcionan un valor estimado del agua requerida a través de todo el ciclo vegetativo, mediante la aplicación de fórmulas empíricas basadas en datos climáticos. 
Para los métodos indirectos se requiere información sobre datos climáticos de: radiación, temperatura máxima y mínima, humedad relativa y viento; parámetros hídricos de los suelos: capacidad de retención, facilidad de infiltración, restricciones a la profundización y parámetros del cultivo. Las variables climáticas y de precipitación pueden ser obtenidas mediante estaciones climáticas que abarquen la zona de estudio, consolidando datos de temperatura mínima y máxima, porcentaje de humedad, viento, horas de sol y precipitación (Aldaya, 2012), los datos climáticos pueden extraerse de fuentes como CLIMWAT 2,0 (FAO 2018b) y LocClim 1,1 , la primera base de datos contiene información entre los años 1.971 y 2.000 y la segunda brinda índices climáticos medios en sitios en los que no se cuenta con observaciones. El software Cropwat 8.0 (FAO, 2018) posibilita la cuantificación del agua necesaria para el desarrollo de un cultivo en particular basado en el método de la FAO Penman-Monteith para determinar la evapotranspiración de referencia de los cultivos (ETo). Este método estándar requiere datos de radiación solar neta, temperatura del aire, velocidad del viento y humedad atmosférica. Los cuales son aplicados a la siguiente formula (FAO, 1998):

$$
\text { ETo }=\frac{1}{\lambda} *\left(\frac{\Delta .(R n-G)+\rho_{a} * C_{p} * \frac{\left(e_{s}-e_{a}\right)}{r_{a}}}{\Delta+\curlyvee\left(1+\frac{r_{s}}{r_{a}}\right)}\right)
$$

ETo = Evapotranspiración de referencia según la ecuación de FAO PenmanMonteith (mm/día)

$\lambda=$ Calor latente de vaporización $(\mathrm{MJ} / \mathrm{kg})$

$\Delta=$ Pendiente de la curva que relaciona la presión de vapor con la temperatura del aire $\left(\mathrm{kPa} /{ }^{\circ} \mathrm{C}\right)$

$\mathrm{Rn}=$ Radiación neta en la superficie del cultivo $\left(\mathrm{MJ} / \mathrm{m}^{2}\right.$ día)

$\mathrm{G}=$ Flujo térmico del suelo $\left(\mathrm{MJ} / \mathrm{m}^{2} \mathrm{dí}\right.$ )

$\rho_{\mathrm{a}}=$ Densidad del aire seco a presión constante $\left(\mathrm{kg} / \mathrm{m}^{3}\right)$

$c_{p}=$ Calor específico del aire $\left(\mathrm{MJ} / \mathrm{kg}^{\circ} \mathrm{C}\right)$

$\mathrm{e}_{\mathrm{s}} \mathrm{ye}_{\mathrm{a}}=$ Déficit de presión de vapor $(\mathrm{kPa})$

$\gamma=$ Constante psicrométrica $\left(\mathrm{kPa} /{ }^{\circ} \mathrm{C}\right)$

$r_{s} y r_{a}=$ Resistencia superficial del cultivo de referencia y aerodinámica $(s / m)$ 
Además, se pueden utilizar imágenes satelitales específicas al área de estudio para recolectar la información requerida, como área y rendimiento del cultivo (FAO, 2010).

\subsubsection{Estimación de los colores del agua para un cultivo}

La HH se calcula como el uso del agua en campo dividido por el rendimiento del cultivo ( $\mathrm{m}^{3} /$ ton), la $\mathrm{HH}$ verde se estima con base en el volumen de agua de lluvia que se evapora del área de cultivo durante el período de crecimiento. La HH azul, se estima con base en el volumen de agua de riego que se pierde por evapotranspiración a partir del área de cultivo durante el período de crecimiento. La HH gris se calcula como la división entre carga másica y la diferencia entre el límite máximo permitido y la concentración natural de ese compuesto en el cuerpo de agua (Hoekstra et al., 2011). Para facilitar el cálculo, es posible utilizar como base el nitrógeno lixiviado a partir de la concentración en excretas y/o el uso de fertilizantes (frecuencia, cantidad y área de aplicación del fertilizante y porcentaje de nitrógeno según la composición del producto comercial o natural), sobre su concentración de referencia de $10 \mathrm{gr} / \mathrm{m}^{3}$ según la WFN (2011).

\subsubsection{Estimación de la HH en un animal}

\subsubsection{Información requerida para la estimación de la HH en el sector pecuario}

La HH de un animal vivo consiste en la sumatoria de la generada por la alimentación y la $\mathrm{HH}$ relacionada con el agua potable y el agua de servicio consumida y contaminada (Mekonnen y Hoekstra, 2012) La huella hídrica de un animal puede, ser expresada en términos de la ecuación propuesta por Mekkonnen y Hoekstra (2011).

$$
\text { WF[a,c, s] = WFalim }[a, c, s]+\text { WFbebida }[a, c, s]+\text { WFserv[a,c, s] }
$$

Donde WFalim [a,c,s], WFbebida [a,c,s] y WFserv [a,c,s] representan la huella hídrica, para un animal categoría "a" en un lugar "c" y en un sistema de producción del tipo "s" en lo que respecta a alimentación, aguas de bebida y agua de servicios consumida (Mekonnen y Hoekstra, 2011).

\subsubsection{Información sobre la alimentación}

Los forrajes son utilizados como alimento base, principalmente, para rumiantes y equinos, por lo que se debe tener en cuenta la información requerida en la 
producción de cultivos (Guevara, (2006), Hoekstra, 2008). Mientras que la huella hídrica indirecta de un animal relacionada con el alimento consumido consta de dos partes: el agua de los diversos ingredientes de la alimentación y el agua que se utiliza durante la producción del alimento concentrado, el cálculo del consumo de alimento concentrado puede ser realizado teniendo en cuenta el peso vivo (PV) de los animales, los requerimientos alimenticios y la cantidad de agua necesaria para la producción de un kilo de MS o a partir de información secundaria que referencie la HH de los ingredientes del concentrado (GAIA, 2011).

\subsubsection{Información sobre el consumo directo (agua bebida)}

Para realizar el cálculo del agua de bebida es posible medir de manera directa el consumo individual de agua/día de los animales o utilizar valores de referencia obtenidos de información secundaria, lo cual resulta más práctico. Por ejemplo, estudios realizados en Holanda por Hoekstra y Chapagain, (2003) generaron valores de referencia analizando la cantidad de agua consumida por la vaca en la alimentación, bebida y en los servicios de obtención de la leche, a lo largo de toda la vida del animal. En estos estudios también se comparan sistemas de producción intensiva y de pastoreo como se muestra en la Tabla 19.

Tabla 19. Datos de referencia consumo de agua en vacas de leche.

\begin{tabular}{|c|c|c|c|c|c|}
\hline Sistema & Agua bebida & $\begin{array}{c}\text { Agua } \\
\text { evapotranspirada } \\
\text { por cultivos }\end{array}$ & $\begin{array}{l}\text { Agua de } \\
\text { servicios }\end{array}$ & $\begin{array}{c}\text { Litros } \\
\text { de leche a } \\
\text { lo largo de la } \\
\text { vida de la vaca }\end{array}$ & HH \\
\hline & (m³/animal) & (m³/animal) & (m³/animal) & (L leche/animal) & (m³/leche) \\
\hline Intensivo & 219,0 & 39.075 & 64,4 & 51.779 & 0,76 \\
\hline Pastoreo & 123,7 & 32.110 & 15,7 & 17.500 & 1,84 \\
\hline
\end{tabular}

Fuente: Hoekstra y Chapagain, (2003)

\subsubsection{Información sobre el agua de servicio}

Esta información se refiere al agua utilizada para limpiar el corral, el galpón, las porquerizas e instalaciones en general, utensilios y realizar otros servicios necesarios dentro del predio que están relacionados con la producción (Hansen, 2014). Estos datos se pueden obtener de estudios locales o regionales. En caso de no estar disponibles, éstos pueden adquirirse de bases de datos internacionales que aportan valores medios mundiales (Suizagua, 2014). 
La huella hídrica de un animal y sus tres componentes se pueden expresar en

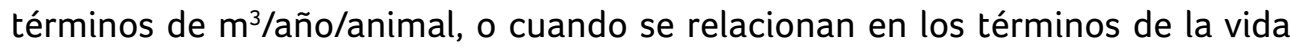
del animal, en $\mathrm{m}^{3}$ /animal. Para los animales de interés zootécnico cuyo objetivo productivo es la carne (cerdos, ovejas, cabras, bovinos para carne y pollos de engorde) por ser animales que proveen sus productos después de que han sido sacrificados, es más útil estimar la $\mathrm{HH}$ del animal al final de su vida, porque es este total el que será asignado a los productos.

Mientras que para ganado tipo leche y gallinas ponedoras, es la más sencillo estimar la HH por año (promediado durante su vida útil), debido a que se puede relacionar fácilmente esta $\mathrm{HH}$ anual con la producción anual promedio (leche, huevos) (Mekonnen y Hoekstra, (2012); Arévalo y Campuzano (2013)).

Después de obtener la información requerida la $\mathrm{HH}$ verde se estima teniendo como base el agua lluvia para el cultivo dividido por el rendimiento del mismo y de manera similar, la $\mathrm{HH}$ azul se calcula con el agua superficial y subterránea utilizada para el cultivo sobre el rendimiento (Arévalo y Campuzano, 2013). En los dos casos para el sector agrícola se estiman con el uso de un modelo de simulación agronómico, como Cropwat 8.0 (FAO, 2010).

La HH gris se estima con base en la cantidad del contaminante y la diferencia existente entre la concentración máxima permitida y la concentración natural en el cuerpo de agua que lo está recibiendo, de manera directa con base en la descarga en cuerpos de agua superficial y la infiltración hacia el agua subterránea, por lo que el cálculo de $\mathrm{HH}$ gris corresponde entonces a la contaminación escurrida e infiltrada (Hansen, 2014). En el forraje como cultivo base de la alimentación animal se le brinda especial importancia al uso de fertilizantes que contienen nitrógeno y fósforo, ya que la información existente para pesticidas es muy escasa, la estimación de la $\mathrm{HH}$ gris se basa entonces en la cantidad de fertilizante utilizado, sobre la diferencia entre la concentración máxima permisible de los elementos en el agua y la concentración natural de los mismos (Hoekstra, et al. 2011).

\subsubsection{Análisis de estimaciones en el sector agrícola}

Estudios en el sector agropecuario evidencian que al realizar comparaciones entre resultados de estimación de la $\mathrm{HH}$ es importante analizar parámetros específicos de cada estudio, incluyendo, la metodología utilizada (Análisis de Ciclo de Vida o enfoque de la WFN), el alcance de la estimación, si se calcula la HH 
directa, la indirecta o las dos y si los datos utilizados corresponden a información primaria o secundaria, esto refleja su carácter espacial y temporal, pero además la sensibilidad metodológica que permite su uso como herramienta para evaluar la sostenibilidad del recurso hídrico, acorde a las particularidades de los diferentes tipos de sistemas productivos (Corredor, Castro y Páez, 2017; Alvarenga, Cherubini, Zanghelini, Galindro, y Soares, 2014; Mekonnen y Hoekstra 2011; Manazza, 2012). Es así como estimaciones de la $\mathrm{HH}$ azul muestran valores de 19, 11 y $7 \mathrm{Lt} /$ $\mathrm{Kg}$ de leche en sistemas estabulados, semiestabulados y basados en pastoreo, respectivamente y de la verde de $1.478,2.209$ y 1.584 para los mismos sistemas (Alvarenga, et al. 2014), siendo la $\mathrm{HH}$ verde el mayor porcentaje (Alvarenga, et al. (2014); Sánchez, et al (2014); Mekonnen y Hoekstra, (2012)). El uso de la HH para evaluar la sostenibilidad se ve reflejado en el estudio de caso realizado en la Pampa, Argentina, en el que se estimó la $\mathrm{HH}$ de la producción primaria de la Provincia para el año 2009 en 124,4 Hm³ , identificando que el 33\% de la $\mathrm{HH}$ se genera en sistemas con productividad por debajo de la media, con lo cual en términos generales son menos ecoeficientes (Manazza, 2012).

Hasta ahora la mayoría de los investigaciones, estimaciones y prácticas se enfocan en los esfuerzos se centran en aumentar la eficiencia del uso del agua en la producción de cultivos (más cultivos por gota) y eficiencia de conversión alimenticia en el sector ganadero (más carne con menos alimento) (Mekonnen y Hoekstra, 2012). Para el sector pecuario es una realidad que las modificaciones en las prácticas deben llevar a una producción sostenible y tender a disminuir la $\mathrm{HH}$ debido a que el sector se puede enfrentar a una visión que vaya más allá de la «Producción sostenible» tendiendo al «consumo sostenible». En otras palabras, a que se enfoquen los esfuerzos en un mayor valor nutricional por gota, necesidad planteada por Hoekstra, (2014) dado que al comparar la $\mathrm{HH}$ de productos pecuarios y de origen agrícola, evidencian que los alimentos de origen animal no solo requieren más tierra para obtener un cierto valor nutricional, sino también más energía y agua. Mekonnen y Hoekstra (2012) muestran que la $\mathrm{HH}$ de cualquier producto animal es mayor a la de un cultivo alternativo con valor nutricional equivalente. Por ejemplo, el promedio de $\mathrm{HH}$ por caloría para carne de res (10 L/ $\left./ \mathrm{kcal}^{-1}\right)$ es 20 veces más grande que para los cereales $\left(0.5 \mathrm{~L} \mathrm{kcal}^{-1}\right)$. Autores que se enfocan en el cambio de la dieta como solución parcial a la escasez de agua han estimado reducciones de la $\mathrm{HH}$ potencial global en países industrializados del $36 \%$ y del $15 \%$ en países en desarrollo (Hoekstra, 2010), en la $\mathrm{HH}$ verde global del $23 \%$ y en la azul del $16 \%$ ) si se reemplazan alimentos de origen animal por cultivos locales 
con el mismo valor nutricional (Mekonnen y Hoekstra, 2012). Sin embargo, es claro que la reducción dependerá de los hábitos alimenticios en cada país y se debe profundizar en la evaluación de los diversos colores del agua en cada producto y si en las regiones se requiere mayor relevancia debido a la escasez o a la contaminación (Hoekstra, 2014). Adicionalmente es importante determinar el aporte del conjunto de factores que explican la $\mathrm{HH}$ del producto, para lo cual es posible aplicar técnicas matemáticas y estadísticas, realizando por ejemplo modelación econométrica teniendo en cuenta las variables más importantes que integran la $\mathrm{HH}$, haciendo posible determinar el modelo de factores que la explican la $\mathrm{HH}$ y en consecuencia lograr relacionar índices de los sistemas con la estimación obtenida (Corredor, et al. 20017).

\section{Conclusiones}

El recurso hídrico resulta fundamental para el desarrollo social y económico de los países, mejorar su uso en pro de evitar la pérdida o contaminación del agua dulce es un requerimiento prioritario, especialmente para el sector agrícola que tiene la mayor participación en las extracciones de agua a nivel global correspondientes según la FAO (2016) al 69\%, un aporte a la HH global del 92\% (Hoekstra y Mekonnen, 2012) y la fuente más importante de nitrógeno y fósforo que llegan al medio ambiente (WWDR, 2018).

Existen particularidades que deben ser analizadas desde la política pública, desde la producción de cada país, pero también desde la complejidad de los diversos sistemas agrícolas en los que este recurso hídrico hace parte de las entradas, las salidas y es fundamental para la interacción entre sus componentes. Por ejemplo, las producciones ganaderas tecnificadas, al utilizar mayor cantidad de alimento concentrado y de productos químicos tendrán $\mathrm{HH}$ azul y gris más altas y los extensivos por el contrario debido al uso de forraje presentarán $\mathrm{HH}$ verde mayor.

Uno de los factores más relevantes al momento de analizar la aplicación de la $\mathrm{HH}$ como indicador es que el agua gris estimada en el sector agrícola podría ser inferior a la real, esto debido a que existen diferentes tipos de sustancias contaminantes que no se están teniendo en cuenta, bien sea por la dificultad de determinar su concentración, por centrarse solamente en el uso de fertilizantes o cuando la estimación depende de la norma de calidad ambiental que rija en el lugar en que se realicen las descargas. 
Aunque, los resultados de la $\mathrm{HH}$ en diferentes investigaciones tienen una amplia variabilidad, especialmente en lo que respecta a la obtención de datos y en tal sentido, para realizar comparación entre resultados es necesario tener en cuenta la metodología utilizada, los objetivos de los estudios, los alcances, así como a los supuestos usados, se evidencia la gran importancia que tiene la $\mathrm{HH}$ como metodología para la sostenibilidad agropecuaria, a través de relación entre los sistemas agrícolas y el agua, la descripción metodológica para estimar la HH y los ejemplos de la aplicabilidad.

\section{Bibliografía}

Aldaya M. (2012). Introducción a la Evaluación de la Huella Hídrica Seminario Internacional: Información Estadística y Geográfica para el Mejor Manejo del Agua en México, INEGI-UAM D.F., México, 6-7 Marzo 2012 Consultora, PNUMA Investigadora, OA-FMB Asociada, WFN

Alvarenga, R., Cherubini, M., Zanghelini M., Galindro, B.y Soares, S. (2014). Estimating the water footprint of milk produced in the southern region of Brazil. Proceedings of the 9th International Conference on Life Cycle Assessment in the Agri-Food Sector

Ardila, A. y Vergara W. (2012). El sector pecuario frente al cambio climático: una realidad incómoda. Rev. Cienc. Anim. n. ${ }^{\circ}$ 5. Pág. 107-120

Arévalo y Campuzano. (2013). Evaluación de la Huella Hídrica en la cuenca del río Porce. Recuperado de https://www.goodstuffinternational.com/images/PDF/LibroHuellahidrica.pdf

Chapagain A. Hoekstra, A. (2003). Virtual water flows between nations in relation to trade in livestock and livestock products. Value of Water Research Report Series No. 13.

CONAMA. (2014). HUELLA HÍDRICA: La nueva norma internacional ISO 14046:2014 y su implementación. Universidad de León. Recuperado de http://www.conama.org/conama/download/files/conama2014/CT\%202014/1896712004.pdf

Corredor, E., Fonseca, J. \& Páez, E. (2012). Los servicios ecosistémcios de regulación: tendencias e impacto en el bienestar humano. Revista de Investigación Agraria y Ambiental, 3 (1) enero-junio, 77-83. Recuperado de: http://hemeroteca.unad.edu.co/index.php/riaa/article/ view/936/934

Corredor E.S., Castro E.S., Páez E.M. 2017. Estimación de la huella hídrica para la producción de leche en Tunja, Boyacá. Rev. Cien. Agri. 2017; 14(2): 7-17.

FAO. (1997). Lucha Contra la Contaminación Agrícola de los Recursos Hídricos. (Estudio FAO Riego y Drenaje - 55). Recuperado de http://www.fao.org/docrep/W2598S/w2598s00. htm\#Contents

FAO. (2016). Sitio web AQUASTAT. Organización de las Naciones Unidas para la Alimentación y la Agricultura. Recuperado de http://www.fao.org/nr/water/aquastat/didyouknow/indexesp2.stm

FAO. (2018). CropWat. Recuperado de http://www.fao.org/land-water/databases-and-software/cropwat/en/ 
FAO. (2018b). CLIMWAT. Recuperado de http://www.fao.org/land-water/databases-and-software/climwat-for-cropwat/en/

FAO. (1998). Crop evapotranspiration - Guidelines for computing crop water requirements FAO Irrigation and drainage paper 56. Recuperado de: http://www.fao.org/docrep/X0490E/ x0490e00.htm\#Contents

GAIA. (2011). Huella hídrica grupo Nutresa. Recuperado de http://gaiasa.com/wp-content/ uploads/2013/11/2.-Huella-H\%C3\%ADdrica-Grupo-Nutresa.pdf

Guevara, J. (2006). La fórmula de Penman-Monteith FAO 1998 para determinar la evapotranspiración de referencia, ETo. Terra Nueva Etapa, XXII (31), 31-72.

Hoekstra, A.Y. (2008). Water neutral: reducing and offsetting the impacts of water footprints, Value of Water Research Report Series No. 28, UNESCO-IHE, Delft, the Netherlands

Hoekstra, A. y Chapagain A. (2008). Globalization of Water: Sharing the Planet's Freshwater Resources. Blackwell Publishing, Oxford, UK.

Hoekstra, A. Y., Chapagain, A. K., Aldaya, M. M., y Mekonnen, M. M. (2011). The water footprint network assessment manual: Setting de global standard. London: Earthscan.

Hoekstra, A. Y., y Mekonnen, M. M. (2012). The water footprint of humanity. PNAS. vol. 109, no. 9, pág. 3232-3237

Hoekstra , A. (2012). The hidden water resource use behind meat and dairy. Twente Water Centre, University of Twente, PO Box 217, 7522AE Enschede, the Netherlands April Vol. 2, No. 2

Instituto Interamericano de Cooperación para la Agricultura, Fundación Colegio de Postgraduados en Ciencias Agrícolas - México: IICA (2017). El agua para la agricultura de las américas. Recuperado de http://www.bivica.org/upload/agua-agricultura.pdf

ISO (2014) ISO14046:2014. Recuperado dehttps://www.iso.org/obp/ui\#iso:std:iso:14046:ed$1: \mathrm{v} 1: \mathrm{es}$

ISO (2015). ISO 14040: Análisis del ciclo de vida. Sistemas de Gestión Normalizados. Recuperado de http://www.isotools.com.mx/iso-14040-ciclo-de-vida/

Manazza, F. (2012). Cuantificación y valoración económica del uso consuntivo del agua en los principales productos de las cadenas lácteas de La Pampa y San Luis. - 1a ed. - San Luis Ediciones INTA, 2012. 70 p. ; 28x20 cm. ISBN 978-987-679-109-0 1. Recursos Hídricos. 2. Cadena Láctea. I. Título CDD 333.9

Mahamud, M. y Suárez, A. (2007). La huella ecológica, concepto, potencialidad y aplicación. Facultad de Química. Universidad de Oviedo. Revista No: 448 Junio

Manazza, J. (2012). Cuantificación y valoración económica del uso consuntivo del agua en los principales productos de las cadenas Lácteas de La Pampa y San Luis. - 1a ed. - San Luis: Ediciones INTA, 2012. 70 p. ; 28x20 cm. ISBN 978-987-679-109-0

Mekonnen, M. y Hoekstra, A. (2011). The green, blue and grey water footprint of crops and derived crop products, Value of Water Research Report Series No. 47, UNESCO-IHE, Delft, the Netherlands. http://www.waterfootprint.org/Reports/Report47-WaterFootprintCropsVol1.pdf

Mekonnen, M. y Hoekstra, A. (2012). A Global Assessment of the Water Footprint of Farm Animal Products. Ecosystems 15: 401-415 
ONU (2015). Informe de las Naciones Unidas sobre los recursos hídricos en el mundo 2015. Agua para un mundo sostenible. Departamento de Asuntos Económicos y Sociales de la ONU-UNDESA.

Pinos, R., García L., Peña. A., Rendón, H.y Tristán, P. (2012). Impactos y regulaciones ambientales del estiércol generado por los sistemas ganaderos de algunos países de américa, Agrociencia 46: 359-370.

Renda, A. (2006). Papel de los sistemas agroforestales en el escenario agrario de las cuencas hidrográficas de Cuba. Pastos y Forrajes, Vol. 29, No. 4

RAPAL. (2010). Contaminación y eutrofización del agua. Impactos del modelo de agricultura industrial. RAPAL Uruguay

Revelli, O.A. Sbodio, E.J. Tercero, M. Uberti. (2002). Impacto de la Calidad de Agua para Bebida Animal en Relación a Parámetros Productivos, Composicionales y Reproductivos. FAVE Sección Ciencias Veterinarias. Vol 1, No 1

Sánchez, C., Delgado, R., Bueno, H. y Román L. (2014). Huella hídrica de los forrajes en la Comarca Lagunera. México DF: UAM-, Editado por Bárbara A. Willaarts, Alberto Garrido y M. Ramón Llamas, Routledge, Recuperado de: http://bidi.xoc.uam.mx/tabla_contenido_libro. php?id_libro $=425$

Suizagua. (2014). Proyecto piloto Suizagua Colombia. En: http://www.suizaguacolombia.net/ es/Inicio

UNESCO (2003). Agua para todos. Agua para la vida. Informe de las Naciones Unidas sobre el desarrollo de los recursos hídricos en el mundo. Consultado en Julio de 2015. Disponible para descarga en: http://www.un.org/esa/sustdev/sdissues/water/WWDR-spanish-129556s.pdf

WFN. Water Footprint Network (2012). Una mirada a la agricultura de Colombia desde su huella hídrica. Disponible en: http://www.huellahidrica.org/Reports/Arevalo-2012-HuellaHidricaColombia.pdf

WWDR. (2018). UN World Water Development Report, Nature-based Solutions for Water. Recuperado de: http://www.unesco.org/new/en/natural-sciences/environment/water/wwap/ wwdr/2018-nature-based-solutions/

Zarate (2013). Evaluación de Huella Hídrica de banana para pequeños productores en Perú y Ecuador. Good Stuff International - Switzerland. Technical Assistance For Sustainable Trade \& Environment (TASTE Foundation) 